\title{
FLEXIBILITY TRADE-OFFS IN \\ A RANDOM FLEXIBLE MANUFACTURING SYSTEM: \\ A SIMULATION STUDY
}

by

Sameer Goyal

\begin{abstract}
A thesis
presented to the University of Manitoba in fulfillment of the thesis requirement for the degree of Master of Science in

Actuarial \& Management Sciences
\end{abstract}

\author{
Winnipeg, Manitoba \\ (c) Sameer Goyal, 1989
}




\section{National Library
of Canada}

Canadian Tineses Service

Otlawa. Canada

KIA ONC
Bibliothèque nationale du Canada

Service des thèses cánadiennes

The author has granted an irrevocable nonexclusive licence allowing the National Library of Canada to reproduce, ban, distribute or sell copies of his/her thesis by any means and in any form or format; making this thesis available to interested persons.

The author retains ownership of the copyright in his/her thesis. Neither the thesis nor substantial extracts from it may be printed or otherwise reproduced without his/her permission.
L'auteur a accordé une licence irrévocable et non exclusive permettant à la Bibfiothèque nationale du Canada de reproduire, prêter, distribuer ou vendre des copies de sa thèse de quelque manière et sous quelque forme que ce soit pour mettre des exemplaires de cette thèse à la disposition des personnes intéressées.

Lauteur conserve la proprièté du droit d'auteur qui protège sa thèse. Ni la thèse ni des extraits substantiels de celle-ci ne doivent être imprimés ou autrement reproduits sans son autorisation. 
FLEXIBILITY TRADE-OFFS

IN A RANDOM FLEXIBLE MANUFACTURING SYSTEM:

A SIMULATION STUDY

BY

SAMEER GOYAL

A thesis submitted to the Faculty of Graduate Studies of the University of Manitoba in partial fulfillment of the requirements of the degree of

MASTER OF SCIENCE

() 1989

Permission has been granted to the LIBRARY OF THE UNIVERSiTY OF MANITOBA to lend or sell copies of this thesis. to the NATIONAL LIBRARY OF CANADA to microfilm this thesis and to lend or sell copies of the film, and UNIVERSITY MICROFILMS to publisin an abstract of this thesis.

The author reserves other publication rights, and neither the thesis nor extensive extracts from it may be printed or otherwise reproduced without the author's written permission. 


\section{to my parents}


I hereby declare that I am the sole author of this thesis.

I authorize the University of Manitoba to lend this thesis to other institutions or individuals for the purpose of scholarly research.

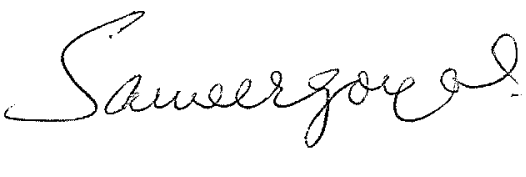

Sameer Goyal

I further authorize the University of Manitoba to reproduce this thesis by photocopying or by other means, in total or in part, at the request of other institutions or individuals for the purpose of scholarly research.

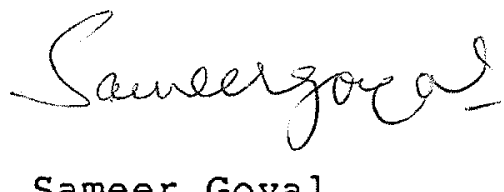

Sameer Goyal 


\section{ACKNOWLEDGEMENTS}

The completion of this MSc thesis has been a lengthy but enriching experience. When I look back, all the efforts in writing, trips to obtain statistical advice, and frustrating nights in front of the computer terminal have been worthwhile.

It is my pleasure to thank Dr Suresh Bhatt, my thesis advisor, for his valuable assistance. I thank the members of my thesis committee, Dr Roger Hall and Dr Walter Willborn, for their assistance. Special thanks go to Dr Yash Gupta, my external examiner, who has given me numerous suggestions throughout the course of this study. I would also like to thank Dr C R Bector for his assistance and advice through all these years. As well, I thank Professor E R Vogt, Head of the Department of Actuarial \& Management Sciences, who was instrumental in introducing me to Operations Research.

I consider myself very fortunate to have a group of close friends to work with. First I thank David Chin, my friend since the high school days, for being my colleague. I treasure him as a friend for many years to come. Also, I earnestIy thank Mahesh Gupta for providing me with his advice and ideas through Bitnet. I thank my roommate Om Nayak for drawing some of the figures on his Mac IIci. In addition, Linda 
Neden and Wendy Stubson have shared with me some of the niceties in statistical analysis.

Finally, I would like to acknowledge the members of my family. They have been a constant source of love and support throughout my life. 


\begin{abstract}
The present world market has posed several new challenges for manufacturers. For many of the firms, the market's need for product differentiation and shorter product life cycles has resulted in diversified production requirements. Unless a firm has high demand for each type of item it produces, it may not be efficient for the firm to automate that item's production through traditional hardtooling approaches, such as transfer lines. Yet companies with low and intermediate volumes of diversified products with short life cycles, are seeking some of the advantages of the automation.
\end{abstract}

One way of achieving the advantages of diversified, low volume production is a Flexible Manufacturing System (FMS). The flexibility provided by an FMS improves the ability of the system to respond to change. Several types of manufacturing flexibility (MF) have been identified in the literature, for example, machine, product, routing, and volume flexibility. Ideally, it is desirable to provide an FMS with all the flexibilities. However, there is a general consensus on the discordant nature of some of the flexibilities. This makes it imperative for the management to recognize the flexibilities that it deems critical to the manufacturing strategy of the firm. This allows the management to trade- 
off some of the less important flexibilities for the more important ones, as the need arises. This knowledge can be of immense help in focusing the long-term objectives of the firm and designing manufacturing systems that are concomitant with these objectives.

This study is an attempt toward an empirical examination of the flexibility trade-offs in an FMS. Through the use of computer simulation, we study the flexibility trade-offs in the stochastic environment of a random FMS. Various configurations of the FMS are simulated under the influence of a wide variety of loading and dispatching strategies. The simulation results are presented in a graphical format to aid comprehension. Further, statistical analysis is conducted on the data to detect significant differences due to the influence of the scheduling environment.

The results show that there is a trade-off among the various flexibility types under most circumstances. However, some scenarios illustrate that an appropriate combination of the variables like scheduling environment, product variety, and system configuration, can be effective in containing these trade-offs. In other cases, it is seen that an FMS can accommodate more that one flexibility type simultaneously.

The simulation results are analyzed in depth and several managerial implications and directions for further research are provided. 
CONTENTS

ACKNOWLEDGEMENTS

iv

ABSTRACT

vi

Chapter

page

I. INTRODUCTION

Flexible Manufacturing Systems . • • . • . . 5

Flexibility . . . . . . . . . . . . . . . 7

Motivation . . . . . . . . . . . . . 8

objective . . . . . . . . . . . . . . . . . . 11

Organization of the Thesis......... . 12

II. LITERATURE REVIEW . . . . . . . . . . . . . . . . 13

Types of Manufacturing Flexibility . . . . . . 14

Measures based on Economic Consequences • • . 16

Quantitative . . . . . . . . . . 17

Measures based on Performance Criteria. . . . 21

Qualitative... . . . . . . . . . . 21

Quantitative . . . . . . . . . . . . 28

The Multi-Dimensional Approach . . . . . . 31

Qualitative . . . . . . . . . . . . . 31

The Petri-nets Approach . . . . . . . . 36

Quantitative . . . . . . . . . . . 36

The Information Theoretic Approach . . . . . 39

Quantitative . . . . . . . . . . . 39

The Decision Theoretic Approach . . . . . . 4 41

Qualitative . . . . . . . . . . . . 41

Quantitative . . . . . . . . . . . . 41

Classification of Literature . . . . . . . . . 44

Discussion . . . . . . . . . . . . . . . . 49

Summary . . . . . . . . . . . . . . 53

II . FMS SCHEDULING . . . . . . . . . . . . . . 55

The FMS Scheduling Problem . . . . . . . . 57

Loading . . . . . . . . . . . . . 59

Dispatching . • . . . . . . . . . . 60

Classification of Flexible Manufacturing

Systems . . . . . . . . . . . 61

Shanker \& Tzen Loading Algorithm . . . . . . 63

Justification . . . . . . . . . . . 63

The Algorithm............... 64

Summary ............... 66 
IV. SIMULATION MODELING . . . . . . . . . . 67

Benefits of Simulation .......... 68

Types of Simulation Modeling . . . . . . . 70

Discrete-event Simulation . . . . . . . . 71

Modeling Approaches . . . . . . . . . 71

Simulation Languages . . . . . . . . . . 73

Overview of GPSS . . • . . . . . . . . . . 74

The Simulation Model. . . . . . . . . . 77

Definitions . . . . . . . . . . . . . . . 78

Assignment of Job Attributes . . . . . . 80

Loading . . . . . . . . . . . . . 81

Dispatching . . . . . . . . . . . 82

Summary

83

V. EXPERIMENTAL DESIGN . . . . . . . . . . . 84

Problem . . . . . . . . . . . . . . . 85

Methodology . . . . . . . . . . . . . . 85

System Design and Specifications . . . . . . 88

Scope ..................... . 9 90

Variance Reduction . . . . . . . . . . . 94

Model Validation and Verification . . . . . 94

Validation . . . . . . . . . . . . 95

Verification . . . . . . . . . . . . 96

Operational Validity . . . . . . . . . . 96

Summary . • . • • • . . • . • • . . 97

VI ANALYSIS . . . . . . . . . . . . . . 98

Graphical Output ............. 99

Simple Loading Rules ........ . 100

FIFO / FIFO . . . . . . . . . 100

SPT / FIFO . . . . . . . . . 101

SPT / WINQ •............ 102

$\mathrm{LPT} / \mathrm{FIFO}$. . . . . . . . . . 103

LPT / WINQ . . . . . . . . . . . 103

EDD / FIFO . . . . . . . . . 104

EDD / WINQ . . . . . . . . . . 105

Arrival Time / FIFO . . . . . . 105

Arrival Time / WINQ ........ 106

Shanker \& Tzen Loading Algorithm . . . 107

FIFO . . . . . . . . . . . 107

SPT •.............. 108

LPT . . . . . . . . . . . 109

EDD . . . . . . . . . . . . 109

Arrival Time . . . . . . . . 110

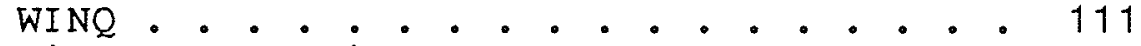

Discussion of Graphical Output . . . . . 111

Simple Loading Rules . . . . . . . . 113

Job Waiting Time.......... . 113

Machine Idle Time ........ 115

Shanker \& Tzen Loading . . . . . . . 116

Job Waiting Time.......... 116

Machine Idle Time . . . . . . 117 
Statistical Analysis . . . . . . . . 123

Simple Loading Rules . . . . . . . . . 127

Job Waiting Times . . . . . . . . 127

Machine Idle Times . . . . . . . . 127

Shanker \& Tzen Loading . . . . . . . . 128

Job Waiting Times . . . . . . . . 128

Machine Idle Times ......... . 128

Summary . . . . . . . . . . . . . 129

VII. CONCLUSION . . . . . . . . . . . . 130

Summary • . • . . . . . • • • . 130

Job Waiting Time . . . . . . . . . . 131

Machine Idle Time . . . . . . . . . 132

Implications . . . . . . . . . . . . . . 133

Directions for Further Research . . . . . . 136

BIBLIOGRAPHY . . . . . . . . . . 138

Appendix $\quad$ page

A. GRAPHICAL OUTPUT. SIMPLE LOADING RULES . . . . 149

B. GRAPHICAL OUTPUT. SHANKER \& TZEN LOADING . . . 159

c. MULTIPLE COMPARISONS OF THE MEAN JOB WAITING

TIMES USING THE LSD METHOD. SIMPLE

LOADING RULES . . . . . . . . . . . 166

D. MULTIPLE COMPARISONS OF THE MEAN MACHINE IDLE

TIMES USING THE LSD METHOD. SIMPLE

LOADING RULES . . . . . . . . . . . 173

E. MULTIPLE COMPARISONS OF THE MEAN JOB WAITING TIMES USING THE LSD METHOD. SHANKER \&

TZEN LOADING ALGORITHM ......... 180

F. MULTIPLE COMPARISONS OF THE MEAN MACHINE IDLE TIMES USING THE LSD METHOD. SHANRER \&

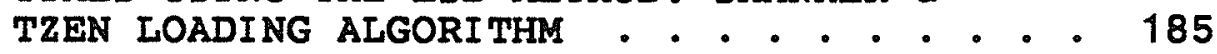

G. GPSS IMPLEMENTATION OF THE SHANRER \& TZEN LOADING ALGORITHM . . . . . . . . . . 190 


\section{IIST OF TABLES}

Table

page

2.1. Classification of flexibility literature Qualitative $v / s$ Quantitative measures . . . . 45

2.2. Classification of flexibility Iiterature Theoretical v/s Non-theoretical measures . . . 46

2.3. Classification of flexibility literature according to Browne et al's (1984) definitions ................ . . 48

5.1. System Configurations Evaluated . . . . . . . 91

6.1. An example of Multiple Pairwise Comparisons . . 126 


\section{LIST OF FIGURES}

Eiqure

page

1.1. Current capabilities of Advanced Manufacturing Systems . . . . . . . . . . . . . 3

1.2. Layout of a Flexible Manufacturing System . . . . 6

2.1. A Petri-net representation of a job processing on a workstation . . . . . . . . . . . 37

3.1. FMS Scheduling Hierarchy . • . . . . . . • . 57

3.2. Structure of Scheduling Problem under study . . . 58

6.1. Simple Loading Rules. Job Waiting Times . . . . 119

6.2. Simple Loading Rules. Machine Idle Times . . . 120

6.3. Shanker \& Tzen Loading. Job Waiting Times . . . 121

6.4. Shanker \& Tzen Loading. Machine Idle Times . • 122

A.1. FIFO / FIFO . . . . . . . . . . . . . 150

A.2. $\mathrm{SPT} / \mathrm{FIFO}$. . . . . . . . . . . . . 151

A.3. SPT / WINQ • . . . . . . . . . . . . 152

A.4. LPT / FIFO . . . . . . . . . . . 153

A.5. LPT / WINQ •. . . . . . . . . . . . . 154

A.6. EDD / FIFO . . . . . . . . . . . . 155

A.7. $\operatorname{EDD} / \mathrm{WINQ}$. . . . . . . . . . . . 156

A.8. Arrival Time / FIFO . . . . . . . . . 157

A.9. Arrival Time / WINQ . . . . . . . . . . . 158

B.1. FIFO . . . . . . . . . . . . . . 160

B.2. SPT . . . . . . . . . . . . . . 161

B.3. LPT . . . . . . . . . . . . . 162 
B.4. EDD . . . . . . . . . . . . 163

B.5. Arrival Time . . . . . . . . . . . 164

B.6. WINQ • . . . . . . . . . . . . . . 165 


\section{Chapter I}

\section{INTRODUCTION}

The past few years have brought about unprecedented changes in manufacturing technology. There has been emerging interest in the use of manufacturing and manufacturing strategy as a competitive weapon (De Meyer et al, 1989). One of the critical challenges for production managers is to improve manufacturing productivity in today's global economy (Bobrowski \& Mabert, 1988). Managers must realize that they have entered a period of competition that requires of them a technology ariven strategy, a mastery of efficient production, and an unprecedented capacity for work force management (Abernathy et al, 1981). The works of Skinner (1985), Hayes \& Wheelwright (1984), and Hill (1984) have greatly contributed to a better understanding of the issues, questions, and variables involved in defining and implementing a manufacturing strategy (De Meyer et al, 1989).

US manufacturing started to experience some environmental changes in the mid 1960 s due to growing technological change, increasing federal regulations, and more important foreign competition. The manufacturing companies started to exhibit serious problems with manufacturing performance as foreign competition gained even more momentum. Deeply embed- 
ded in the dogmas of giant plants, economies of scale, and docile work forces, these companies are now facing the repercussions of competition, shorter product life, and increasing fixed costs. Also, there has been an increasing demand for product quality, reliability, innovation, technology, and quality of work life (Skinner, 1985).

The conventional form of manufacturing has mainly relied on two kinds of equipment. The first - dedicated machinery such as transfer lines - is best suited for mass production of a single part. This process specialization permits low unit costs, but it also inhibits flexibility. The second unautomated general purpose machine tools - is best suited for very small batch production of many different parts. Costs per unit tend to be high, but the flexibility of the process can accommodate design changes, demand fluctuations, and shifts in product mix. Today, Advanced Manufacturing Systems such as Flexible Manufacturing Systems (FMS), Computer Aided Design/Manufacturing (CAD/CAM), and Just-inTime (JIT), offer a third choice - one with more flexibility than transfer lines and lower unit costs than general purpose machine tools (Gerwin, 1982). Figure 1.1 (Edghill \& Davies, 1985) shows the capabilities of these technologies as compared with conventional form of manufacturing.

Recently, these systems have been introduced in the American manufacturing industry to improve productivity (Biegel, 1986). Collectively called Advanced Manufacturing 


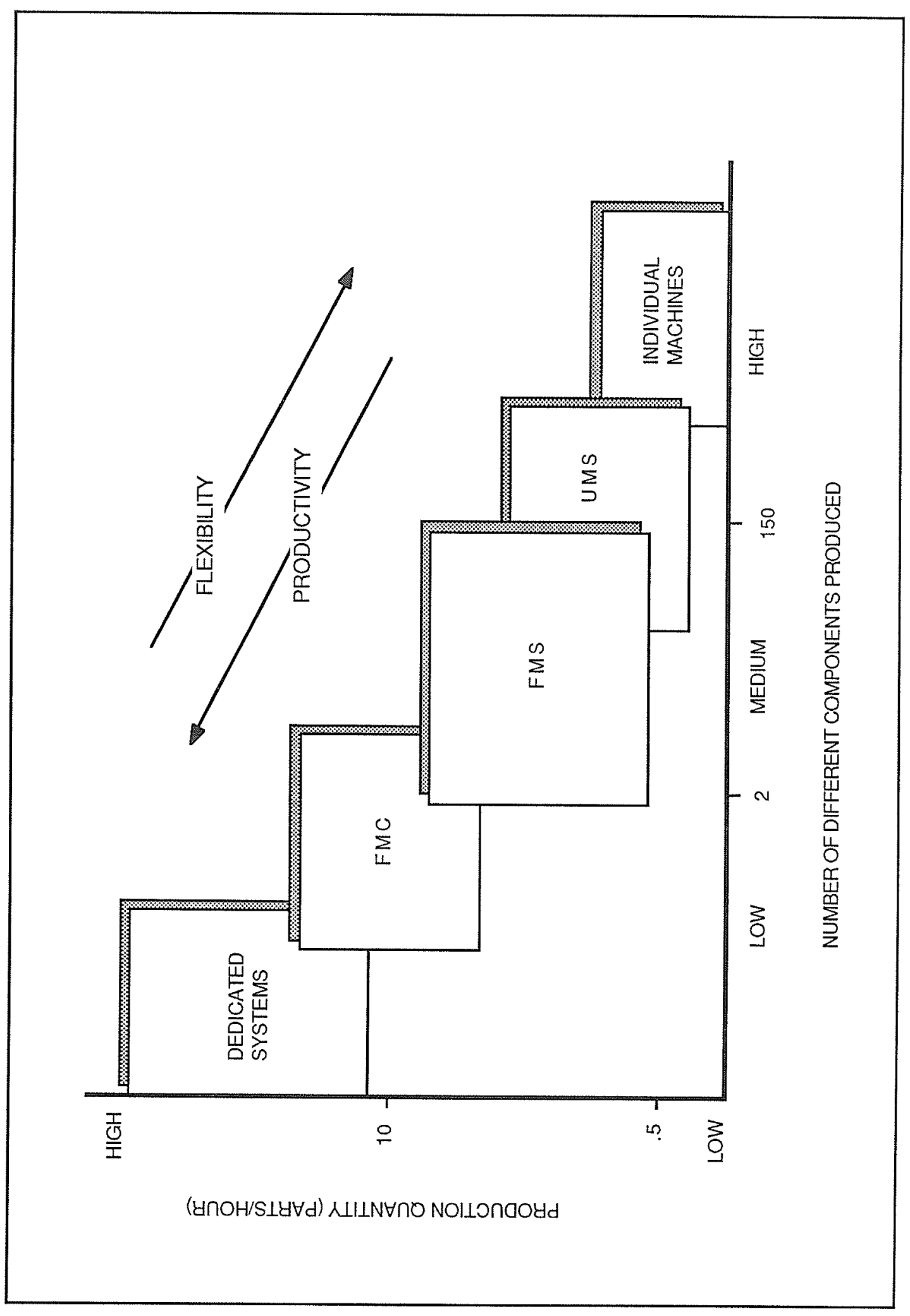

Figure 1.1: Current capabilities of Advanced Manufacturing Systems 
Technologies (AMT), these technologies have made manufacturing systems significantly more 'flexible' or adaptable to change. These technologies provide organizations an avenue to gain a competitive advantage through increased flexibility, integration, and automation (Gupta et al, 1989b). In fact, the Japanese consider FMSs to be the most important action plan to maintain competitiveness in the coming years (De Meyer et al, 1989).

Flexible Manufacturing Systems have brought about significant advantages over traditional batch manufacturing by reducing the work-in-process (WIP) levels of inventory and improving utilization of resources, specifically in the machine tools industry (Groover, 1985; Hatvany, 1983). Many companies have claimed a reduction of $60 \%$ to $90 \%$ in the Wip inventories after the installation of an FMS (Ranky, 1983; Gupta et al, 1989a). FMSs are expected to enhance machine utilization to an $80 \%$ or even a $90 \%$ level (Aggarwal, 1985). In a detailed study of 95 FMSs in US and Japan, the utilization rate of Japanese FMSs was found to be as much as $92 \%$ (Jaikumar, 1986). A recent study of FMSs in 20 US companies showed that FMSs have reduced by more than $50 \%$ the amount of labor required to do the same work, and reduced total product costs by as much as 75\%. FMS installations have achieved significant reductions in the number of indirect workers and staff, reject rates, and the time required to introduce new products (Hayes \& Jaikumar, 1988). 
As compared with conventional systems, the greater flexibility provided by an FMS allows it to be used for successive generations of products and gives it a longer useful life than traditional process investments. Beyond a longer useful life, this technology also provides many additional benefits such as better product quality, reduced inventory and floor space, lower throughput and lead times, and faster response to market shifts (Kaplan, 1986). More important, the manufacturing system's capability grows over time as managers become familiar with the technology and as new hardware and software appear (Gold, 1982).

\subsection{FLEXIBLE MANUFACTURING SYSTEMS}

An FMS is viewed as a building block of an unmanned factory (Hildebrant, 1980). There are many ways in which one could define an FMS: (i) by describing its equipment components, or ( $i$ ) by describing its operating strategies and behavior (Wilhelm \& Subhash, 1983; Yilmaz \& Davis, 1987).

One of the widely used definitions is given by Buzacott (1982a). According to him, an FMS is an integrated system of centrally programmable computers linked with a set of machines which perform such operations as machining, inspection, and assembly. The machines are linked by automated material handling devices such as shuttle pallets, carts and industrial carriers which carry jobs from machine to machine. The raw parts are normally loaded and unloaded at 


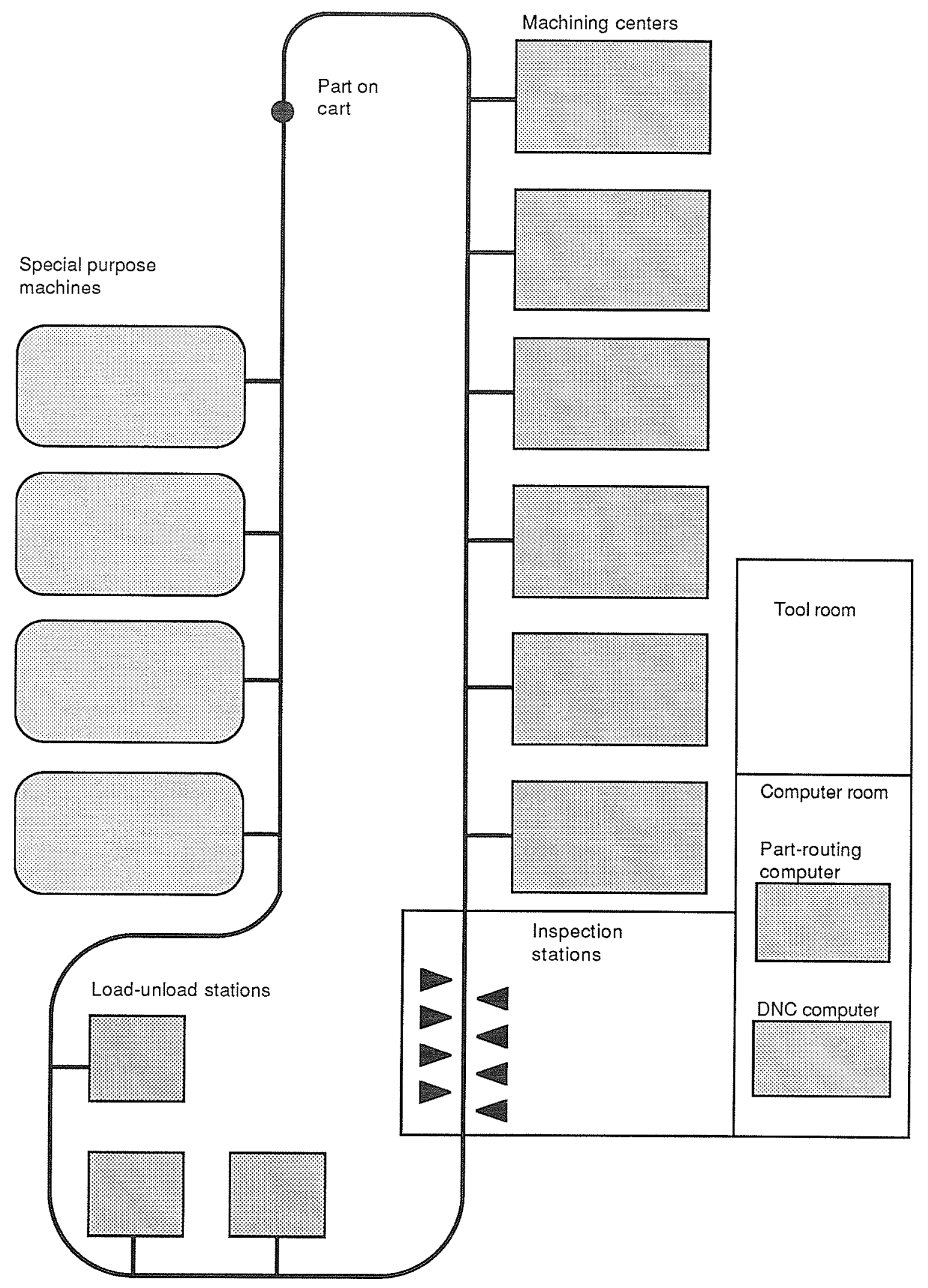

Figure 1.2: Layout of a Flexible Manufacturing System 
the central load and unload stations. Upon completion, the part is transfered by a cart to its next workstation or to the buffer area where it queues temporarily. Figure 1.2 (Gerwin, 1982) shows the layout of a typical FMS.

Overall, an FMS operates as an integrated system and is capable of simultaneously processing a variety of part types at various workstations (Diesch \& Malstrom, 1985; Choi \& Malstrom, 1988). An FMS offers the promise of achieving the efficiency normally associated with high volume manufacturing systems, while retaining much of the flexibility of a job shop (Denzler et al, 1987).

\subsection{FLEXIBILITY}

Flexibility is defined as the ability of a manufacturing system to cope with changing circumstances (Buzacott \& Mandelbaum, 1985) or instability caused by the environment (Mascarenhas, 1981).

Flexibility is one of the key objectives of any manufacturing system (Chatterjee et al, 1984) and a critical measure of total manufacturing performance (DeGarmo et al, 1984, Hayes \& Wheelwright, 1984, Kaplan, 1983, Richardson \& Gordon, 1980, Schneible, 1983, Schonberger, 1982; Son \& Park, 1987). It ensures that manufacturing can be both cost efficient and customized at the same time. As setup time decreases, small batch production can be as economical as 
large scale manufacturing. This enables the organization to change its competitive strategy from economies of scale to economies of scope (Goldhar \& Jelinek, 1983; Gupta et al, $1989 b)$.

More important, flexibility embodies competitive value for a manufacturer.

In conditions of environmental scarcity, organizations with inflexible technologies are the most vulnerable because of limits on the range and variety of output and the high costs of operating below capacity. A substantial level of investment in inflexible manufacturing processes, which deters exit from an industry despite conditions of scarcity (Harrigan, 1981, Porter, 1980) exacerbates such vulnerability. Organizations with flexible technologies are less vulnerable to conditions of scarcity because of the greater adaptability of the core technology, lower costs of operating below capacity, and greater ease with which competitors may exit under conditions of scarcity (Yasai-Ardekani, 1989).

\subsection{MOTIVATION}

Manufacturing Flexibility (MF) has received belated recognition in $N$ America in the past. Only recently has it started to draw attention for its value in gaining and maintaining competitive advantage (Swamidass, 1985). As the concept of MF proliferates with the introduction of FMSs, most companies will have but one alternative to adopt this technology. A failure to do so will reduce the company's competitiveness as compared with those who are already using this technology. 
The introduction of flexibility to a manufacturing system requires high initial investment. For example, a numerical controlled turning center costs $\$ 300,000$ to $\$ 400,000$ while an FMS installation can balloon to $\$ 25$ million (Bobrowski \& Mabert, 1988). For this reason, flexibility and cost efficiency have been considered as conflicting objectives. In a survey conducted on the manufacturing strategy of large manufacturers of $\mathrm{N}$ America, Europe, and Japan, De Meyer et al (1989) reported that "the next competitive battle will be waged over the manufacturers' competence to overcome the age old trade-off between efficiency and flexibility".

There are various types of flexibility that are available to a manufacturer. In recent years, manufacturers have come to realize that certain flexibilities have to be traded off against other more important flexibilities. For example, the production of a wide variety of products may reduce the ability of a manufacturing system to produce in large volumes. This implies that managers should be aware of conflicting flexibilities. Further, in improving manufacturing flexibility, managers should identify and prioritize the relevant flexibility, so that when faced with conflicting situations, they can trade-off a low priority flexibility in favor of a higher priority flexibility (Swamidass, 1985). 
It is clear that the concept of flexibility in manufacturing is becoming an important issue. However,

Improving manufacturing flexibility does not lie with intermittent technological fixes or strategic coups that American companies love so much. Instead, flexibility must continuously be built from the operational level to the strategic level of a company (Cho, 1987).

The need for flexible design of manufacturing systems appears with consistent regularity in production literature (Agosta, 1987, Cho, 1987, Linder, 1985, Muramatsu et al, 1985, Rolstadas, 1988, Van Beek \& Van Putten, 1987, Zelenovic, 1982). Consequently, an understanding of the flexibility trade-offs in a manufacturing system can immensely help an organization in building flexibility into the system. A flexible system is better able to operate effectively under changing environments by using the flexibility as an adaptive response.

Thus, the interests in this study are the concept of flexibility, the ways of achieving and monitoring flexibility, what system configuration optimizes what type of flexibility, and whether a particular system is more flexible than another. This knowledge can help design manufacturing systems that are inherently more flexible and optimal with respect to a desired manufacturing strategy. 


\section{1 OBJECTIVE}

This study is an attempt to examine the flexibility trade- offs associated with an FMS. The technique employed is digital simulation.

The objective is to observe the impact of various types of flexibility on the performance parameters of an FMS (eg, machine idle time) under the influence of different loading/ dispatching strategies and various system configurations. In doing so, we attempt to examine the significant differences between the values of these performance parameters, as caused by imposed changes in flexibility. This information can help the decision maker in understanding how a performance parameter can be used to select an appropriate loading/ dispatching strategy to improve a desired flexibility. The effect of a given system configuration on the performance parameters can have significant implications on the design of the system before the production or process planning stages are implemented. This knowledge can also be useful in developing the manufacturing strategy for introducing a new product, changing the product $\mathrm{mix}$, and investment in new technology.

The potential for conflict among the different types of flexibility makes it imperative for a company to decide earIy on which kinds of flexibility it values most. Setting these priorities accurately requires a prior strategic con- 
sensus formulated by top management. Without such consensus, management simply cannot give its manufacturing operations a well defined mission (Gerwin, 1982). A knowledge of the flexibility trade-offs can therefore help the management position the operations strategy of the manufacturing system to complement the manufacturing strategy of the firm.

\subsection{ORGANIZATION OF THE THESIS}

Chapter II contains a review of the literature related to the area of MF and its measurement. A critical discussion of the literature is included. In Chapter III, the scheduling problem in an FMS is presented. A reference is made to loading and dispatching, the two primary components of scheduling. Chapter IV consists of a description of simulation modeling and the simulation language used in this study. The software implementation of the major loading algorithm used in this study is also described. The experimental design of this study constitutes Chapter V. In Chapter VI, we present the simulation results and conduct statistical analysis. Chapter VII provides a summary of the results, their implications, and further research directions. 


\section{Chapter II}

\section{IITERATURE REVIEW}

The issue of flexibility is assuming increasing importance in manufacturing decision making, planning, and management. Flexibility is important to accommodate changes in the operating environment. Manufacturing systems that are flexible can utilize the flexibility as an adaptive response to unpredictable situations. Flexibility can also be used to expedite the introduction of new products and incorporate design changes in existing products.

Flexibility types can be classified in various ways. One way is to examine flexibility from a short term or a long term perspective. Another way of examining flexibility is to focus on physical measures such as the capability of the system to overcome known changes in the environment. This is in contrast to looking at potential flexibility, which is the capability of the system to cope with unpredictable changes (Barad \& Sipper, 1988).

Various parameters can be used in the analysis of flexibility. These include labor, production, strategy, and organizational structure (Eppink, 1978, Frazelle, 1986, Lim, 1986, Preece, 1986). In this study, our analysis is centered on Manufacturing Flexibility (MF). 
First, we present the definitions of the types of MF according to Browne et al (1984). This is followed by a review of the various flexibility type definitions, models, and measurements appearing in the literature. It seems logical to classify the literature based on the way in which researchers have defined various types of MF. However, noticeable similarities among the proposed definitions suggest a different approach toward the classification.

Our discussion will follow Kumar's (1987b) classification, which is based on the ways of measuring flexibility. Kumar (1987b) classified flexibility according to measures based on: (i) economic consequences, (ii) performance criteria, (iii) multi-dimensional approach, (iv) petri-nets, (v) information theory, and (vi) decision theory. Our classification also emphasizes a distinction between qualitative and quantitative measures within this scheme. For cases where measurements have not been suggested, the literature has been classified within the same framework by the nature of the flexibility type definitions.

\subsection{TYPES OF MANUFACTURING FLEXIBILITY}

The definitions of Browne et al (1984), being the most comprehensive, describe the nature of $\mathrm{MF}$ in terms of the following eight characteristics (Lim, 1986): 
MACHINE Flexibility - The ease of making the changes required to produce a given set of part types. It can be measured by the time to replace defective tools, the time to change tools in a tool magazine, and the time to assemble or mount new fixtures.

PROCESS Flexibility - The ability to produce a given set of part types, each possibly using different materials, in several ways. It can be measured by the number of part types that can be processed simultaneously without using batches.

PRODUCT Flexibility - The ability to change over to produce a new (set of) product(s), economically and quickly. It can be measured by the time required to switch from one part mix to another, not necessarily of the same part types.

ROUTING Flexibility - The ability to handle breakdowns and to continue producing the given set of part types. It can be measured by the robustness of the FMS when breakdowns occur, that is, the production rate does not decrease dramatically and parts continue to be processed.

VOLUME Flexibility - The ability to operate an FMS profitably at different production volumes. It can be measured by the minimum volumes of all part types for which the system can be run profitably.

EXPANSION Flexibility - The capability of building a system and expanding it as needed, easily and modularly. It can be measured by the maximum possible size of the FMS. 
OPERATION Flexibility - The ability to interchange the ordering of several operations for each part type.

PRODUCTION Flexibility - The universe of part types that the FMS can produce. It can be measured by the level of existing technology. Production flexibility is dependent on all the other flexibility types.

\subsection{MEASURES BASED ON ECONOMIC CONSEOUENCES}

One way of evaluating flexibility in a manufacturing system is by monitoring the economic consequences of the system's ability to cope with change. For example, a reduction in production volume due to disturbances such as machine breakdowns and demand fluctuations can lead to losses. These losses or economic consequences of such a reduction in volume can be used to measure flexibility.

Mandelbaum (1978) presented a comprehensive review of the literature on flexibility. He observed that flexibility can be described in two main contexts: (i) Action flexibility relates to situations where decisions are made sequentially, without knowledge of the future, and (ii) state flexibility relates to situations where a given system is able to operate well in many different circumstances. A system has state flexibility if the capacity to respond to change is contained within the system. A system has action flexibility if intervention required to respond to change must come from 
outside the system. However, in the context of an FMS, the emphasis on 'flexible' implies state flexibility, that is, the ability of the system to process a wide variety of parts or assemblies, without a need for outside intervention (Buzacott, 1982b).

\subsubsection{Quantitative}

Building upon Mandelbaum's discussion, Buzacott (1982b) evaluated the flexibility of a manufacturing system by considering the nature of the change and disturbances that the system should be able to cope with. He suggested a distinction between external and internal changes. External changes are variations in the type, mix, processing requirements, and quantity of jobs allocated to the system, while machine breakdowns, variability in processing times, and quality problems, exemplify internal changes.

In order to clarify the effect of both types of change on the system, Buzacott (1982b) defined two types of flexibility. Job flexibility is defined as the ability of the system to cope with changes in the jobs to be processed by the system (external change). Machine flexibility is defined as the ability of the system to cope with changes and disturbances at the machines and workstations (internal change).

Buzacott (1928b) related the measurement of flexibility to the effectiveness of the system in coping with each con- 
ceivable change, as measured by the loss or benefit if the change were to occur. With a manufacturing system, the loss associated with a change will have 'infeasibility' as a dominant component, that is, the change may be such that the system cannot process parts of a particular type because it is incapable of doing so, thus rendering the system inoperable.

In evaluating the job flexibility of a system, Buzacott (1982b) considered the set of all jobs that must be processed by the manufacturing unit. The job flexibility of a specific system is then the size of the subset that contains only the jobs that can be processed by the system. However, a flexibility measure based only on the size of a subset does not account for the probability that a particular set of job characteristics will occur. Therefore, another suggested measure of job flexibility is the probability that the job occurs, and can be processed by the system.

Disturbances at the machine level can temporarily render the system incapable of processing certain job types, or in some cases, all job types. This means that an appropriate measure of machine flexibility can be obtained by determining the expected loss in production due to the disturbances, that is, the ratio of the expected production rate with disturbances to the expected production rate without disturbances. 
Son \& Park (1987) identified that little work has been done in measuring flexibility because of the difficulty of quantifying flexibility in dollar terms. They proposed four types of flexibility measures for a given production period and quantified each measure on the basis of a related cost.

Equipment flexibility is the capacity of the equipment to accommodate new products and some variants of existing products. It is measured in terms of idle cost, that is, the opportunity cost for equipment underutilization. Equipment flexibility is defined as the ratio of the physical output of the manufacturing system to the idle cost of the equipment. Equipment flexibility measures the opportunity of equipment to add value to the raw material.

Product flexibility is the adaptability of a manufacturing system to changes in product mix. The frequently changing demand for new and different products results in shorter life cycles for the products, and smaller lot sizes, as variety increases. A smaller lot size leads to higher setup costs. Reducing setup costs is often viewed as the way to increase product flexibility. Product flexibility is defined as the ratio of the physical output of the system to the setup cost of the equipment. Product flexibility measures the opportunity of adding value to the products with changes in product mix. 
Process flexibility is the adaptability of the system to various changes in part processing, such as equipment and tool breakdowns. Poor response to these changes results in a large Work-In-Process (WIP). The WIP is proportional to the waiting time or the cost of parts processed. If the response is quick, then the waiting cost in process decreases. Process flexibility is defined as the ratio of the physical output of the system to the waiting cost of parts processed. Process flexibility indicates a foregone opportunity to add value to material processed.

Demand flexibility is the adaptability to changes in demand. It can be measured in terms of inventory cost of the finished product and the raw material. A decrease in inventory cost due to higher inventory turnover suggests a reduced difference between supply and demand with respect to raw material and finished goods, that is, good response to internal and external demand. Demand flexibility is defined as the ratio of the physical output of the system to the inventory cost of finished product and raw material. Demand flexibility measures the opportunity of adding value to the products according to job scheduling and forecasting.

Besides these partial flexibility measures, a total flexibility measure is also defined as a global measure of the opportunity of a manufacturing system to add value to the products. The total flexibility is the ratio of the physical output of the manufacturing system to the sum of the four 
costs mentioned in the partial measures. The partial flexibility measures are useful only for explaining the changes in total flexibility. On the other hand, total flexibility measures the adaptability of the whole system to change.

\subsection{MEASURES BASED ON PERFORMANCE CRI TERIA}

Several researchers have proposed the measurement of various types of flexibility on the basis of selected performance criteria. An example is Browne et al's (1984) definitions that appear earlier in this chapter.

\subsubsection{Qualitative}

Zelenovic (1982) suggested that a production system be planned so that its flexibility can ensure productivity and stable functioning of the system under changing conditions. He defined application flexibility as the value of design adequacy. Design adequacy is the probability that the given structure of a production system will adapt itself to environmental conditions and to the process requirements, within the limits of the given design parameters. Design adequacy is closely related to the degree of utilization of system parameters, that is, it is possible to design a highly flexible system that has a low degree of utilization of these parameters in relation to simple tasks. Adaptation flexibility is defined as the amount of time needed for the system to adapt to a change in the job task. 
Gerwin (1982) gathered the opinion of some batch manufacturers on the developments in flexible production technology and manufacturing flexibility. One of the findings of the survey is that most manufacturers are unfamiliar with this technology and thus apprehensive about implementing it. Moreover, they have widely differing views about the meaning of flexibility in manufacturing. They use the term in at least five different contexts.

Mix flexibility is considered as the ability of the system to process simultaneously a mix of different parts that are loosely related to one another. Parts flexibility is the ability of the system to handle the addition to, or the removal of parts from the mix over time. Routing flexibility is the ability of the system to reroute a given part if the machine used in its manufacture is incapacitated. Design change flexibility is the ability of the system to implement quickly engineering design changes for a particular part. Volume flexibility is the ability of the system to accommodate shifts in volume for a given part.

In another study, Gerwin (1985) attempted to develop an analytical framework for analyzing the flexibility of manufacturing processes. Besides the flexibility types he proposed in the previous (1982) study, Gerwin (1985) defined material flexibility as the ability of the system to handle uncontrollable variations in the items being processed. In a similar study, Gerwin (1989) identified two more flexibility 
types. Modification flexibility is the potential of the manufacturing system for implementing minor design changes in a given product. Specification flexibility allows a manufacturing technology to contribute toward reducing defects and maintain product quality.

Frazelle (1986) described flexibility and how it is created and maintained in the business context. He also outlined the design of flexible facilities, layouts, manufacturing systems, and information systems. He described five types of manufacturing flexibility.

Parts manufacturing flexibility requires that changes in product mix, volume, routing, and design be absorbed quickly and economically. Product mix flexibility requires the simultaneous processing of a mix of different parts loosely related to one another by shape or routing. Volume flexibility allows the accommodation of shifts in volume for a given part. Volume flexibility requires flexible layouts that adapt easily to a change in the number of machine tools. It also demands a modular and flexible material handling system, such as automated guided vehicles, so that when the volume of manufacturing activity increases, the vehicles can be added to the existing fleet. Routing flexibility is the ability of the system to assign dynamically parts to the machines, quickly and economically. Routing flexibility is dependent upon material handling flexibility. Design change flexibility permits the rapid and inexpensive implementation 
of engineering design changes for a particular part. A system has design change flexibility when the product design, process planning, and manufacturing functions are integrated.

Carter (1986) defined six types of flexibility in a way that aids analysis and design. Machine flexibility is the ability of a machine to perform a variety of processing or assembly operations. It can be measured by: (i) the tasks that can be performed by the machine, (ii) the range of possible dimensions, (iii) the cost incurred in making the changeover, and (iv) the time required to change over to a different operation. Machine flexibility defines the possible uses of a machine and the ease of converting from one of these uses to another.

Routing flexibility is the ability of the system to perform operations on alternative machines, in alternative sequences, or with alternative resources. Routing flexibility facilitates production under conditions of equipment breakdowns, defective materials, and late delivery of materials or tools. Routing flexibility is also a method of achieving mix flexibility. Product mix changes or new product introductions can cause bottlenecks that can be alleviated by activating alternative routings to allow increased production. 
Mix flexibility is the ability of the system to produce simultaneously or periodically, multiple products in a steady state operating mode. This minimizes redundancy by allowing machines to be shared among different products. Mix flexibility can be measured by: (i) the number of different parts that can be produced in the system, ( $i$ ) the range of change in the product mix while maintaining efficient production, ( $i i i$ ) the cost of making the changeover, and (iv) the time required to change over.

Mix-change flexibility is the ability of the system to change the product mix inexpensively and rapidly. Mix-change flexibility is a short term flexibility in that it requires a quick response to changing market demand. Mix flexibility pertains to the steady state operation of the system, which encompasses the whole range of possible product mixes. The ease of the system in alternating between these steady states requires mix-change flexibility.

Production flexibility is the ability of the system to produce a range of products without the need for adding major capital equipment. Production flexibility is determined by factors such as machine size, variety of machines, material handling, and software capability. Production flexibility is strategic in that it allows the introduction of new products in a short period of time and at a reduced cost. 
Expansion flexibility is the ability of the system to handle an increase in capacity or a change in the product range. It eases the addition to or the deletion of machines from the manufacturing system. Expansion flexibility has to be included in the original design of the system.

Azzone \& Bertele (1987) established relationships between types of flexibility and the costs incurred by a system in obtaining strategic performance. The strategic performance of a firm is determined by designated performance indexes. They suggested a model that partitions the general concept of flexibility into six elementary concepts or flexibilities. These flexibilities have been synthesized from the work done by Browne et al (1984), Buzacott (1982b), and Gerwin (1982). Each of these flexibilities can be measured deterministically or stochastically.

Routing flexibility is defined as the ability of the system to operate with one or more machines not working. It is measured by the ratio of the manufacturing system's expected production, to the production of a fully operating system. Process flexibility is the ability of the system to operate product changes among a given set of part types. It is measured by setup times. Produce flexibility is the ability of the system to produce new products with minimal cost. The indicator is the expected cost incurred in introducing a new product. Production flexibility is defined as the size of the set of parts that the manufacturing system can produce. 
It can be measured by the probability that the system can produce a new product with the same set of machines. Volume flexibility is the ability of a system to operate with a low reduction in the operating margin caused by a decrease in demand. The suggested indicator is the operating leverage. Expansion flexibility is defined as the number of product mixes the system can produce by adding new machines. It can be measured by the number of machines that can operate simultaneously.

Barad \& Sipper (1988) reviewed the proposed definitions and models of manufacturing flexibility. Their discussion mainly follows Browne et al's (1984) definitions while emphasizing a time span classification. They segmented the various flexibility types under the categories of 'short to medium term' and 'long term'.

Machine setup flexibility is defined as the ease of making the changes required to produce a given set of part types. The proposed measure is time. Process flexibility is defined as the system process variety. This is considered as a potential flexibility, unrelated to a specific product mix. Transfer flexibility is defined as the system's capability to move parts between machining centers. This is also a potential flexibility, expressing another system design feature and thus unrelated to a specific product mix. Routing flexibility is specified as product mix dependent, while retaining its classical definition. Volume flexibility is 
refered to as system setup flexibility. This is based on the assumption that low volumes lead to unprofitability and do not justify the investment in system setup. Operation flexibility is presented as the ability to interchange the ordering of several operations on each part, while complying with the design restrictions. All these flexibility types are categorized under 'short to medium term'. The additional flexibility types appearing in Browne et al (product, production, and expansion) are considered as long term flexibilities that are compound outcomes of the short and medium term flexibilities.

\subsubsection{Quantitative}

Chatterjee et al (1984) developed computable measures of manufacturing system flexibility for use in manufacturing planning and control and in the evaluation of the costs and benefits of alternative process technologies. They proposed a modeling scheme for manufacturing systems, based on the description of a manufacturing system as a collection of processing modules.

A processing module (PM) is defined as a machine that accepts raw material input from an input buffer, performs a set of processing operations on the material, and places the material in an output buffer. A PM could range from a simple hand tool to a multi-function, multi-tool machine with automatic tool changing and load/unload capability. A module 
center (MC) is defined as a collection of PM's with a dedicated inter-PM transport system. The capacity and capability of an MC is defined by its assigned set of PMs. A distinction is made between comprehensive and non-comprehensive module centers. If an MC can perform all the operations on a particular routing of a given part, then the $\mathrm{MC}$ can serve as a comprehensive module center (CMC) for that particular routing of the given part. Any processing of the part in one of its comprehensive MCs allows intra-PM movement only.

The possible measures of flexibility concerning MC design are then proposed as part specific and part mix. The part specific measure of flexibility is given by the ratio of the number of alternative CMCs to the total number of MCs. The part mix measure is given by the number of part types for which an MC is a CMC. In addition, routing flexibility for a part is defined as the number of available routings for that part.

A material handing network is specified by all the possible linkages between MCs. All linkages among PMs within an MC are also allowed. The network of MCs and transport links gives rise to the set of all possible material paths that can be supported in the factory. The total number of these paths is the suggested measure of the overall system flexibility. 
Gustavson (1984) discussed methods for calculating different flexibility levels and strategies for a more flexible view of products and processes. He examined three different types of flexibility and related them to the anticipated changes in environment. Demand flexibility relates to the possibility of demand fluctuation over a period. Product flexibility relates to the possible changes in the products. These include improvements in existing products and entirely new products. Machine flexibility relates to projected changes in the production system. These involve new machinery and production methods, new systems (for example, computerization), and new personnel.

Gustavsson (1984) further suggested that good flexible capacity in a manufacturing system can be achieved by using the parallel principle whereby a parallel product line can be added or deleted, depending on the demand. The flexibility of machinery can be measured as the ratio of the investment's residual value for the next product model to the original investment. Product flexibility can be measured as the ratio of the residual value of the old model to the new model, divided by the original value for the old model.

Falkner (1986) suggested a plant-wide ratio of setup time to processing time as a measure of machine flexibility. A very low value of this ratio suggests the existence of process and product flexibility. The relationship between throughput and machine down time hours indicates routing and operation flexibility. 
Primrose \& Leonard (1986) suggested a similar measure for routing flexibility in an FMS. They considered an FMS as a network with work centers as nodes and a permissible part movement as an arc. A network with all possible arc connections is regarded as 'ideally' flexible. The ratio of the number of arcs for a particular FMS to the same number for an 'ideal' FMS with the same number of work centers, can measure routing flexibility (Kumar, 1987b).

\subsection{THE MULTI-DIMENSIONAL APPROACH}

\subsubsection{Qualitative}

Slack (1983) examined the nature of flexibility in production management by considering flexibility as the ability to assume different dimensions, or the ability to adopt a range of states. A given production system is more flexible than another if it is capable of exhibiting a wider range of states. These states could be manifested in the system's ability to make a greater variety of products, manufacture in different volumes or different quality levels, and so on. However, the flexibility of a production system is dependent not only on the range of states it can adopt, but also on the ease with which it can move from one state to another. A production system that moves from one state to another, smoothly and economically, should be considered more flexible than a system that achieves the same change at a greater cost or organizational disruption. 
Slack further distinguished the cost element of a system's flexibility on the basis of: (i) the cost of making the change, and (ii) the cost of providing the capability to make the change. It is the cost of making the change that determines flexibility rather than the cost of providing the capability. The latter cost is not a direct element of flexibility; it is the price one pays for having the flexibility. The other factor in a system's flexibility is the time it takes to make the transition from one state to another. The time and cost elements of flexibility are inversely related in that the time taken to change from one state to another may be shortened at extra cost, and the cost of making the change may be reduced by extending the time allowed for the change. Thus, flexibility has three dimensions: (i) the range of states a system can adopt, (ii) the cost of moving from one state to another, and (iii) the time necessary to make the transition.

Within the defined framework, Slack (1983) examined the dimensions of five types of flexibility according to: the range of feasible change, and ( $i i)$ the cost and time required to make the change.

New product flexibility is defined as the ability of the system to make something novel. The range of products that a manufacturing system can produce is determined by the capabilities of its process technology and its labor skills. The cost and timing of product change are also affected by 
process capabilities, and in addition, the design process, the emphasis on flexibility in job design, and the ability of the material management system to procure any new materials.

Product mix flexibility is the ability of the system to manufacture, not necessarily simultaneously, a particular mix of products within the minimum planning period used by the company. The determinants of the range of possible product mixes are the process technology and the overall design of the production system. The cost and timing of changing the product $\mathrm{mix}$ is influenced by the organization's ability to reschedule production and ensure material supply.

Quality flexibility is the ability of the system to change the quality level of its products. This flexibility type is limited by the capability of the process technology and the skills of the work force. The cost and the time required to make the change are primarily influenced by the ability of the work force to alter working methods and standards, the ability of payment systems to reflect quality changes, the efficiency with which quality standards can be revised, and the rate at which material supply can be changed.

Volume flexibility is the ability of the system to change output volume. In the short term, the range of possible changes in a production system's total output volume is reg- 
ulated by its level of operating capacity. In the long term, capacity management would describe such changes. The time and cost of aggregate changes are dictated by the manpower strategy, that is, hire and fire, overtime, and extra shifts.

Delivery flexibility is the ability of the system to vary its delivery time, or bring back and put forward production. The minimum value of delivery time depends on the stage reached in the manufacturing process and is given by the sum of the remaining operation times. The cost of making delivery changes can also be determined by the stage in the manufacturing process at which the change is required.

With respect to the measurement of flexibility, slack (1983) described the difficulty in meeting this objective. Flexibility is difficult to measure as it is different from other operations objectives in that it is an indication of potential; it does not have to be demonstrated to be real. Flexibility is not an end in itself; it needs to be applied to other production criteria such as product quality, volume, and delivery. More important, flexibility has three dimensions - range, cost, and time. These factors inhibit the measurement of flexibility in a straightforward sense.

Gupta \& Buzacott (1987) further characterized the range of flexibility with the concepts of sensitivity and stability. Sensitivity relates to the magnitude of tolerable 
change before there is a corrective response. Stability relates to the magnitude of the change that the system can accommodate while still maintaining its (the system's) performance targets. They suggested that sensitivity and stability correspond to the minimum and maximum magnitudes of change for each system within which the property of flexibility holds (Kumar, 1987b).

Yilmaz \& Davis (1987) examined manufacturing flexibility through different dimensions of time. They defined flexibility in an automated manufacturing system in terms of the following attributes: (i) flexibility at times, (ii) flexibility after a time, and (iii) flexibility over time, and classified Browne et al's (1984) flexibility types according to these attributes.

'Flexibility at times' refers to the ability of the manufacturing system to cope with unpredictable and sporadic changes that are usually interior to the system, for example, machine breakdowns. Machine flexibility and routing flexibility can be related to 'flexibility at times'. 'Flexibility after a time' refers to the ability of the system to handle foreseeable, short term changes in the environment, for example, a variation in production volume due to demand fluctuation. Product, process, and process sequence flexibilities can be related to 'flexibility after a time'. 'Flexibility over time' refers to the ability of the system to handle known, long term, and sometimes perma- 
nent changes, for example, a change in the system configuration due to the installation of new equipment. Volume, expansion, and production flexibilities can be related to 'flexibility over time'.

\subsection{THE PETRI-NETS APPROACH}

\subsubsection{Quantitative}

Petri-nets have recently started to gain popularity as a modeling and analysis tool for FMS (Alanche et al, 1984, Dubois \& Stecke, 1983, Narahari \& Visvandham, 1985). Petrinets are useful for representation of systems with concurrent activities (Peterson, 1981). They have been used as a design representation of information and control flow in systems, mostly to analyze the set of possible states (Agerwala, 1979; Barad \& Sipper, 1988).

Barad \& Sipper (1988) considered 'operational flexibility' as the most relevant feature of a system's flexibility. Operational flexibility is defined as the system's adaptability to change during operation. They proposed the evaluation of this flexibility type on the basis of the time needed for system adaptation. Having assessed that the operational flexibility of a system can be expressed in terms of time, they used petri-nets as a design representation of an FMS to evaluate its operational flexibility. 
A Petri-net models the static properties of a discrete event system based on events and conditions. The formal definition of Petri-net structures consists of (i) a set of 'places', representing conditions, (ii) a set of 'transitions', representing events, (iii) an input function, and (iv) an output function.

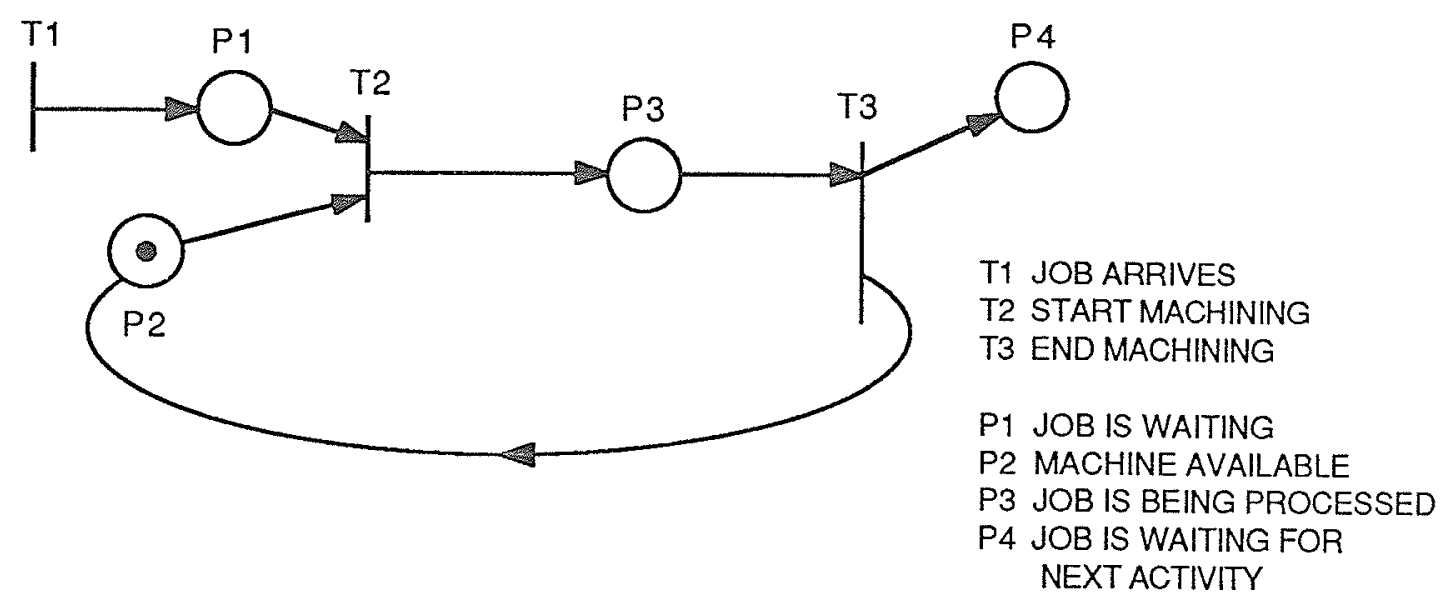

Figure 2.1: A Petri-net representation of a job processing on a workstation

In figure 2.1 (Barad \& Sipper, 1988), $\mathrm{Pi}$ are the places (represented by circles) and $\mathrm{Ti}$ are the transitions (represented by bars). The directed arcs define the input place and the output place for each transition. A Petri-net is 'executed' by defining a 'marking' and then 'firing' transitions. A marking is a distribution of 'tokens' to the places of a Petri-net. In the above example, the machine is 
available (a token in P2) and there are no jobs waiting to be processed. The marking of a Petri-net is changed by the firing of transitions. A transition is 'enabled' if there is at least one token in each of its input places.

There is no inherent concept of time in a classical petri-net. The firing of a transition is considered to be a primitive event - an instantaneous event taking zero time. If the event is not primitive, it can be decomposed into two transitions representing two primitive events, commencement and termination. The place between these two transitions represents the occurrence of a non-primitive event. In figure 2.1, T2 and T3 are two such transitions and P3 is the place between them.

The purpose of developing a Petri-net model for an FMS is to develop a general understanding of the way in which the performance of an FMS is affected by disturbances, and how operational flexibility can diminish these effects. In the Petri-net representation, places represent resources or conditions (machines, parts). A token in a place indicates the availability of a machine or the status of a part. Time is expressed by tokens being delayed in places, representing occurrences of non-primitive events such as processing and transfering (Sifakis, 1977). Petri-nets portray a system through a sequence of events. A particular FMS possessing a given flexibility will have a different sequence of events as compared with an FMS lacking that flexibility. The esti- 
mation of a sequence duration and comparisons between durations of different sequences can demonstrate the system's flexibility level.

\subsection{THE INFORMATION THEORETIC APPROACH \\ 2.6.1 Quantitative}

A system facing uncertainty uses its flexibility as an adaptive response to cope with the uncertainty. The flexibility in the action of the system depends on the decision options or the choices available and on the freedom with which various choices can be made. A greater number of choices leads to more uncertainty and hence increased flexibility. The choices available following a decision reflect the flexibility of the current decision. The uncertainty associated with subsequent actions is used to measure the flexibility of the current decision (Kumar, 1987b).

Kumar (1986) proposed an information theoretic measure of workstation loading flexibility - the ability of the system to control the frequency of part visitation among different workstations. The flexibility of the transition probability matrix of a markovian system is defined and used to calculate the loading flexibility of a stochastic system such as an FMS. In another study, Kumar (1987a) developed an objective theory of flexibility in manufacturing systems. This theory is based on conventional axioms for the measure of entropy. Entropy is defined as a measure of randomness or 
uncertainty in a system. Kumar showed the inherent relationship between the entropy measures and the flexibility measures that he proposed in the study. Four such entropic measures are defined to quantify various types of flexibility. A model is also presented for the computation of operation flexibility.

Yao (1986) considered an FMS as consisting of two basic modules: (i) the material module (parts, workstations, material handling system), and ( $i i)$ the information module (on-line information and computers). Physical transactions circulate in the material module and information circulates in the information module. Yao studied the information flow about parts routing and developed: (i) an information theoretic concept of routing entropy to measure routing flexibility, and (ii) a principle of 'least reduction in entropy' for part routing in an FMS. The main theme of the study is that routing flexibility can only be achieved through adequate handing of the information flow in the system. In keeping with the entropic approach, the possible routings available to a part are considered as the options. These routes pass through different workstations and hence not all routes are always available. This routing flexibility combined with the principle of least reduction in entropy is used to choose a feasible route for the part.

Gupta et al (1989b) developed several models to study the relationship between manufacturing flexibility and other 
manufacturing objectives such as system availability. The proposed models determine the availability distribution of Flexible Manufacturing Cells (FMC) that maximizes the flexibility of an FMS. Using the availability distribution, the models provide the allocation of load on FMCs, and the probability that a job will be processed by a given cell when two or more cells are available.

\subsection{THE DECISION THEORETIC APPROACH}

\subsubsection{Qualitative}

Mandelbaum \& Buzacott (1986) suggested that if precise estimates could be obtained about future events, then the system can be designed to cope with those events, thus eliminating the need for the measurement of flexibility. Realizing the difficulty of predicting future contingencies, they proposed a decision theoretic approach according to which flexibility is an objective and its desirability is dependent upon the decision maker's uncertainty about the future. This leads to a multiple criteria decision problem (Kumar, 1987b).

\subsubsection{Quantitative}

Hutchinson \& Sinha (1989) focused on two aspects of flexibility: (i) the ability to change manufacturing mission, and (ii) the ability to change capacity. Manufacturers are often faced with the choice of a production method for a 
product whose demand is based on a sales forecast. Their choices range from production methods with low flexibility and low marginal costs (transfer line) to production methods with high flexibility and high marginal costs (job shop). Sometimes, the decision maker must choose among alternatives by balancing costs against the benefits of flexibility. As an assistance to the decision maker, a decision theoretic model is developed. This model assigns quantifiable economic values to these two aspects. The model uses the standard deviation of demand as a measure of uncertainty. The sensitivity of the model is examined with respect to several parameters of interest. The conclusion is that the value of flexibility increases with uncertainty. When there is no uncertainty, flexibility has no value.

Brill \& Mandelbaum (1989) presented a framework for defining measures of flexibility in manufacturing systems. The suggested measures are based on the theory of probability. These measures quantify the adaptability of a machine or a group of machines, to changes in the manufacturing environment, such as demand variability, tooling changes, and capacity expansion. Analogous to the concepts of sample space, set of events, and random events in the theory of probability, the authors introduce the notions of 'task sets', groups of machines for accomplishing 'tasks', and weights for tasks, in a manufacturing system setting. These entities are used to define measures of flexibility that are similar to probability theory measures. 
The authors defined two types of flexibility measures: (i) for individual machines, and ( $i$ ) for groups of machines and manufacturing systems. For individual machines, the suggested measures are related to: (i) a specific manufacturing problem, for example, in an individual plant, and (ii) the inherent flexibility of a machine. Several measures are presented for groups of machines. These measures originate from a common formula, but differ according to the way machines are assigned to tasks. Thus, group machine flexibility depends on the way the decision maker believes the tasks or machines will be assigned. Lastly, the proposed measures are demonstrated to be time dependent.

In a related study, Mandelbaum \& Brill (1989) explored measures of flexibility and adaptivity for machines and groups of machines relative to required task sets. The measures are analogous to probabilities in a sample space. The major difference between the two studies is that in this study, task sets are considered to be discrete whereas in the previous one, they are considered as being continuous. Thus, the flexibility measures discussed in this study apply only to static situations. The measures depend on the task sets to be done relative to a background task set, the relative importance of the tasks, and the efficiency of the machines in doing them. The authors have presented computational examples and definitions of single machine and machine group flexibility relative to finite task sets. 


\subsection{CLASSIFICATION OF LITERATURE}

We have attempted to place the notion of manufacturing flexibility in context by examining the relevant literature. Various types of MF were discussed along with the proposed definitions and measurements. Our discussion followed Kumar's (1987b) classification while highlighting a distinction between qualitative and quantitative measures (Table 2.1). This classification can also be based on the distinction between: (i) theoretical and non-theoretical measures (Table 2.2), (ii) probabilistic and deterministic measures, and (iii) applicational and non-applicational measures. The literature can also be classified according to the comprehensive flexibility types of Browne et al (1984).

Table 2.3 illustrates the classification of various types of $M F$ appearing in the literature, according to Browne et al's (1984) Elexibility type definitions. A few comments need to be made about this table. Although the researchers are unanimous about the concept of $\mathrm{MF}$, there seems to be a multitude of opinions about the various flexibility types. For example, Gustavsson (1984) related machine flexibility to the projected changes in the production system. This view is not consistent with the way Browne et al (1984) defined machine flexibility, that is, the ease of the system in making the changes to produce a given set of part types. For this reason, the classification in Table 2.3 is based on a subjective view. In some cases a particular flexibility type 
TABLE 2.1

Classification of flexibility literature - Qualitative v/s Quantitative measures

QUALITATIVE QUANTITATIVE

\begin{tabular}{|c|c|c|}
\hline $\begin{array}{l}\text { ECONOMIC } \\
\text { CONSEQUENCES }\end{array}$ & & $\begin{array}{l}\text { Buzacott }(1982 b) \\
\text { Son \& Park }(1987)\end{array}$ \\
\hline $\begin{array}{l}\text { PERFORMANCE } \\
\text { CRI TERIA }\end{array}$ & $\begin{array}{l}\text { Zelenovic (1982) } \\
\text { Gerwin } \\
\text { (1982,1985,1989) } \\
\text { Browne et al (1984) } \\
\text { Frazelle (1986) } \\
\text { Carter (1986) } \\
\text { Azzone \& Bertele } \\
\text { (1987) } \\
\text { Barad \& Sipper (1988) }\end{array}$ & $\begin{array}{l}\text { Chatterjee et al } \\
\text { (1984) } \\
\text { Gustavson (1984) } \\
\text { Falkner (1986) } \\
\text { Primrose \& Leonard } \\
(1986)\end{array}$ \\
\hline $\begin{array}{l}\text { MULTI- } \\
\text { DIMENSIONAL } \\
\text { APPROACH }\end{array}$ & $\begin{array}{l}\text { Slack (1983) } \\
\text { Gupta \& Buzacott } \\
(1987) \text { \& Davis (1987) }\end{array}$ & \\
\hline PETRI-NETS & & Barad \& Sipper (1988) \\
\hline $\begin{array}{l}\text { I NFORMATION } \\
\text { THEORY }\end{array}$ & & $\begin{array}{l}\text { Kumar }(1986,1987 a) \\
\text { Yao }(1986) \\
\text { Gupta et al }(1989 b)\end{array}$ \\
\hline $\begin{array}{l}\text { DECISION } \\
\text { THEORY }\end{array}$ & $\begin{array}{l}\text { Mandelbaum \& Buzacott } \\
(1986)\end{array}$ & $\begin{array}{l}\text { Hutchinson \& Sinha } \\
(1989) \\
\text { Brill \& Mandelbaum } \\
(1989) \\
\text { Mandelbaum \& Brill } \\
(1989)\end{array}$ \\
\hline
\end{tabular}

definition proposed by a researcher has been approximated to one of Browne et al's (1984) definitions. This has been 
TABLE 2.2

Classification of flexibility literature - Theoretical v/s Non-theoretical measures

THEORETICAL

NON-THEORETICAL

\begin{tabular}{|c|c|c|}
\hline ECONOMIC & Son \& Park (1987) & Buzacott (1982b) \\
\hline $\begin{array}{l}\text { PERFORMANCE } \\
\text { CRITERIA }\end{array}$ & $\begin{array}{l}\text { Chatterjee et al } \\
\text { (1984) } \\
\text { Gustavsson (1984) } \\
\text { Falkner (1986) } \\
\text { Primrose \& Leonard } \\
(1986)\end{array}$ & $\begin{array}{l}\text { Zelenovic }(1982) \\
\text { Gerwin } \\
(1982,1985,1989) \\
\text { Browne et al (1986) } \\
\text { Frazelle }(1986) \\
\text { Carter }(1986) \\
\text { Azzone \& Bertele } \\
\text { (1987) } \\
\text { Barad \& Sipper (1988) }\end{array}$ \\
\hline $\begin{array}{l}\text { MULTI - } \\
\text { DI MENS I ONAL } \\
\text { APPROACH }\end{array}$ & & $\begin{array}{l}\text { Slack (1983) } \\
\text { Gupta \& Buzacott } \\
(1987) \\
\text { Yilmaz \& Davis (1987) }\end{array}$ \\
\hline PETRI -NETS & Barad \& Sipper (1988) & \\
\hline $\begin{array}{l}\text { INFORMATION } \\
\text { THEORY }\end{array}$ & $\begin{array}{l}\text { Kumar }(1986,1987 a) \\
\text { Yao (1986) } \\
\text { Gupta et al (1989b) }\end{array}$ & \\
\hline $\begin{array}{l}\text { DECI SION } \\
\text { THEORY }\end{array}$ & $\begin{array}{l}\text { Hutchinson \& Sinha } \\
\text { (1989) } \\
\text { Brill \& Mandelbaum } \\
(1989) \\
\text { Mandelbaum \& Brill } \\
(1989)\end{array}$ & $\begin{array}{l}\text { Mandelbaum \& Buzacott } \\
(1986)\end{array}$ \\
\hline
\end{tabular}

done with the intention of incluaing a greater number of definitions in the classification. For example, Son \& Park (1987) defined demand flexibility as the adaptability of the 
system to changes in demand. A change in demand usually leads to a change in the production volume, depending on the direction of change. This change in production volume will be determined by the manufacturing system's ability to accommodate changes in volume, that is, volume flexibility. Because of comparisons like these, this classification is not unique and it is subject to modifications. In some cases it was necessary to exclude a flexibility type definition due to its incongruity with Browne et al's (1984) definitions. Barad \& Sipper's (1988) definition of transfer flexibility is one such example. For similar reasons, measures based on petri-nets, information theory, and decision theory, have not been included. 


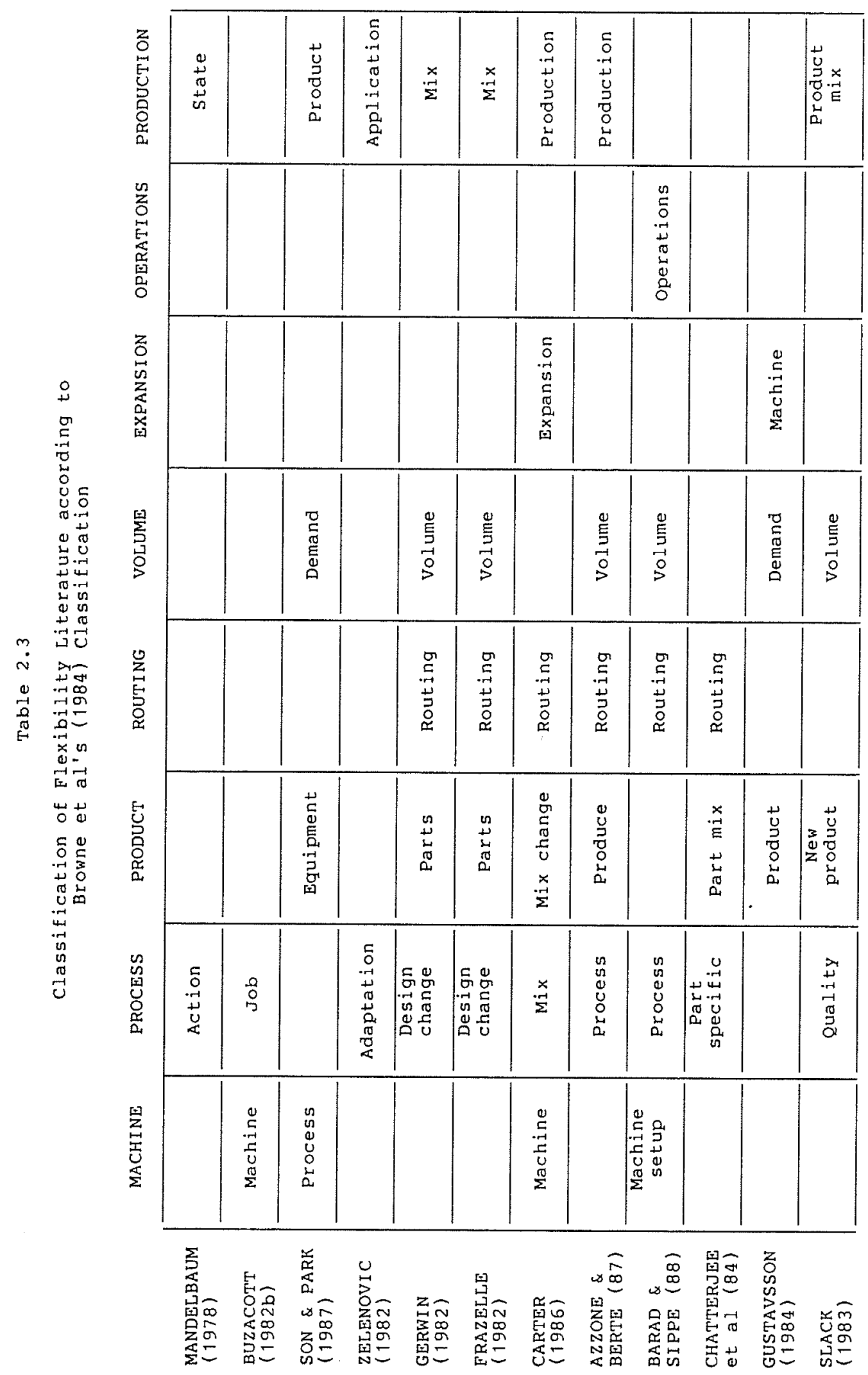




\subsection{DISCUSSION}

As can be seen from the tables, the research on $M F$ is still in the inception stage. The concept of $\mathrm{MF}$ is only about a decade old and there have been only a few research studies in this field. About the only similarity among these studies is the way in which various researchers view MF. The flexibility type definitions show the widely contrasting connotations of the researchers. The intangible nature of $\mathrm{MF}$ has further served to exacerbate the issue.

Buzacott (1982b) based the measurement of flexibility on the economic consequences of the change experienced by the system. In evaluating the job flexibility of a system, he considered the set of jobs that must be processed by the system. However, it is not clear from his definition whether the system should be able to process the jobs within a specified time period. A sufficiently long time period would enable almost any system to process the set of jobs. In suggesting a measure for machine flexibility, Buzacott (1982b) considered the expected loss in production due to disturbances at the machine level that can temporarily render the system incapable. Factors such as setup times, and loading of operations onto the machines should also be considered in such a measure. This would give a more accurate rendition of the expected production rate. 
Son \& Park (1987) also proposed flexibility measures based on economic consequences. The measures are based on ratios of the form: physical output of the system divided by a related cost. For example, equipment flexibility is defined as the ratio of the output of the system, to idle cost of the equipment. However, if the equipment is not idle and it is processing similar parts, this ratio could erroneously imply high equipment flexibility. Similarly, the other flexibility measures proposed by Son \& Park (1987) also offer simplistic views.

Zelenovic (1982) defined application flexibility as the probability that the given structure of the production system will adapt itself to environmental conditions. However, without some knowledge of future contingencies, this probability is difficult to compute. He defined adaptation flexibility as the time needed for the system to adapt to a change in the job task. This measure does take the job characteristics into account. If the change is such that the system is processing similar jobs before and after the change, then the system would need a short period of time to adapt to this change. This could incorrectly imply high adaptation flexibility.

Gerwin (1982) presented mix flexibility as the ability of the system to process simultaneously a mix of different parts that are loosely related to one another. Parts are usually manufactured in batches. It is not clear why a sys- 
tem should be able to handle a mix of different parts simultaneously. A system should be considered 'mix flexible' as long as it is capable of processing the given part mix within a specified production period. Gerwin's (1982) connotation of parts flexibility does not consider the part characteristics. Volume flexibility is presented as the ability of the system to handle shifts in volume for a given part. However, a system may be processing more than one part type. A system would be genuinely 'volume flexible' only if it can accommodate the shifts in volume for all these parts. The flexibility types proposed by Frazelle (1986) are similar to those suggested by Gerwin (1982).

Azzone \& Bertele (1987) defined routing flexibility as the ability of the system to operate with one or more machines not working. This definition assumes a dependency of the system on the material handing network, which is not mentioned. They defined expansion flexibility as the number of product mixes that the system can produce by adding new machines. The suggested measure is the number of machines that can operate simultaneously. This measure seems to be superfluous in that the machines can be operating simultaneously and processing the same part type. A more realistic approach would be to examine the part variety that the machines can process. Azzone \& Bertele (1987) proposed some other flexibility types and related measures. Synthesized from the works of Buzacott (1982b) and Gerwin (1982), these measures suffer from similar limitations. 
Chatterjee (1984) et al proposed two measures of flexibility concerning module center (MC) design. A module center is defined as a collection of machines with a transport system. Part flexibility is measured by the ratio of the number of MCs that can completely process a given part to the total number of MCs. Part mix flexibility is measured by the number of part types that can be completely processed on a single machine. These measures share the drawback of some of the measures mentioned earlier; they do not account for the part characteristics.

A problem that is inherent in all the measures discussed so far is with the treatment of routing flexibility. The FMS may be laid out so as to maintain optimum distances among machines on the material handing path. However, with more than one route available to the job, it is highly probable that the lengths of these routes are considerably different from one another. A longer route may not be as efficient as a shorter one, causing WIP, transport delays, blockages, and deadlocks. Thus, the overall flexibility of the system will be a function of the specific routes that the jobs take through the machines.

Slack (1983) presented one of the more graphic views of MF. According to him, the flexibility of a system depends on: (i) the range of states that a system can adopt, (ii) the cost of transiting between these states, and (iii) the time required to make these transitions. However, not unlike 
the other multi-dimensional approaches, Slack's (1983) treatment of flexibility is primarily qualitative.

Barad \& Sipper (1988) modeled flexibility in manufacturing systems by using Petri-nets. The problem with Petri-nets is that they grow extremely complex with increasing system size. There have also been attempts at measuring flexibility through information theory and decision theory. These measures are predominantly theoretical and they tend to lose mathematical tractability with increasing system size.

The above discussion has revealed some of the deficiencies in the flexibility types and the corresponding measures appearing in the literature. Most of these measures are often constrained in that they submit an incomplete rendition of the measured flexibility type. A majority of the measures do not consider the characteristics of the jobs. Some measures have no specified units of measurement, while some others are too complex.

\subsection{SUMMARY}

The very concept of flexibility and its surrounding issues make flexibility an interesting subject to study. As noted earlier, flexibility is a property of the system that indicates the system's potential behavior, rather than its actual performance. As the various flexibility type definitions suggest, flexibility is not a self-contained concept; 
it needs to be applied to other production objectives such as products, volume, and quality. Also, time and cost are two dominant factors in the evaluation of flexibility (Slack, 1983). All these mediating issues render the study of flexibility a challenging task and all but negate any attempts at measuring flexibility in a straightforward sense.

It is evident that the research on flexibility is in its early stages and the issues mentioned above have only served to complicate the subject. A single, all-encompassing measure of MF seems to be an evasive issue and such a measure is yet to be developed. In addition, there has not been an empirical study on the trade-offs among the various flexibility types.

For the purposes of this study, we will examine four types of MF: (i) machine, (ii) product, (iii) routing, and (iv) volume (Browne et al, 1984), and the trade-offs among these flexibility types. We are studying the flexibility trade- offs in the context of an FMS, and under the influence of various scheduling rules. In the following chapter we formally present the scheduling problem in an FMS and the two primary components of scheduling - loading and dispatching. We also describe the major loading heuristic implemented in this study and the justification for choosing this heuristic. 


\section{Chapter III}

\section{FMS SCHEDULING}

The success of an FMS depends on many factors, such as the appropriate selection of parts, machine tools and material handling systems, effective planning, and a full specification of the control software (Bastos, 1988). In particular, effective planning at various levels presents one of the most challenging tasks in operating an FMS profitably. "Hundreds of robots and millions of dollars worth of computer controlled equipment are worthless if they are underutilized or spend their time working on the wrong part because of poor planning" (Classen \& Malstrom, 1982).

An FMS is a component of a larger manufacturing environment, where the order processing system translates customer orders into finished goods. At the FMS level, decisions must be taken regularly to determine 'when' and 'how' to manufacture the orders that are released to the FMS by the order processing system (Bastos, 1988). Scheduling is the central part of the order processing system. It is a decision process that takes place at the plant level. With the help of control software, scheduling translates the orders that are available to be loaded in the FMS, into a series of executable operations. System constraints such as tools, break- 
downs, and real capacities are considered during the process (Bastos, 1988).

As illustrated in figure 3.1 (Gupta et al, 1989a), scheduling in FMSs can be described by a hierarchical structure ranging from top level decision making to detailed level scheduling decisions. Top level scheduling emphasizes production planning and plant operations over extended time periods. The objective at this level is the coordination of activities of multiple function areas. Software products such as MRP II, OPT, and JIT are employed for this purpose. The output of this scheduling function is a tentative plan or a master schedule. It sets the production targets and serves as a basis for the estimation, planning, and procurement of resources (Vaithianathan \& McRoberts, 1981, Walker \& Miller, 1986; Gupta et al, 1989a).

At the detailed level, scheduling regulates daily demand and provides a means to achieve production targets. It attempts to find the optimal routing of jobs while making efficient use of constrained resources. This is accomplished by allocating resources such as machine tools, fixtures, and raw material, according to time (due dates) and place (routing) constraints (Walker \& Miller, 1986). Jobs are assigned to specific workstations on a weekly, daily, or hourly basis taking into account the type, quantity, and placement of resources, and the associated time values and processing priorities (Groover, 1985, Harrington, 1984; Gupta et al, 1989a). 


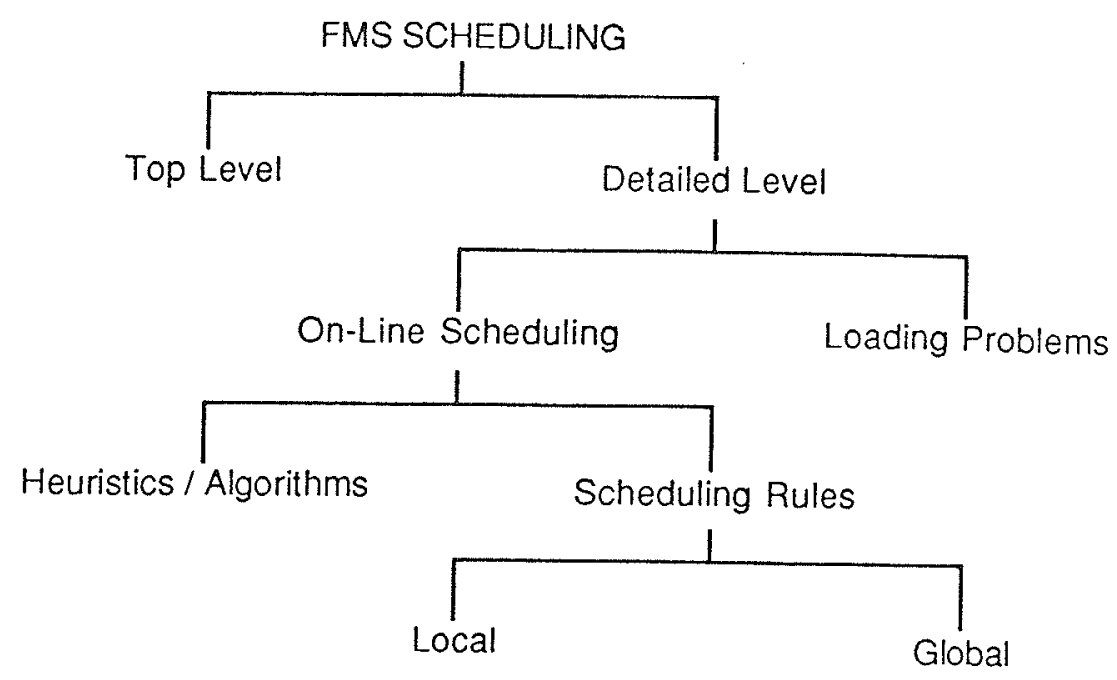

Figure 3.1: FMS Scheduling Hierarchy

\section{- 3.1 THE FMS SCHEDULING PROBLEM}

The short-term FMS scheduling problem can be stated as (Denzler et al, 1987):

Given an FMS with a known number of machine centers and a requirement to produce given quantities of different parts, how should the parts be sequenced to enter the FMS and then routed from one machine to another to complete the required parts in the shortest possible time?

Sequencing orders to complete a schedule in the shortest possible time is equivalent to maximizing the productivity of the FMS. 
FMS scheduling involves the consideration of two distinct, but related activities: (i) loading, and (ii) dispatching. Figure 3.2 ( $\operatorname{Lin} \&$ Lu, 1986) illustrates the structure of the scheduling problem under study.

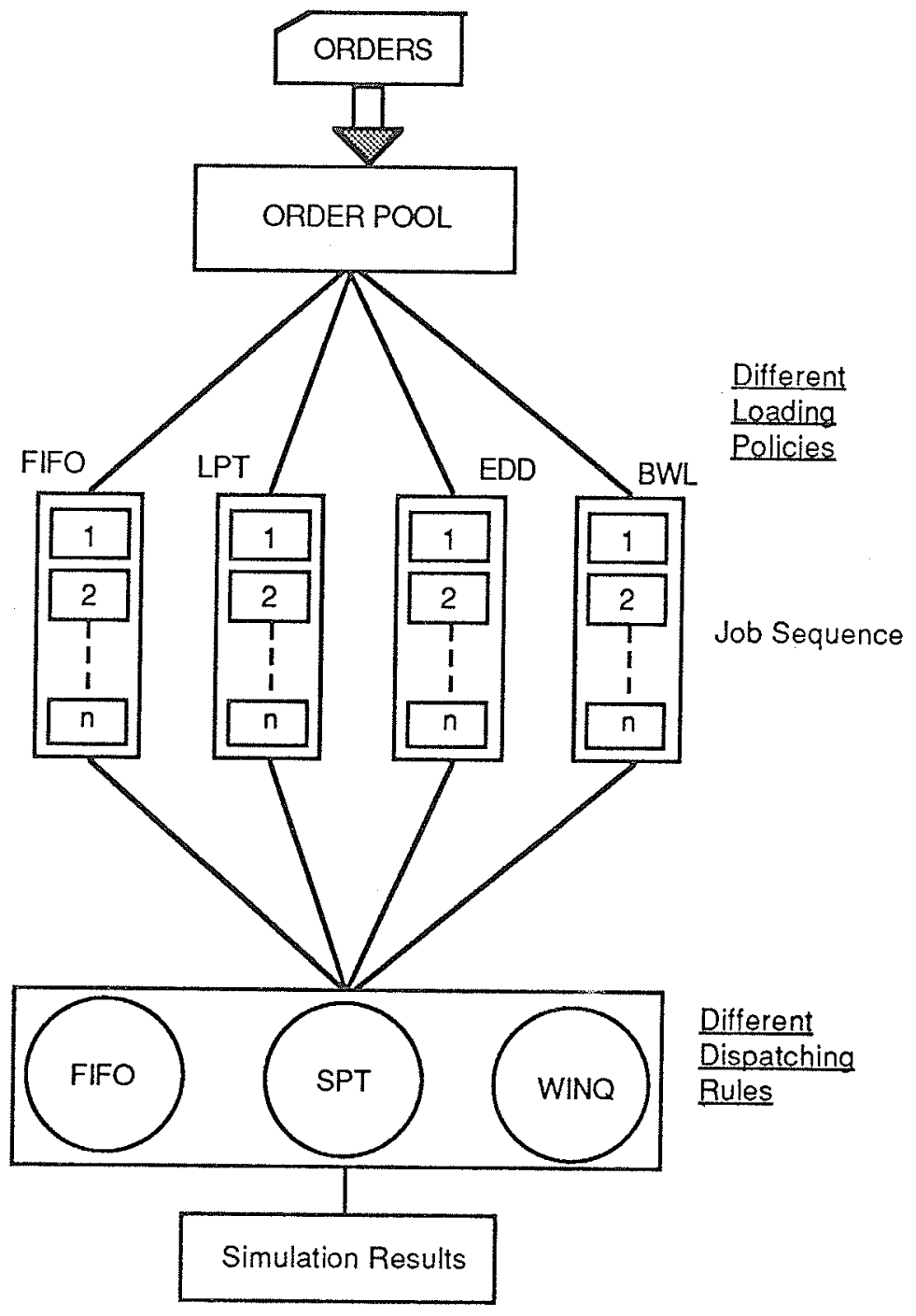

Figure 3.2: Structure of Scheduling Problem under study 


\subsubsection{Loading}

The loading problem is to allocate the operations and the associated tools required for the selected set of part types among the machine groups subject to the technological and capacity constraints of the manufacturing system (Stecke, 1981). Stecke \& Solberg (1981) identified a set of necessary constraints associated with the loading problem:

1. Each required operation and all associated tools must be assigned to at least one machine.

2. An operation can be assigned only to the machines that are capable of performing it.

3. The tools required for the entire set of operations, assigned to any machine, must not exceed the capacity of the tool magazine for that machine.

When deciding on which part to load next, it is necessary to have: (i) an order for that part, (ii) a pallet capable of holding it, (iii) the necessary raw material or WIP part, and (iv) an open slot at the load center. If a set of parts satisfies the above conditions, then a scheduler chooses to use either an 'order file oriented' part loading rule or a 'systems oriented' part loading rule (Denzler et al, 1987).

An order file oriented part loading rule selects the part to be loaded next by considering only the characteristics of the parts in the order file, such as processing times or due dates, but not the status of machines in the FMS. It assumes 
that the flexibility of the FMS will adequately accommodate any sequence of parts that have been loaded. One such widely used rule is to load that part next which has the shortest processing time (SPT). A systems oriented part loading rule selects the next part so as to improve the utilization of the FMS (Denzler et al, 1987). An example of such a rule is to assign the operations to the machines so as to minimize the inter-machine part movements (Stecke \& Solberg, 1981).

\subsubsection{Dispatching}

Subsequent to loading, the next step is running the FMS in real time. This involves scheduling the operations according to some dispatching rule, as the machines become available. FMS pose unique and challenging problems about the real time scheduling of work parts. For example, according to Chang et al (1986),

1. After a part is loaded, which machines should it visit and at what time should it be processed on specific machines?

2. If a machine fails, how should the schedule be adjusted for each part in the system?

3. If a high priority part is loaded, how should the schedules be adjusted for each part so as to accommodate this high priority part? 
Dispatching rules or heuristics can be classified as '10cal' or 'global'. A local dispatching rule only requires information about the job competing for service at a particular machine center. A global dispatching rule requires additional information about the jobs or machine status at other machine centers or waiting lines (Gere, 1966; Gupta et al, 1989a).

Local dispatching rules are easily implemented.However, they fail to take advantage of the global information that is available in an FMS environment. An example of a local dispatching rule is FIFO. According to this rule, jobs are scheduled in the sequence in which they arrive at the machines. Global dispatching rules capitalize on the information about various machining centers in the FMS. However, because of complex data requirements, global rules are extremely difficult to implement (Chang et al, 1986). A popular global dispatching rule is WINQ (Work-In-Next-Queue). This rule selects the job that will go on to its next operation at the machine with the least work load.

\subsection{CLASSIFICATION OF FLEXIBLE MANUFACTURING SYSTEMS}

Flexible Manufacturing Systems can be classified in various ways. A classification scheme proposed by Kusiak (1985) is based on the number of numerically controlled (NC) machines, material handling system (MHS), and their arrangements in the manufacturing system. Another classification 
scheme is based on the geometry of the part being processed by the system (Groover, 1985). A widely recognized classification of FMSs characterizes them as being 'dedicated' or 'random'.

A dedicated FMS employs a set of general or special purpose machines, an automated MHS, part specific pallet fixtures and magazines, with a fixed set of tools on each machine. It produces a small family of similar parts with a known and limited variety of processing requirements. (Denzler \& Boe, 1987b).

A random FMS employs a set of general purpose machines, an automated MHS, modular pallet fixtures, and an automated tool loading system. It is capable of producing a large family of widely differing parts. The product mix is not completely specified and the production schedule is subject to frequent change (Denzler \& Boe, 1987b).

As a comparison, a job shop employs several general purpose machines in a functional layout. Each machine has a resident operator. It is evident that the production planning problems tend to be more complex in a random FMS. However, there is a definite trend toward using random FMSs in order to compete in the world market (Jaikumar, 1986, Merchant, 1982). 


\subsection{SHANRER \& TZEN LOADING ALGORITHM}

\subsubsection{Justification}

As stated earlier, the loading problem is specified as selecting a subset of jobs from the job pool, and assigning their operations to the appropriate machines in the ensuing planning period so as to achieve certain specified objectives while meeting the system constraints (Shanker \& Tzen, 1985).

Stecke (1983), described a set of objectives of loading in FMS:

1. Balancing the machine processing times.

2. Minimizing the number of part movements.

3. Balancing the work load per machine for a system of groups of pooled machines of equal sizes.

4. Unbalancing the work load per machine for a system of groups of pooled machines of unequal sizes.

5. Filling the tool magazines as densely as possible

6. Maximizing the sum of operation priorities.

In some situations, some of the objectives may be conflicting, while in others, more than one objective may be applicable. As part of scheduling, the effects of loading on system performance depend on the way the jobs are dispatched through the machines. For NC machines (which are very expensive), machine idle time is the most important cost related measure of system performance. The loading of an FMS should 
pave the road for dispatching in order to reduce the machine idle time. The flexibility of an FMS suggests that the system can perform well to reduce the machine idle time if each machine is assigned a balanced work load (Shanker \& Tzen, 1985). Balancing the work load of the machines is a common industrial practice (Olker, 1978, Solberg, 1977; Chan \& Pak, 1986). A balanced work load also serves to avoid unnecessary bottlenecks in the system (Stecke \& Solberg, 1981) and reduce WIP (Stecke \& Kim, 1989).

Among the loading strategies used in this study, the Shanker \& Tzen (1985) algorithm was chosen due to its ability to balance the work load among machines. It is one of the most comprehensive loading algorithms in FMS scheduling literature. It was also felt that it would be interesting to examine the effects of such an algorithm along with various dispatching rules, on the flexibility trade-offs mentioned earlier.

\subsubsection{The Algorithm}

The steps of the heuristic are outlined below.

1. For each job, consider all possible routes and for each route, sum up the processing time on each machine. This gives a route processing time (RPT) list for each machine showing the total time for each job on its each route. 
2. For each machine, rearrange the RPTs in descending order. If there is a tie, the job that has the highest total processing time will be placed first.

3. Compare the machine remaining capacity for each machine. From the machine with maximum remaining capacity, select the first job from the RPT list as obtained in step 2. If more than one machine has the same maximum remaining capacity, select the job with the largest RPT from the RPT lists of these machines. If there is again a tie, select the job that has the highest overall processing time.

4. Test the feasibility to check whether the tool slot constraint is satisfied; test the acceptability to examine whether the objective function is improved.

5. If both feasible and acceptable, select the job on that route, and delete all the RPTs that relate to the job selected. Otherwise, delete the RPT from the list of the machine being examined. The job, however, will be retained on the RPT lists of other machines.

6. If the RPT list is exhausted, go to step 7, otherwise update the remaining capacity of all the related machines by subtracting the processing time of the job selected from the previous values of the remaining capacities, and go to step 3 .

7. (In anticipation of further improvement) Do pairwise interchanges between the sets of selected and unselected jobs by removing one selected job and adding 
one unselected job. The interchange that is feasible and acceptable, is used to revise the sets of selected and unselected jobs. The selected jobs are processed in the current production cycle, and the unselected jobs are included for consideration in the list of jobs for the next production cycle.

Since the system performance depends on loading as well as dispatching, it may not pay for the extra effort to balnce the load as outlined in the last step of the algorithm. The effort can possibly improve the objective of balancing but this objective may not fully dictate the system performance (Shanker \& Tzen, 1985). For this reason, the last step of the algorithm was not implemented in this study.

\subsection{SUMMARY}

In this chapter we examined the scheduling problem in an FMS, along with the two components of scheduling, loading and dispatching. It may be easily infered that scheduling an FMS is an inordinately challenging task, especially when the FMS is of the random nature. We studied the predominant loading heuristic used in this study and the justification for choosing this particular heuristic. The following chapter covers simulation modeling, discrete event simulation, the simulation language used in this study, and the implementation of the Shanker \& Tzen (1985) loading algorithm in this simulation language. 


\section{Chapter IV}

\section{SIMULATION MODELING}

In an effort to derive maximum benefit from available resources, performance analysis of a system has become an important part of the planning process. Among the available performance analysis tools, simulation, in particular, is gaining wide acceptance due to its extensive range of applicability (Thesen \& Travis, 1988).

Simulation is generally used in circumstances where the problem at hand is too complex to be tackled by analytic means (Pak et al, 1984, Weston, 1971). Buzacott \& Yao (1986) gave a comprehensive review of the analytic methods that have been developed to model manufacturing systems. However, an FMS is very complex and suitable analytic models cannot be easily constructed to deal with the general characteristics of these systems (Pak et al, 1984). Usually, many assumptions are made (Buzacott \& Shanthikumar, 1980, Solberg $\&$ Nof, 1980) that restrict the prediction of performance to systems with a limited transient nature. Some analytic models based on closed network of queuing theory have been introduced (Hahne, 1981, Hildebrand, 1980) but these models still depend on many assumptions, which hinder their potential application to real manufacturing problems. Attempts 
have also been made to incorporate network queuing theory in a hybrid model using discrete simulation (Shanthikumar \& Sargent, 1981). However, these models rely on queuing theory with single server resources. Therefore, only simple FMSs can be modeled and assessed by the existing analytic methods (Dupont-Gatelmand, 1982) and these models usually address a small subset of issues (Rahnejat, 1986). So far, the dominant modeling tool of FMSs has been simulation (eg, see Abed et al, 1985b, Bell \& Bilalis, 1982, Chan \& Pak, 1986, Chang et al, 1986, Choi \& Malstrom, 1988, Co et al, 1988, Denzler \& Boe, 1987, Denzler et al, 1987, ElMaraghy, 1982, Law, 1988, Lin \& Lu, 1986, Nof et al, 1979, Rahnejat, 1986, Schriber, 1985, Stecke \& Solberg, 1981).

\subsection{BENEFITS OF SIMULATION}

There has been a dramatic increase in the use of simulation in manufacturing during the past few years. Reducing computing costs and improvements in simulation languages. have also led to the increased use of simulation. The general benefit of simulation in manufacturing is that it allows one to obtain a system wide view of the effect of a change in the manufacturing system. For example, the effect of adding an additional machine to a workstation may be predicted by using queuing theory. However, this technique will not be adequate to determine the effect of this change on the entire manufacturing system (Law, 1988). Simulation of FMSs 
is essential to verify design concepts, evaluate alternative configurations, assist in selecting machinery and material handling systems, and test system control strategies. The rapid feedback provided by simulation on the advantages and disadvantages of a given design, enables the designer to make the necessary revisions and arrive at a more efficient system (ElMaraghy, 1982). On the other hand, simulation has the disadvantage of being alienated from the conditions under which a real system operates.

There are many instances of manufacturers gaining quantifiable dollar savings from improved designs and effective operational schedules (Pritsker, 1989). For example, the Dyestuffs \& Chemicals Division of CIBA-GEIGY decided to use computer simulation to justify the construction of their new Dyestuff Production Facility in St Gabriel, Louisiana. CIBA-GEIGY recognized the benefits of modeling their production facility during the design phase of the project. Using the model, the company was able to verify the scope of the new plant from an equipment perspective, and determine that its production capacity would be adequate to meet forecasted demand. The use of simulation allowed them to test and refine the proposed system design and to increase their detailed understanding of the entire manufacturing process (Branstrator \& McCormick, 1989). 


\section{A.2 TYPES OF SIMULATION MODELING}

There are two main methods of simulation, depending on the time related behavior of the system being assessed. A system can be categorized as discrete or continuous. "Few systems in practice are wholly discrete or continuous, but since one type of change predominates for most systems, it will usually be possible to classify a system as being either discrete or continuous" (Law \& Kelton, 1982). A discrete system is one in which the state variables change only at a discrete set of points in time (eg, the number of customers in a bank). A continuous system is one in which the state variables change continuously over time (eg, the head of water behind a dam). However, a discrete simulation model is not always used to model a discrete system, nor is a continuous simulation model always used to model a continuous system. In addition, simulation models may be discrete as well as continuous. The choice of whether to use discrete or continuous (or both discrete and continuous) simulation model is a function of the characteristics of the systems and the objectives of the study.

Simulation models may also be classified as being static or dynamic, and deterministic or stochastic. A static simulation model represents a system at a particular point in time. A dynamic simulation model represents a system as it changes over time. Simulation models that do not contain random variables are classified as deterministic whereas 
stochastic simulation models have one or more random variables as inputs (Banks \& Carson, 1984).

\subsection{DISCRETE-EVENT SIMULATION}

The characteristics of an FMS lend the system particularly well to discrete event simulation. For example, arrival of a job, commencement of processing, and completion of processing are all events that occur at discrete points in time. For this reason, the simulation model formulated for this study is of the discrete variety. In addition, due to the constantly changing conditions (eg, arrival of new jobs) and uncertainty in the inputs to the system (eg, parameters of the arriving jobs), the simulation model is dynamic as well as stochastic.

\subsubsection{Modeling Approaches}

Discrete event simulation can be divided into three distinct types. This division is based on the way used to formulate the model. A discrete simulation model can be formulated by: (i) the event oriented approach - defining the change in state that occurs at each event time, (ii) the activity oriented approach - describing the activities in which the entities engage in the system, and (iii) the process oriented approach - describing the process through which entities flow in the system. For example, the machining of a job can be considered as a process comprising the 
events of arrival, commencement of machining, and completion of machining, with the latter two events forming an activity (Abed et al, 1985a).

In the event oriented approach, a system is modeled by defining the changes that occur at event times. The modeler defines the events, their characteristics, and the potential changes that they bring about (Pritsker, 1974). In the activity scanning approach, the modeler describes the activities in which the entities engage in the system and prescribes the conditions that cause an activity to start or end. In the process oriented approach, a system is simulated by describing the process through which the entities flow in a system. A process is a set of sequenced events that are associated with a system behavior description (Pritsker \& Pegden, 1979; Abed et al, 1985a).

Process oriented methods employ network structures comprised of specialized symbols and blocks that model elements of a process such as queues, servers, and decision points (Pritsker, 1979). These blocks define the sequence of events that are executed automatically by the simulation language as the entities proceed through the process (Pritsker \& Pegden, 1979). As such, process oriented simulation languages offer simpler model building procedures and easier model manipulation (Rahnejat, 1986). 


\subsubsection{Simulation Lanquages}

A decision to employ computer based simulation elicits the need to choose an appropriate language for use in model formulation. A recent survey suggests that general purpose languages like FORTRAN are still in wide use for simulation studies (Christy \& Watson, 1983). Nevertheless, an increasing number of practitioners are adopting modeling oriented languages such as GPSS, SIMSCRIPT, SLAM, and DYNAMO. GPSS is a process oriented simulation language useful for modeling discrete change systems. SIMSCRIPT employs discrete simulation while allowing the use of event oriented and process oriented modeling frameworks. SLAM provides modeling frameworks for simulating systems that are discrete, continuous, or both discrete and continuous. DYNAMO is used for building and simulating continuous feedback models.

Process oriented simulation languages are most suitable for modeling manufacturing systems, which are inherently process dependent. The most popular discrete-event simulation language, GPSS, lends itself especially well to the modeling of manufacturing systems. The compeling reasons for choosing a modeling language such as GPSS are as follows (Henriksen \& Crain, 1983; Schriber, 1985):

1. By providing for automatic collection and output of statistics, GPSS relieves the user of responsibility for specifying tedious programming details such as output formats. 
2. GPSS provides extensive run-time error detection. If a simulation were to be built 'from scratch' in another language, the incorporation of such checks would be a major burden.

3. Some of the algorithms employed by the GPSS simulator are very sophisticated and provide capabilities that could not easily be achieved if a simulation were to be built 'from scratch'.

In addition, GPSS is easy to learn, allowing the programmer to build a complex model in a short time period. As compared to other simulation languages, the recent implementations of GPSS are usually faster to compile and execute, while using less CPU and memory time (Abed et al, 1985b).

\subsection{OVERVIEW OF GPSS}

GPSS is a highly popular simulation language useful for modeling systems in which discrete units of traffic compete for scarce resources. GPSS was originally released by IBM in 1961. It subsequently evolved through a series of IBM releases (GPSS II, GPSS III, GPSS/360, and in 1970, GPSS V), each offering enhancements over its predecessor. Paralleling the IBM releases, a variety of GPSS implementations was made available both for IBM and non-IBM hardware by organizations external to IBM. The state-of-the-art GPSS implementation for IBM mainframe hardware is now GPSS/H, which became available in 1977 (Schriber, 1985). 
A basic step in developing a simulation model is the selection of a conceptual framework to describe the system being modeled. This framework is usually implied by the 'world view' of the language. The world view of a language describes the way in which the language designer conceptualized modeling a system using the language (Shannon, 1975).

In the GPSS world view, or stylized way of looking at a problem, units of traffic (which are called transactions) are visualized as moving from one point to another point in a system, obtaining and using constrained resources. For example, a transaction might be a part moving through a manufacturing system, and each point it moves through in the system could be a machine of a specified type. As a part (transaction) moves from point to point (machine to machine), it is transformed over time to a finished part. The GPSS world view provides a natural, convenient, and powerful way to model a variety of systems, and is a primary reason that GPSS has become a classic language. GPSS is also versatile enough to support alternative approaches to the modeling of systems (Henriksen, 1981; Schriber, 1985).

In a manufacturing system, machines are constrained resources for which parts contend. GPSS provides entities that can be used to represent such constrained resources. The 'facility' entity is used to model unit resources and the 'storage' entity is used to model pools of resouces of identical type. A variety of queue disciplines can be mod- 
eled in GPSS to resolve conflicts when contention for constrained resources occurs. Use of the facility and storage entities results in automatic collection and automatic postsimulation display of the statistics associated with these entities (eg, fraction of time in use, capture count, average holding time per capture; and, for the storage entity, maximum number of resource units in simultaneous use). GPSS also offers additional types of entities that can be used to enhance the statistical information produced in a simulation. For example, the 'queue' entity can be used to collect information about units of traffic waiting to capture constrained resources and the 'table' entity can be used to tabulate observed values of random variables of interest. By providing for such automatic collection and output of statistics, GPSS enhances the statistical insights that a simulation provides about the characteristics and behavior of the system being modeled (Schriber, 1985).

GPSS offers a collection of types of blocks that the modeler arranges in appropriate ways in block diagrams to express the rules governing the operation of the system being modeled. Each block can be thought of as a point at which an underlying subroutine is called, with such a call occuring whenever a unit of traffic moves into a block. Blocks are provided for such functions as introducing units of traffic into the model, having a unit of traffic issue a request for a unit resource, having a unit of traffic relin- 
quish control of the previously captured resources, observing and tabulating values of user specified random variables, checking into or out of waiting lines, being removed from a model, and so on. In total, about 45 different blocks are available in GPSS, providing a rich set of modeling capabilities. An executing GPSS model can also invoke FORTRAN subprograms to accomplish certain effects that might be more easily implemented in a FORTRAN environment (Schriber, 1985).

A GPSS model can take the form of either a block diagram or the statements corresponding to a block diagram. One of the more comprehensive models implemented for the purposes of this study appears in Appendix G. A cursory description of the model appears in the following section.

\subsection{THE SIMULATION MODEL}

This section contains a description of the GPSS implementation of the Shanker \& Tzen (1985) loading heuristic in conjunction with various dispatching rules. The implementations of other loading strategies are generally subsets of this model. The model can be divided into four major segments: (i) definitions, (ii) assignment of job attributes, (iii) loading, and (iv) dispatching. 


\subsubsection{Definitions}

The initial model segment begins with the function definitions. A GPSS function has two operands. The first operand supplies the argument of the function. The second operand specifies the type of function and the number of points defining the function. The function follower statement consists of the function values in the form of $(x, y)$ coordinates. The function is evaluated by linear interpolation between the given points. This interpolated value is then multiplied by the first operand and the result is truncated. A function that is often used in queuing models is the inverse of the exponential distribution, which generates inter-arrival times corresponding to a Poisson distribution. It is usually defined as a continuous function with 24 points (C24). This is the first function that appears in the model (XPDIS). It specifies the inter-arrival time distribution of the incoming jobs. The first operand of this function, RN2, indicates that the function uses the second GPSS random number stream as the function argument. In keeping with the random nature of the FMS under consideration, the functions following XPDIS assign various parameters to the incoming jobs. These parameters are specific to a particular job type and are as follows: (i) BSIZE - batch size of the job, (ii) ROUTE - number of routes that the job can take through the machines, (iii) OPER - number of operations to be performed on the job, (iv) TIME - time for each opera- 
tion, (v) FDUE - due date of the job, and (vi) TSLOT - the number of tool slots required by each operation.

The function definitions are followed by 'savevalue' initializations. Savevalues are used to store numeric data that can be retrieved for later use. The savevalues defined are: (i) JTOT - the maximum number of job types, (ii) MTOT - the maximum number of machines, (iii) MINZ - minimum value of the objective function (as defined in the heuristic), and (iv) RCAPi - remaining capacities of the machines.

Following the savevalue initializations, some matrices are defined. These matrices hold various job parameters such as (i) the job type, (ii) the number of operations to be performed on the job, (iii) the time required for each operation, (iv) the number of machines the job can visit, ( $v$ ) the number of routes that the job can take through these machines, (vi) the visitation sequence of the job, (vii) the due date of the job, and (viii) the batch size of the job. In addition, the matrices are used to hold information such as the parameters of jobs that are infeasible with respect to the tool slot constraint, the route processing list of the jobs, and the loading allocation of the machines. The variable definitions complete this model segment. 


\subsubsection{Assignment of Job Attributes}

Transactions simulate parts or jobs moving through the system. The GENERATE block introduces transactions into the system. These transactions correspond to distinct job types. The inter-arrival times follow an exponential distribution with a mean of 70 time units. The ASSIGN block is used to enter a numerical value into, or modify the contents of a transaction parameter. The block is used to assign various parameters to the jobs such as the job type, arrival time of the job, due date, batch size, and the number of routes. The SPLIT block creates 'offsprings' of the incoming 'parent' transactions, corresponding to different routes. Each of these offsprings is assigned the number of operations to be performed on the job. Since the offsprings originate from the same parent (same job type), all these offsprings will have the same number of operations. Each of these offsprings is further split according to the number of machines in the visitation sequence. As in the previous split, each offspring shares the attributes of the parent, except the visitation sequence. Thus, after the two splits, a job is assigned a particular machine on a given route. These offsprings represent the original transactions (jobs) introduced into the model. Each of these offsprings can be visualized as an individual operation on an incoming job, on a particular machine, on a given route. 
The ADVANCE block delays the propagation of transactions passing through it. The ADVANCE block appearing in this model segment is pivotal to the random nature of the FMS under consideration. The block permutes the visitation sequence of the transactions, that is, the job can visit its assigned machines in any order. For example, if the job needs to use five machines, then it can visit the machines in any one permutation of $\{1,2,3,4,5\}$. This notion is central to the concept of a random FMS. Following the permutation, parameters such as operation time and tool slot requirement are assigned to the jobs. All this information is simultaneously stored in a matrix (Matrix 1).

The jobs are then checked with respect to the tool slot constraint. If a job requires more than six tool slots for an operation, then that job is considered infeasible. The job type and the route number of that job are stored in a matrix for later retrieval (Matrix 2).

\subsubsection{Loading}

For each job, all possible routes are considered and for each possible route, the processing time on each machine is summed up. This gives a route processing time (RPT) list for each machine showing the total time for each job on each of its routes. The RPT Iist for each machine is sorted in descending order according to the total processing time and stored in Matrix 3. The jobs that are infeasible with 
respect to the tool slot constraint are deleted from the RPT list. The RPT list of the feasible jobs is stored in Matrix 4.

Each transaction is then checked to determine whether it improves the objective of balancing the workload. If so, the transaction is selected for the machine with the maximum remaining capacity. The remaining capacity of that machine is then updated by subtracting from it, the batch processing time of the job just loaded. Consequently, the job is loaded onto the machine if the job number/route number combination of that job has not already been loaded onto that machine. Thus, a job cannot take more than one route in the loading process. The loading allocation of the machines is stored in matrix 5 .

\subsubsection{Dispatching}

The final segment of the model schedules the jobs through the machines. The incoming jobs are rearranged according to the dispatching rule being tested. Initially, jobs are released to their corresponding machines. Thus, all the machines start operating at commencement of the scheduling period. A machine keeps operating until the operation time of the corresponding job elapses. When the operation time elapses, the system scans the visitation sequence of the job to check if the job needs further operations done. If this is the case, then the job waits for the next machine in its 
visitation sequence. If the machine is not busy at that time, then the job engages that machine. Simultaneously, as the operation time of the job elapses on the first machine, the system immediately schedules the next job on that machine. However, it may be the case that the job is currently being operated upon at some other machine (recall that the original transactions were split according the route and the visitation sequence). When this happens, the machine waits for the job, and this time comprises the idle time for that machine. This idle time is stored in a savevalue specific to the machine. Similarly, the jobs are scheduled on the other machines in the system. The scheduling of jobs continues in this manner until all jobs have been scheduled, at which time the model terminates.

\subsection{SUMMARY}

This chapter contained a general description of simulation modeling and the loading heuristic used in this study. We commented on the inadequacy of analytic models of manufacturing systems and the benefits of simulation in manufacturing. This was followed by a description of the types of simulation modeling. We observed the advantages of using discrete event simulation for the purposes of this study, and in particular, the simulation language GPSS. We also examined the GPSS implementation of the loading heuristic used in this study. In the next chapter, we present the experimental design of this study. 


\section{Chapter V}

\section{EYPERIMENTAL DESIGN}

Modeling and coding a simulation is a challenging task. The objective of conducting these simulations is to use the model to gain a better understanding of the system being simulated. Such use of a simulation model can be thought of as being composed of two parts: design and analysis.

The design phase is concerned with setting the various parameters of the model and deciding upon the conditions under which the model will be run. For example, in a manufacturing study we would need to decide which scenarios to consider, and also the length and simulation runs of each scenario (Kelton, 1988).

The analysis phase is concerned with analyzing and using the output from the simulation runs to infer something about the system. The analysis that is possible depends on what was decided in the design phase. For example, we would be able to make inferences only on the scenarios considered and the accuracy of our inferences could depend on the length and number of runs we decided to make (Kelton, 1988).

The present chapter focuses on the design phase of this study. The analysis phase will be considered in the next chapter. 


\subsection{PROBLEM}

As we have seen earlier, various types of manufacturing flexibility can be attributed to an FMS. However, not all types of flexibility can be built into an FMS. A system may be highly mix-flexible but this might inhibit its volume flexibility. This suggests that there is a possibility of conflict among the various flexibilities and some flexibilities might have to be traded-off for others.

The purpose of this study is to examine the flexibility trade-offs associated with a random FMS. A knowledge of these trade-offs can immensely help the management in forming a manufacturing strategy that is in keeping with the long term objectives of the firm. More important, this knowledge can help design manufacturing systems that are more flexible.

\subsection{METHODOLOGY}

There is a wide variety of performance measures that are commonly used in manufacturing simulation studies, for example, throughput, makespan, WIP, equipment utilization, and the time jobs spend in queue (Law, 1988). In an expensive system like FMS, high equipment utilization is of prime importance. The importance of this performance measure has been recognized in various studies (eg, see Avonts et al, 1988, Bastos, 1988, Law, 1988, Smith et al, 1986, Stecke, 
1981). In this study, we use machine idle time (MIT) and job waiting time (JWT) as the performance measures to examine the flexibility trade-offs in the FMS under study. We observe the effect of the flexibility types under consideration on these performance measures, under the influence of different loading and dispatching strategies, and various system configurations.

As an example, let us consider an FMS that has six machines in operation. These machines will accumulate some idle times during operation. This could happen when a machine is waiting to process a job that is currently being operated upon by another machine in the system. In another system configuration the FMS could have eight machines in operation. These machines will also accumulate some idle times during operation. These idle times will be different from the ones generated in the previous configuration. A statistically significant difference would indicate an increase or decrease in the mean idle times. If the latter configuration results in higher idle times, it would be safe to infer that an increase in the number of machines has caused a reduction in the system's physical output, that is, the volume flexibility.

Less obvious may be the impact of a change in the number of machines on product flexibility and machine flexibility. Using Browne et al's (1984) definitions, machine flexibility is the ease of the system in making the changes required to 
produce a given set of part types. A greater number of machines would enhance the ability of the system to accommodate these changes. This would reduce the waiting times for the jobs, thus enhancing machine flexibility. A lower value of the waiting times would supplement the system's capability to change over to produce a new part, thus improving product flexibility.

In another situation, the system may be subject to processing a wider variety of products. This increase in product variety inherently involves an increase in product flexibility. Based on the machine idle times, a similar conclusion can be made regarding the impact of this increase on volume flexibility. Additionally, an increase in the product variety can also affect process flexibility since the new products might utilize the system's unused ability to perform different tasks. If the new products do utilize this ability, then this will decrease the system's process flexibility. Intuitively, a greater product variety would also render the machines less flexibile. However, machine flexibility is largely product specific in that the new products may require significant changes to the machines.

Another possibility is an increase in the number of routes that the jobs can take through the machines. Increasing the number of routes also increases the routing flexibility of the system. An increase in the number of routes may also enhance machine utilization, thus affecting other 
flexibility types. However, MIT may still be used to explain the impact of this increase on volume flexibility.

A more involved situation could entail a combination of one or more of the above scenarios. It is difficult to elaborate on the outcomes of such a change as it would be influenced by factors such as the loading and dispatching rules. An explanation of the outcomes would take these factors into consideration.

The above discussion centers on the use of MIT as the performance measure. Inferences can also be made by using JWT as the performance measure. Another possibility is to use the quality of the product as the deciding factor. The choice of a performance measure would be a function of the manufacturing strategy of the management and which performance measure is considered more detrimental to the operation of the manufacturing system.

\subsection{SYSTEM DESIGN AND SPECIFICATIONS}

(adapted from Shanker \& Tzen (1985))

Product variety: The FMS under consideration can process upto 15 job types.

Number of machines: The FMS employs upto 10 machines.

Number of routes: The jobs can take upto 5 routes through the machines. 
Job arrival: Job inter-arrival time follows an exponential distribution with an arbitrarily chosen mean of 70 minutes.

Batch size: The batch size is assumed to be uniformly distributed from 5 to 20 .

Due date: The total work content (TWK) method (Conway, 1965) is used to assign the due dates of jobs using the following definition,

$$
D=A+k P
$$

where $D$ - due date of the job

$$
\begin{aligned}
& \text { A - arrival time of the job } \\
& \text { P - total processing time of the job } \\
& k \text { - parameter specified by the management }(\geq 1)
\end{aligned}
$$

Number of operations: The number of operations is assumed to be uniformly distributed from 6 to 10 .

Processing time: Processing time for each operation is assumed to be uniformly distributed over 6 to 30 minutes.

Tool requirement: The tool requirement for each operation is given by the following distribution.

Number of tools Percentage requirement

$\begin{array}{lr}5 & 80 \\ 6 & 15 \\ 7 & 5\end{array}$

Scheduling period: The simulation is run until all the jobs are processed. 


\section{$5.4 \quad$ SCOPE}

A total of four models were coded in GPSS. The first model was for simulating simple loading rules (eg, FIFO, SPT) in combination with simple dispatching rules (eg, LPT, EDD). The second model was for simulating simple loading rules in combination with the WINQ dispatching rule. The third model was for simulating the Shanker \& Tzen (1985) loading algorithm in combination with simple dispatching rules. The fourth model was for simulating the Shanker \& Tzen (1985) loading algorithm with the WINQ dispatching rule. Because of its global nature, the WINQ dispatching rule required extraordinary time and effort in coding.

The FMS under consideration: (i) employs upto 10 machines, (ii) can handle upto 15 job types, and (iii) can accommodate upto 5 routes through the machines. All the possible combinations of these three parameters result in a total of 750 system configurations. In order to keep the system specifications realistic and the problem size practical, only 18 system configurations (Table 5.1) were simulated. However, it is possible to simulate all the 750 configurations using the GPSS model. The 18 configurations were individually tested under various scheduling environments composed of a loading rule and a dispatching rule. The rules that were tested and their descriptions are as follows:

\section{LOADING ONLY}

Shanker \& Tzen (1985) loading algorithm. 


\begin{tabular}{|cccc|}
\hline \multicolumn{5}{c}{ TABLE 5.1 } & & \\
& & \\
& System Configurations Evaluated & \\
& & & \\
Configuration & Job types & Machines & Routes \\
\hline & & & \\
2 & 7 & 6 & 3 \\
3 & 7 & 6 & 5 \\
4 & 7 & 8 & 3 \\
5 & 7 & 8 & 5 \\
6 & 7 & 10 & 3 \\
7 & 7 & 10 & 3 \\
8 & 11 & 6 & 5 \\
9 & 11 & 6 & 3 \\
10 & 11 & 8 & 5 \\
11 & 11 & 8 & 5 \\
12 & 11 & 10 & 3 \\
13 & 11 & 10 & 5 \\
14 & 15 & 6 & 3 \\
15 & 15 & 6 & 5 \\
16 & 15 & 8 & 3 \\
17 & 15 & 8 & 5 \\
18 & 15 & 10 & \\
& 15 & & \\
\hline
\end{tabular}

\section{DISPATCHING ONLY}

WINQ - select the job that will go to its next operation to a machine that has the least workload.

LOADING \& DISPATCHING

FIFO - Eirst in first out. SPT - schedule the jobs according to their processing times; shortest processing time first. LPT - schedule the jobs according to their processing times; longest processing time first. 
EDD - schedule the jobs according to their due dates; earliest due date first. ARRIVAL TIME - schedule the jobs according to their initial arrival time in the system.

SCHEDULING ENVIRONMENTS:

The following scheduling environments (loading / scheduling) were tested:

Shanker \& Tzen / FIFO

Shanker \& Tzen / SPT

Shanker \& Tzen / LPT

Shanker \& Tzen / EDD

Shanker \& Tzen / Arrival Time

Shanker \& Tzen / WINQ

FIFO / FIFO

SPT / FIFO

SPT / WINQ

LPT / FIFO

LPT / WINQ

EDD / FIFO

EDD / WINQ

Arrival Time / FIFO

Arrival Time / WINQ

The reason for the recurrence of FIFO and WINQ as the dispatching rules in the latter part of the list is that FIFO is considered as one of the inferior scheduling rules and 
WINQ is considered as one of the better scheduling rules in scheduling literature.

In the course of simulation, a scheduling environment is first selected and the 18 configurations of the FMS are then simulated under this environment. The system reaches steady state in a very short period of time. The simulation is run until the system processes all the jobs for a production run. This technique might seem in contrast with the more conventional approach of running a simulation for a specified period of time (eg, 8 hours) and then terminating the simulation. However, to calculate accurately the values of JWT and MIT, the simulation should be run until all the jobs are processed. This is particularly important when a scheduling rule such as SPT is being simulated. SPT is biased against jobs with long processing times, increasing the probability of their remaining as WIP toward the end of the simulation.

Each simulation was conducted three times. The number of replications was kept low due to the need for manual compilation of data. This resulted in roughly 350 hours of simulated time for each configuration under the given scheduling environment. Over 1000 simulations were conducted and approximately 20000 samples of data were compiled. The data are used for the statistical analysis and graphical output. 


\subsection{VARIANCE REDUCTION}

In many simulation studies, there is often an opportunity to run the simulation in a way that would get more precise estimates, than would otherwise be possible by running the simulation in a normal, straightforward way. A primary means of obtaining more precise estimates of the relevant parameters is by reducing the variance of these parameters. One approach toward reducing variability is to operate the different models under identical random conditions. This eliminates a source of variability thus causing the performance measures to have lower variance (Thesen \& Travis, 1988).

In this study, all the models were operated under identical conditions and the same random number streams were used throughout. For example, jobs arrive at identical times, and are assigned identical parameters such as job type, machine visitation sequence, operation time, batch size, and due date.

\subsection{MODEL VALIDATION AND VERIFICATION}

Validation and verification of a simulation model address the concern whether the information derived from the model can be used with confidence. Model validation usually means that "a computerized model within its domain of applicability possesses a satisfactory range of accuracy consistent with the intended application of the model" (Schlesinger et 
al, 1979). Model verification is usually defined as ensuring that the computer program of the model and its implementation are correct (Sargent, 1988).

\subsubsection{Validation}

Model validation is a part of the total model development process. The validation process consists of performing tests within the development stage to determine whether a model is valid. These tests are conducted until sufficient confidence is obtained that a model can be considered valid for all its intended applications (Sargent, 1988).

There are various validation techniques that can be used for validating a model (eg, see Balci \& Sargent, 1984). The following techniques (Sargent, 1988) were used to validate the models used in this study.

Comparison with other models: Various results of the simulation model being validated are compared with results of similar valid models.

Degenerate tests: The degeneracy of the model's behavior is tested by removing portions of the model or by appropriate selection of the values of the input parameters.

Sensitivity analysis: The values of the input and the internal parameters of the model are changed to determine the effect on the model. 
Predictive validation: The model is used to predict the system behavior and comparisons are made to determine if the system behavior and the model's forecast are the same.

Traces: The behavior of different types of specific entities in the model is traced through the model to determine if the model's logic is correct.

\subsubsection{Verification}

Model verification was accomplished by ensuring the correct programming and implementation of the conceptual model. Dynamic testing was used to verify the computer model. The model was executed under different conditions and the values obtained were used to determine the accuracy of the computer program and its implementations. Other techniques used for model verification were traces, consistency checks, and reprogramming some components to determine if the same results were obtained.

\subsection{OPERATIONAL VALIDITY}

Operational validity is primarily concerned with determining that the model's behavior is sufficiently accurate for the model's intended purpose over the domain of its intended application. This is where most of the validation testing and evaluation take place. The computerized model is used in operational validity and all the validation tech- 
niques are applicable. To obtain a high degree of confidence in a model and its results, comparison of the model's and the system's input/output behavior for at least two different sets of experimental conditions is required. There are three primary comparison methods used: (i) graphical comparison, (ii) confidence intervals, and (iii) hypothesis tests (Sargent, 1988). Graphs are the most commonly used approach and this is the technique used in this study.

\subsection{SUMMARY}

In this chapter we focused on the experimental design of this study. We examined the methodology proposed in this study to observe the flexibility trade-offs and to make inferences about the optimal configuration of the system with respect to a desired flexibility. We also commented on the variance reduction measures, and the validation and verification techniques employed in this study. In the next chapter we present the simulation results in a graphical format and we perform statistical analysis on the data. 


\section{Chapter VI}

\section{ANALYSIS}

Simulations are often used to compare the performance of different solutions to a problem. In this study we use the performance measures of an FMS to study the trade-offs between various flexibility types. As mentioned earlier: (i) we are using the job waiting times (JWT) and the machine idle times (MIT) as the performance measures, and (ii) we are primarily concerned with machine, product, routing, and volume flexibilities (Browne et al, 1984) and the trade-offs between them.

First we present graphical output that depicts the variation in the mean values of the performance measures as the system configuration and the scheduling environment are altered. It becomes evident from these graphs that system configuration and scheduling environment have a discernible effect on the performance measures. However, statistical analysis is necessary in order to detect differences that are significant. Therefore, subsequent to the presentation and discussion of graphical output, we perform statistical analysis on the data to determine significant differences between the mean values of the performance measures. 


\subsection{GRAPHICAL OUTPUT}

As stated earlier, each simulation corresponding to a given system configuration was conducted three time. The simulations resulted in values of JWT and MIT for each machine in the system. These values, averaged over the corresponding number of machines and then over the number of replications, resulted in the mean values of JWT and MIT. The mean values were then used for plotting the graphs.

The 18 system configurations examined in this study (Table 5.1) involve a change in three basic parameters of the FMS: (i) number of job types, (ii) number of machines, and (iii) number of routes through these machines. The impact of a change in one of these parameters is examined while considering the configurations in which the other two parameters are kept constant. For example, a change in the number of routes would entail an examination of the configurations $1-2,3-4, \ldots, 17-18$.

Each graph corresponds to a schedule comprising a loading rule and a dispatching rule. The 18 system configurations form the $x$-axis and the mean values of the performance measures are plotted against these configurations. These graphs appear in appendixes $A$ and $B$. 


\section{1 .1 Simple Loading Rules 6.1 .1 .1 FIFO / FIFO}

The graph (fig A.1) shows the increasing trend of JWT as the product variety is increased. This is to be expected as a greater product variety also implies an increased work load on the machines. An increase in JWT indicates that the volume flexibility of the system has decreased. Adding machines to the system also causes an increase in JWT. This signifies a decrease in volume flexibility, although machine flexibility, and therefore product flexibility has been enhanced by the introduction of more machines. Usually, increasing the number of routes leads to an increase in JWT. This suggests a decrease in volume flexibility. An irregular trend occurs in JWT in configurations $1-2,6-7,10-11$, and then 12-13. As the number of routes is increased in configuration 2, a decrease in JWT shows that it is possible for routing flexibility and volume flexibility to increase simultaneously. Similarly, it can be seen that an increase in the product variety, when accompanied by a decrease in the number of machines and the number of routes, causes a decrease in JWT. This hints toward configurations of the FMS with a small number of machines and routes.

This effect is much more pronounced in the case of MIT. Increasing the product variety causes only a slight increase in MIT thus indicating a small decrease volume flexibility. The sharp declines in MIT, although difficult to analyze, 
show that the various flexibility types are not always discordant. It is possible for product flexibility and volume flexibility to increase even with a decrease in machine flexibility and routing flexibility. Similarly, configuration 14 results in a slightly lower value of MIT as compared with configuration 8 . However, the difference merits enough significance to state that the FMS with a small number of machines is able to process a large product variety with no apparent loss of flexibility. Increasing the number of machines leads to a rapid increase in MIT. This displays a large decrease in volume flexibility. From the graph, routing flexibility always increases with volume flexibility in the small system configuration ( 6 machines). However, there is a trade-off between these two flexibility types in some of the other configurations.

\section{1 .1 .2 SPT / FIFO}

The graph (fig A.2) indicates that JWT increases with the introduction of more job types. This signals a decrease in volume flexibility. Incorporating more machines in the system also adds to the JWT indicating a loss of volume flexibility. Increasing the number of routes generally increases JWT. As in the previous schedule (FIFO/FIFO), enhancing the product variety when accompanied by a switch to a small system configuration leads to a reduction in JWT. This denotes an increase in product flexibility and volume flexibility. 
An increment in the product variety generally causes small fluctuations in MIT. In the small configurations (6-8 machines) MIT generally decreases whereas in the large configuration MIT shows an increase. This implies that there is a gain in volume flexibility along with product flexibility in the small system configurations. Increasing the number of machines in the system produces a sharp rise in MIT. This signifies a decrease in volume flexibility at the expense of machine flexibility and product flexibility. Adding routes to the system also causes MIT to increase. Once again, switching to small system configurations leads to a drastic reduction in MIT.

\section{1 .1 .3 SPT / WINQ}

This graph (fig A.3) is similar to the previous one (fig A.2). JWT is slightly higher in value whereas MIT is slightly lower as compared with SPT/FIFO. This is because of the global nature of the WINQ dispatching rule. Increasing the product variety causes JWT to rise except when the increase is accompanied by a shift to a small system configuration. Including more routes leads to a loss of volume flexibility.

An interesting observation is that MIT generally decreases with increasing product variety. The implication is that product flexibility and volume flexibility are enhanced simultaneously. Adding machines causes MIT to increase. Proviaing more routes also leads to an increase in MIT. This 
increase is more evident in the large system configuration (10 machines).

\section{1 .1 .4 LPT / FIFO}

The graph (fig A.4) displays the consistent increasing pattern of JWT. As compared with previous graphs, this one is notably free of fluctuations. This shows a loss of the relevant flexibility types with an increase in the value of the corresponding system parameters. Increasing the product variety always leads to high values of JWT indicating a loss of volume flexibility. Similarly, adding machines to the system causes JWT to increase. Adding routes also causes an increase in JWT in most cases.

Machine iale time shows the familiar cyclic trend. Introducing more job types causes only a slight variation in MIT. This implies that there is no trade-off involved between product flexibility and volume flexibility. Adding machines causes sharp increases in MIT. However, incorporating more routes generally causes a decrease in MIT, implying an increase in volume flexibility along with routing flexibility.

\section{1 .1 .5 IPT / WINQ}

The graph (fig A.5) shows a trend similar to the previous graph (fig A.4). JWT increases with product variety. Adding 
machines generally causes JWT to increase. This signifies a loss of volume flexibility. Similarly, providing the jobs with more routes leads to a loss of volume flexibility.

An increased job variety causes slight deviations in MIT. Sometimes it leads to lower values of MIT while some other scenarios show an increase. MIT decreases significantly when an increase in product variety is accompanied by a change to a small system configuration. MIT increases with the number of machines showing a loss of volume flexibility. Adding routes reveals an interesting pattern. When the product variety is small ( 7 job types), MIT decreases with the addition of routes. However, a large product variety (11-15 job types) reveals a reverse trend in MIT. This suggests that WINQ favors small system configurations in terms of routing flexibility.

\section{1 .1 .6 EDD / FIFO}

The graph (fig A.6) exhibits an increasing trend in JWT as more job types are processed by the system. This indicates a loss of volume flexibility. Increasing the number of machines also causes an increase in JWT. However, adding routes causes merely a slight increase in JWT in small system configurations (6-8 machines) whereas a large increase is evident in the large configuration (10 machines). This indicates that EDD/FIFO favors small system configurations when routing flexibility is of importance. 
The cyclic nature of MIT is more evident in this graph than the previous ones. Enhancing the product variety causes marginal variations in MIT. This shows no significant change in volume flexibility. Adding machines always leads to a loss of volume flexibility. Similarly, providing more routes leads to a loss of volume flexibility. The loss is more apparent when there is a large number of machines (8-10).

\subsubsection{EDD / พINQ}

An increased product variety invariably causes JWT to increase (fig A.7). However, a switch to a small configuration lowers JWT. This effect is more pronounced than in EDD/FIFO. More machines also effect an increase in JWT especially when the number of routes is high. Adding routes invariably leads to high JWT. The increase is particularly noticeable when the product variety is large (11-15 job types).

Machine idle time exhibits minor variation with an increase in product variety. Configurations with 10 machines in operation show a decrease in MIT as product variety is increased. Adding machines and routes cause MIT to increase indicating a loss of volume flexibility.

\subsubsection{Arrival Time / FIFO}


The graph (fig A.8) illustrates the growing trend of JWT as more products are processed by the system. Increasing the number of machines also causes JWT to $r$ ise. Adding routes to small system configurations ( 6 machines) reduces JWT whereas adding routes to large configurations (8-10 machines) increases JWT. This signifies that in large configurations, routing flexibility is in conflict with volume flexibility.

Machine idle time shows the familiar cyclic trend. Switching to a small system configuration enhances the volume flexibility even though machine flexibility and routing flexibility have decreased. Increasing the product variety causes minimal increase in MIT. Adding machines raises the value of MIT. Allowing more routes for the jobs lowers MIT in small system configurations ( 6 machines) and vice versa.

\subsubsection{Arrival Time / WINQ}

The graph (fig A.9) exhibits a steep increase in JWT. Increasing the product variety leads to a significant loss of volume flexibility. JWT also increases with the number of machines suggesting a loss of volume flexibility. This increase is drastic when the product variety is large (11-15 job types). Adding routes causes a gain in volume flexibility in the small system configuration ( 6 machines).

Machine idle time increase with product variety. MIT drops when the system configuration is altered to a small 
one. This implies a simultaneous gain in product flexibility and volume flexibility. Adding machines generally causes a loss of volume flexibility. However, in some configurations (7-9, 13-15) adding machines enhances volume flexibility. Including more routes decreases MIT only in the small system configuration ( 6 machines).

\subsubsection{Shanker \& Tzen Loading Algorithm 6.1 .2 .1 FIFO}

As compared with the simple loading rules, this graph (fig $B .1$ ) shows a significant reduction in the value of the performance measures. This is because the algorithm balances the work load among the machines and it discards some of the jobs. An increase in the number of job types from 7 to 11 generally increases JWT, after which it stays fairly constant. However, a change from 11 to 15 job types along with a reduction in the number of machines and routes, causes a sharp drop in JWT. This implies a gain in product flexibility and volume flexibility. Unlike the previous schedules, JWT does not drop for a similar change from 7 to 11 job types (configuration 6 to 7 ). This could suggest that the schedule favors large system configurations. Adding machines to the system also causes an increase in JWT. This denotes a loss of volume flexibility. Adding routes generally leads to an increase in JWT. 
Machine idle time shows little variation as the product variety is increased. There is a slight decrease in MIT when the product variety is large ( 15 job types). Adding machines causes MIT to rise. Incorporating more routes generally causes a gain in volume flexibility especially when there are 11 job types in the system. Similar to the case of JWT, MIT drops when the product variety is increased. This drop is more apparent when the product variety is increased from 11 to 15 (configuration 12 to 13 ).

\section{$6.1 .2 .2 \quad \mathrm{SPT}$}

Job waiting time increases with an increase in product variety ( $f i g$ B.2). However, when accompanied by a change to a small system configuration, an increase in product variety causes a drop in JWT. Usually, adding machines and routes lead to a loss of the related flexibility types.

Machine idle time generally decreases with an increase in product variety, especially when the number of machines and routes are also decreased. Adding machines causes MIT to increase. This increase is less apparent when the product variety is large (15 job types). This suggests that the trade-off between volume flexibility and machine and product flexibilities is less severe when the product variety is large. Adding routes leads to a loss of volume flexibility when the product variety is small ( 7 job types). In the other configurations, MIT generally decreases with an increase in the number of routes. 


\section{$6.1 .2 .3 \quad$ LPT}

Job waiting time increases when the number of job types is increased from 7 to 11 ( $f$ ig B.3). Therefore, there is a loss of volume flexibility when product flexibility is increased. However, JWT shows a slight decrease when the number of jobs is increased from 11 to 15. This indicates a gain of product flexibility and volume flexibility. Adding machines causes JWT to increase. This illustrates a loss of volume flexibility. Including more routes generally increases JWT.

Machine idle time displays a similar trend with respect to product variety. An increase from 7 to 11 job types causes MIT to rise whereas an increase from 11 to 15 job types reduces MIT. The cyclic pattern is also evident from the graph. More machines generally increase MIT. Adding routes does not reveal any discernible pattern in MIT.

\section{1 .2 .4 EDD}

An increase in the product variety from 7 to 11 leads to an increase in JWT (fig B.4). A further increase in product variety effects little variation in JWT. Adding machines to the system causes JWT to increase. This increase is more apparent when the product variety is large (11-15 job types). Providing more routes reduces JWT when the product variety is large (15 job types) and increases JWT otherwise 
(7-11 job types). This exhibits a trade-off between routing flexibility and volume flexibility when the product variety is smali.

Machine idle time varies in a similar fashion, that is, an increase followed by a decrease as the product variety is increased. Adding machines causes MIT to increase particularly when the number of job types is eleven. Increasing the number of routes increases volume flexibility when there are 11 job types in the system. This could signify that the availability of a large number of routes is conducive to this schedule.

\subsubsection{Arrival Time}

Job waiting time exhibits a pattern that is similar to the previous schedules (fig B.5). It appears that this trend is largely a feature of the loading algorithm as opposed to the local dispatching rules. Job waiting time increases with the number of machines. The increase is minimal when the product variety is small ( 7 job types). Adding routes provides a gain in volume flexibility when the product variety is large ( 15 job types).

Machine idle time increases as the product variety is increased from 7 to 11 and decreases thereafter. Adding machines causes MIT to increase. The increase is minor if the product variety is large (15 job types). An increase in 
the number of routes does not reveal any plausible trend in MIT. As in all the cases considered so far, MIT displays the familiar cyclic trend.

\section{1 .2 .6 WINQ}

The graph (fig B.6) shows that there is a consistent increase in JWT as the product variety is increased. This is in sharp deviation from the trend displayed by the schedules that incorporate local dispatching rules. Adding machines and routes generally cause JWT to increase.

Enhancing the product variety or the number of machines does not reveal any distinguishable trend in MIT. Adding routes lowers MIT when the product variety is moderate (11 job types).

\subsection{DISCUSSION OF GRAPHICAL OUTPUT}

The preceding analysis has revealed some intriguing and seemingly counter-intuitive results. It would appear that adding machines and routes to the system would lower the values of JWT and MIT as the resources are being utilized more effectively. Also, it is not yet apparent why an increase in the product variety leads to a reduction in the value of the performance measures, especially MIT, despite a small system configuration. The unexpected behavior of routing flexibility also escapes a simplistic explanation. 
If there is only one job in the system and it requires processing at all machines then the machines can be arranged as a flow line. This will minimize the distances between the machines and reduce transport delays. However, when there is more than one job type, it becomes necessary to consider the setup time and changeover time for the jobs on the machines and the sequences of operations for each job type (Buzacott, $1982 b)$.

If all job types have the same sequence of operations then the system would usually be operated so that only one job type is being produced at any one time. However, if the jobs have different sequences then the need to have different routes through the system introduces several complications. There is a possibility of blocking and deadlock if there is limited WIP. A job may block a machine because it is not able to move on to another machine as that machine is occupied by another job. More than one job may compete for the same machine, causing deadlock. If the machines are laid out to minimize material movement for one job type with a specific operation sequence then the layout will not be optimal for other sequences, thus causing delays. On the other hand, if the material handing system is flexible enough to accommodate all sequences then all jobs will require more time for material movement, as compared with a system with a dedicated material handing system (Buzacott, $1982 b)$. 
Summarizing, it is apparent that the production output of a system generally declines as the overall flexibility increases. However, it is also possible that the maximum production rate does not necessarily occur when the overall system flexibility is at its minimum. In the probabilistic environment of a random FMS, it is very difficult to predict a combination of the parameters that will simultaneously optimize production rate and system flexibility. Different loading and dispatching strategies affect a system's flexibility and production rate in distinct ways. However, it would be interesting to consolidate the impact of a given schedule on a particular flexibility type, on the extent of the flexibility trade-offs, and on the physical output of the system. It also remains to be seen which schedule optimizes which flexibility type and favors what type of system configuration. The following dialog expands on this subject. The associated graphs appear at the end of the section.

\subsubsection{Simple Loading Rules}

\subsubsection{Job Waiting Time}

It can be seen from the graph (fig 6.1) that for a low product variety ( 7 job types) the schedules do not have significant impact on the performance measure. This is a normal occurrence as with a low product variety, the machines have a moderate work load. This means that a low number of jobs queue up for the machines. As a consequence, the scheduling 
rules have little impact on the job waiting times. This is particularly the case when a work load balancing algorithm is being used for scheduling.

Overall, the graph shows a loss of volume flexibility as product flexibility is enhanced. This trade-off is more apparent in some schedules than in others. SPT, which is considered as one of the better scheduling rules exhibits the least trade-off between volume flexibility and product flexibility. FIFO/FIFO which is surpassed only by SPT, consistently shows better performance than the remaining schedules.

Adding machines invariably results in high values of JWT. For small product variety ( 7 job types), SPT/FIFO, FIFO/FIFO, and LPT/FIFO (in that order) demonstrate the lowest trade-off that occurs by adding machines. For medium product variety (11 job types), SPT/FIFO, LPT/FIFO, and SPT/WINQ show good performance. For large product variety (15 job types), SPT/WINQ, FIFO/FIFO, and LPT/FIFO display good performance.

Adding routes usually decreases volume flexibility of the system. When the product variety is small, increasing the number of routes displays a minimal trade-off in the case of FIFO/FIFO, LPT/FIFO, and LPT/WINQ. When the product variety is medium, SPT/FIFO, SPT/WINQ, and LPT/FIFO display good performance. When the product variety is large, SPT/FIFO, FIFO/FIFO, and LPT/FIFO demonstrate good performance. 


\subsubsection{Machine Idle Time}

The cyclic trend of MIT is the most prominent feature of this graph (fig 6.2). Enhancing the product variety does not always result in a trade-off between product flexibility and volume flexibility. SPT/WINQ does not display any such trade-off. On the contrary, when this schedule is used there is a simultaneous gain in the two flexibility types irrespective of the product variety. SPT/FIFO displays similar behavior for the small system configurations (6-8 machines). LPT/FIFO, EDD/FIFO, and EDD/WINQ also display negligible trade-offs between product flexibility and volume flexibility.

Increasing the number of machines leads to a loss of volume flexibility at the expense of machine flexibility and product flexibility. LPT/WINQ, SPT/WINQ, and LPT/FIFO generally exhibit good performance irrespective of the product variety.

Adding routes reveals interesting patterns. LPT/FIFO shows a gain in volume flexibility as the number of routes is increased. This may also suggest an increase in process flexibility. Arrival Time/FIFO, Arrival Time/WINQ, and FIFO/FIFO also show similar behavior, but only for the small system configuration ( 6 machines). There is a trade-off in the other configurations. Similarly, LPT/WINQ shows a gain in product flexibility and volume flexibility when the prod- 
uct variety is small ( 7 job types). The other schedules display a trade-off in all situations.

\subsubsection{Shanker \& Tzen Loading \\ 6.2.2.1 Job Waiting Time}

The graph (fig 6.3) shows a trend similar to MIT. Job Waiting Times exhibit a sharp dip in configuration 5 ( 7 job types, 10 machines, 3 routes). This indicates a gain of volume flexibility and a loss of routing flexibility. Apparently, the Shanker \& Tzen loading algorithm favors this configuration under the dispatching rules tested.

An increase in product variety generally renders the system less volume-flexible. For small to medium product variety (7-11 job types), SPT and EDD display a trade-off that is lower than the ones exhibited by the other dispatching rules. For large product variety (15 job types) LPT exhibits a gain in volume flexibility as product flexibility is enhanced. FIFO, EDD, and Arrival Time show no discernible trade-off. WINQ exhibits the worst performance with respect to this trade-off.

Adding machines consistently results in a loss of volume flexibility. For small and large product variety, SPT and EDD exhibit good performance. For medium product variety, EDD and FIFO appear to be good dispatching rules. 
Providing more routes usually causes the volume flexibility of the system to decrease. SPT and EDD show a lower trade- off than the other rules when the product variety is low. EDD and FIFO seem favorable for medium product variety. EDD and Arrival Time show a coincident gain in volume flexibility and product flexibility for large product variety.

\subsubsection{Machine Idle Time}

Unlike the trend displayed by simple loading rules, this graph (fig 6.4) shows many fluctuations. The common characteristic among the valleys is the presence of 5 routes in the system. The peaks occur at large system configurations and the valleys occur at small system configurations. It is evident from the graph that this loading algorithm prefers the configurations with 5 routes.

As product variety is enhanced, SPT increases the volume flexibility of the system. A similar trend is shown by FIFO, LPT, and Arrival Time, but only for large product variety (15 job types). For small to medium product variety $(7-11$ job types), FIFO shows no trade-off between product flexibility and volume flexibility. Similarly, for large product variety EDD shows no such trade-off. In all the other cases there is a trade-off involved. WINQ shows no definite trend. 
As in all the previous cases, adding machines causes volume flexibility to decline without exception. For low product variety, EDD and WINQ display a trade-off that is lower than the one seen in other rules. For medium to large product variety, SPT and WINQ perform well to contain the tradeoff.

As the routes are increased, the system generally becomes more volume flexible. The dispatching rules exhibit remarkably similar performance with respect to routing flexibility especially when the product variety is low. EDD and WINQ show good performance for small product variety. SPT and WINQ seem favorable for medium product variety. SPT and LPT display a lower trade-off for large product variety. 

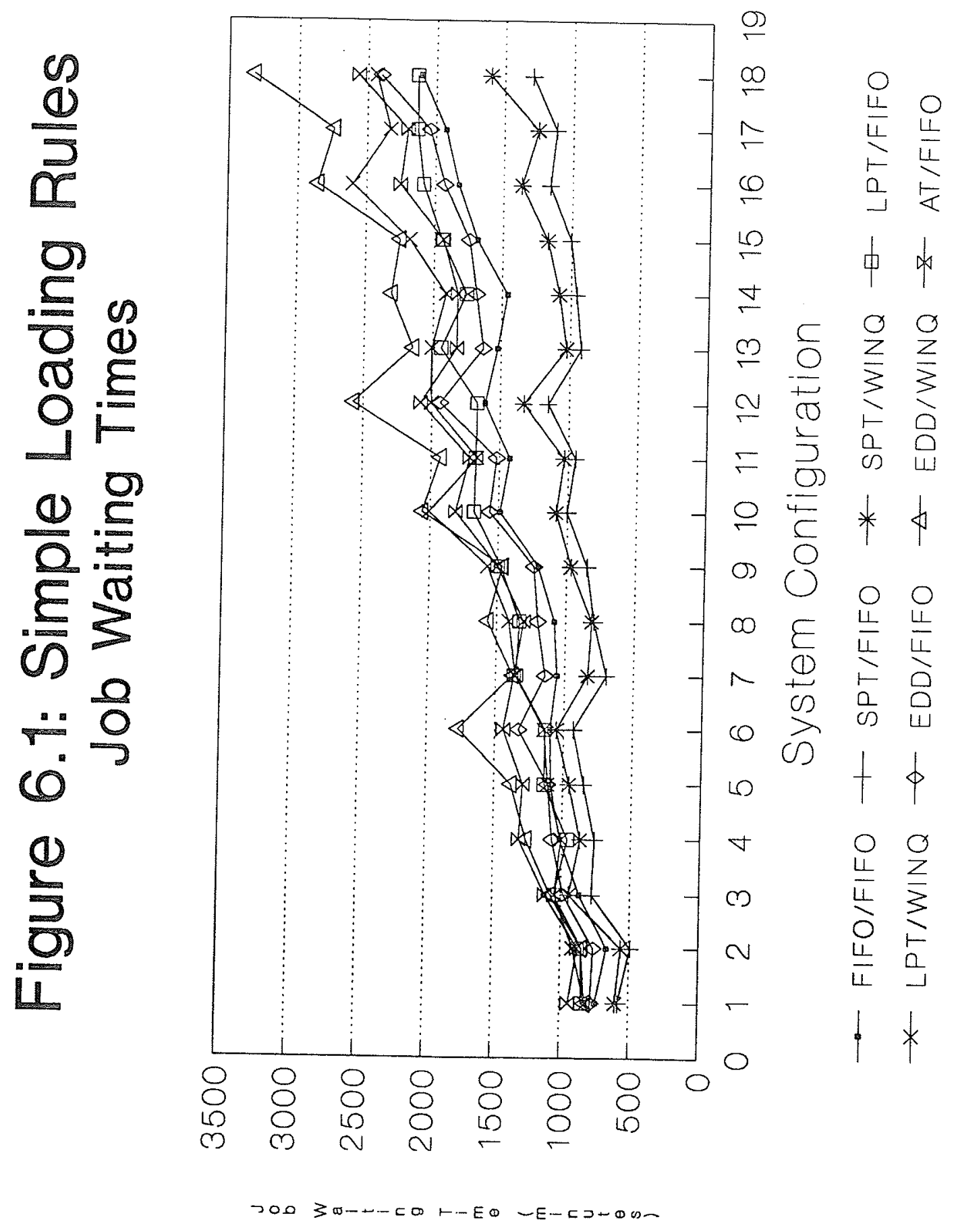

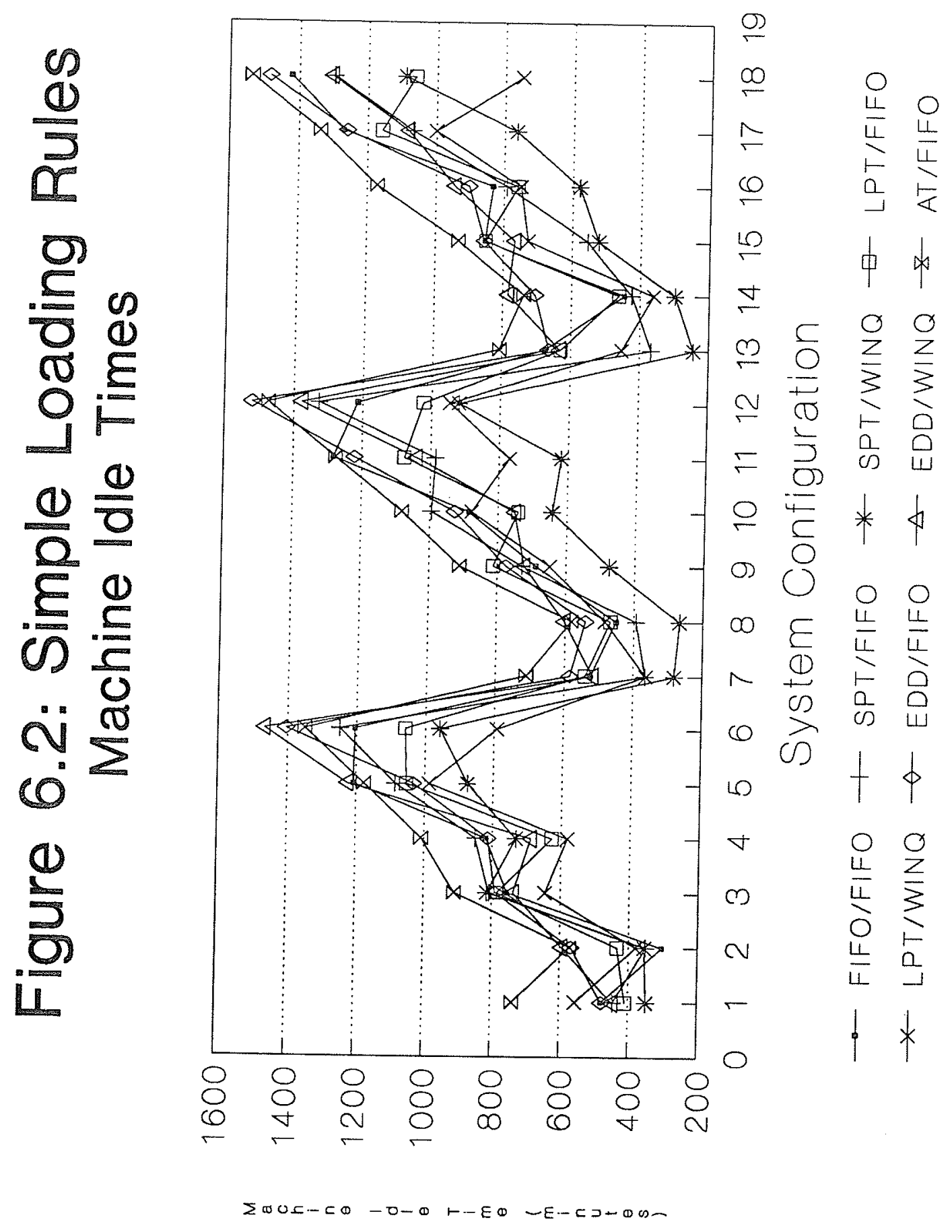


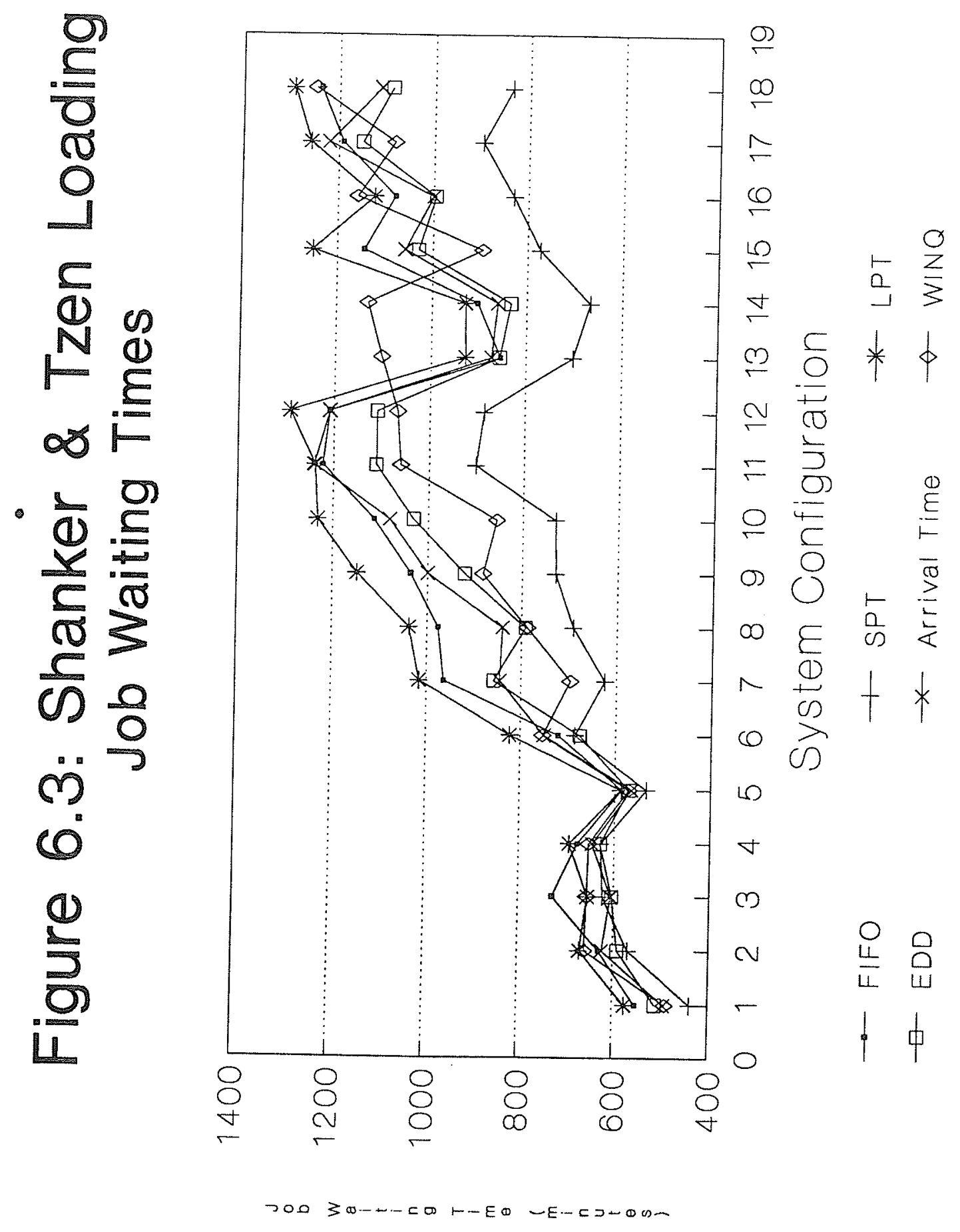




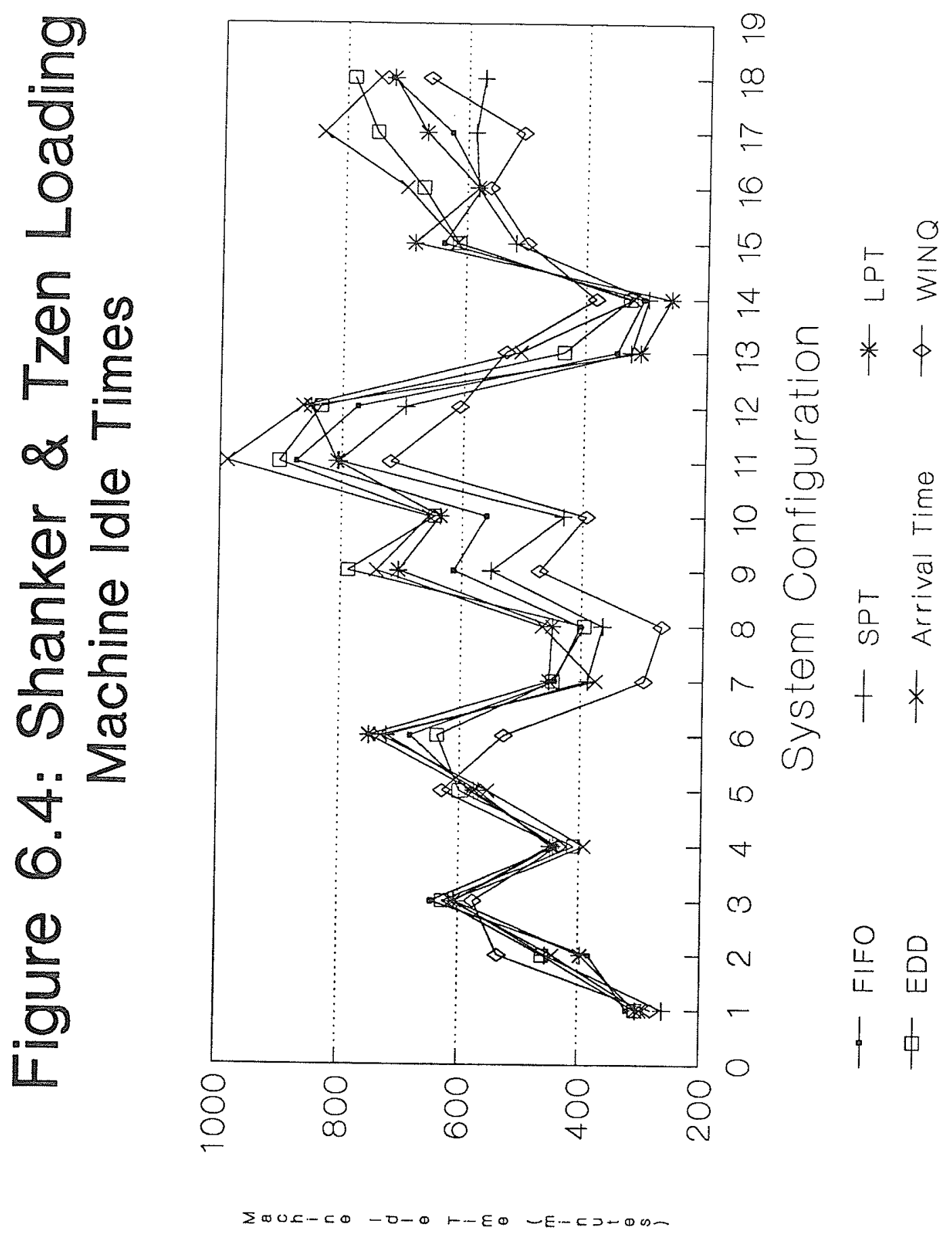




\subsection{STATISTICAL ANALYSIS}

The need for random number generation is indispensable in almost any simulation stuay. Since the input values of most of the parameters are random numbers, the observed values of the performance measures for a simulation run may be thought of as random variables. As a result, the observed differences between the performance of different system configurations will also be random variables. However, because of the identical conditions under which the models are being operated, any variability between corresponding simulation runs is strictly caused by a change in the scheduling rule. Therefore, careful analysis is necessary to determine if the performance differences are statistically significant.

In order to detect significant differences due to the influence of different schedules, we perform multiple comparisons between the values of the performance measures, namely, job waiting time and machine idle time. 'Multiple comparisons' implies more than one comparison among three or more means. When comparing more than two means, an ANOVA-F test indicates whether the means are significantly different from each other. However, it does not specify which means differ from which other means. Multiple comparison methods produce more detailed information about the differences among the means (SAS User's Guide: Statistics, 1985). 
There are many procedures available for performing pairwise multiple comparisons among the observed treatment means from designed experiments. With any particular procedure, the observed difference between any two means is compared with the critical value for that procedure. If the observed difference exceeds the critical value, the two means are considered significantly different; otherwise, the difference is considered nonsignificant. Since the magnitudes of the critical values vary among procedures, results obtained from the application of one procedure to a given set of data will often differ from those obtained by using another procedure (Carmer \& Swanson, 1973).

Carmer \& Swanson (1973) conducted extensive Monte Carlo simulation studies of several multiple comparison methods. They reported that the Least Significant Difference (LSD) method is a very effective test for detecting true differences in means if applied only after the ANOVA F-test is significant at $5 \%$. They also reported good performance in detecting true differences with Duncan's multiple range test. Montgomery (1984) commented on the high 'power' of these two tests.

In this study we use the LSD method for multiple comparisons of the mean values of the performance measures. The statistical analysis in this study was conducted using SAS, version 5. All the tests were conducted at the .05 level of significance. Raw data obtained from the simulations were 
entered into a dataset. The mean values and the variances of the performance measures were computed for each system configuration over all the scheduling environments evaluated. The data were then used for the multiple comparisons. The results of the multiple comparisons appear in tabular form in appendixes $\mathrm{C}$ to $\mathrm{F}$.

The null hypothesis $\left(H_{0}:\right)$ is that all the means are equal. The alternative hypothesis $\left(H_{1}:\right)$ is that at least two means are significantly different. In the interpretation of multiple comparisons, it is important to remember that failure to reject the hypothesis that two or means are equal should not lead to the conclusion that the population means are in fact equal. Failure to reject the null hypothesis implies only that the difference between the population means, if any, is not large enough to be detected with the given sample size. A related point is that nonsignificance is nontransitive; given three sample means, the largest and the smallest may be significantly different from each other, while neither is significantly different from the middle one. Nontransitive results of this type occur often in multiple comparisons (SAS User's Guide: Statistics, 1985).

As an example, Table 6.1 illustrates a sample output from the multiple comparisons of mean JWT using the LSD method. The least significant difference here is 345. Means with the same letter are not significantly different. According to the table AT/WINQ has the highest JWT. EDD/WINQ has the sec- 
TABLE 6.1

An example of Multiple Pairwise Comparisons

11 Job types - 10 Machines - 5 Routes

Schedule Mean JWT T Grouping

AT/WINQ $\quad 3411$

EDD/WINQ $\quad 2571$

AT/FIFO 2080

LPT/WINQ 2004

EDD/FIFO $\quad 1937$

LPT/EIFO $\quad 1665$

FIFO/FIFO 1609

SPT/WINQ 1327

SPT/EIFO $\quad 1150$

$a$

b

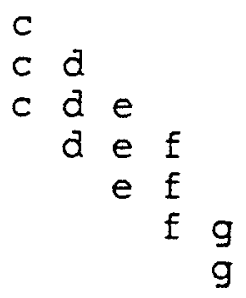

ond highest JWT. There is no significant difference in the performance of (i) AT/FIFO, LPT/WINQ, EDD/FIFO, LPT/WINQ, EDD/FIFO, LPT/FIFO, (iii) EDD/FIFO, LPT/FIFO, FIFO/FIFO, (iv) LPT/FIFO, FIFO/FIFO, SPT/WINQ, and (v) SPT/WINQ, SPT/FIFO. However, AT/FIFO has significantly higher JWT than LPT/FIFO. Similarly, LPT/WINQ has significantly higher JWT than FIFO/FIFO; EDD/FIFO has significantly higher JWT than SPT/WINQ; and LPT/FIFO has significantly higher JWT than SPT/FIFO.

The statistical analysis shows results that are similar to the ones revealed by the graphical output. The analysis allows an extremely detailed examination of the results. However, our discussion will be kept at a peripheral level. 


\section{3 .1 Simple Loading Rules}

Considering the random nature of the FMS and of most input parameters (some of them with large variation), it is remarkable that the tests separate the mean values into various groups.

\subsubsection{Job waiting Times}

Overall, SPT loading displays the best performance. Surprisingly, FIFO/FIFO ranks a close second as opposed to some other schedules. EDD/FIFO and LPT/FIFO are generally behind FIFO/FIFO. Arrival Time/WINQ and EDD/WINQ consistently show poor performance. The local rule FIFO produces better results than the global WINQ.

\subsubsection{Machine Idle Times}

Machine idle times do not display as many differences in performance under the influence of schedules. SPT and LPT loadings generally show good performance. Interestingly, IPT loading produces better results than some other loadings considered in this study. As expected, WINQ exhibits better performance than FIFO. 


\subsubsection{Shanker \& Tzen Loading}

Unlike the comparisons of simple loading rules, the multiple comparisons here do not reveal as many performance differences. This is because of the balancing nature of the algorithm as discussed earlier in this chapter.

\section{3 .2 .1 Job Waiting Times}

For small product variety, the tests do not show any significant differences among the dispatching rules. This observation is similar to the one obtained from the graphs. The differences start to surface as soon as the product variety is increased. For medium to large product variety, SPT consistently shows good results. WINQ generally displays good performance. However, in three configurations WINQ exhibits the worst performance. EDD ranks a close third in most cases. Unlike simple loading rules, LPT generally shows the worst performance. Arrival time and FIFO also perform poorly.

\subsubsection{Machine Idle Times}

Machine idle times generally fail to separate the dispatching rules into different groups for small and high product variety. The few significant differences seen are for medium product variety. SPT and WINQ show good performance but only by a slight margin. Arrival Time, EDD, and LPT exhibit poor performance. 


\section{4 SUMMARY}

The preceding analysis forms the focus of this study. We analyzed the simulation results by examining the data in graphical form and by conducting statistical analysis. The discussion has expectedly revealed the performance differences due to the use of different loading and dispatching strategies. However, more interesting is the observation that identical dispatching rules produce contrasting results when used with loading strategies that are different. In the concluding chapter we present a synopsis of the results, their implications, and directions for further research. 


\section{Chapter VII CONCLUSION}

Flexibility has become a key issue in the present manufacturing environment. Manufacturing flexibility can be segmented into discrete flexibility types. Ideally it is desirable that a manufacturing system have all these flexibilities. However, as manifested by this study, it is not possible to accommodate all these flexibility. types in a manufacturing system.

In this study we have examined the flexibility trade-offs in a random FMS. The study has produced some conceivable results and a few unexpected ones. As in many empirical studies, we have also encountered some questions. The following deliberation provides an abstract of the research results, the implications, and directions for further research.

\subsection{SUMMARY}

We have approached the analysis of manufacturing flexibility by using two of the performance measures of an FMS: Job waiting time and Machine idle time. Each performance measure presents distinct outcomes and implications. Job waiting time consistently suggests a trade-off among the 
various flexibility types whereas Machine idle time exhibits notably distinct behavior.

\subsubsection{Job Waiting Time}

With the use of simple loading rules, JWT invariably increases with product flexibility. An increase in product flexibility also entails an increase in machine flexibility and to some extent, process flexibility. Therefore, there is a trade-off between volume flexibility and product, machine, and process flexibilities. This trade-off is minimized by using SPT loading. FIFO ranks a close second. The addition of machines signifies an increase in machine flexibility and indirectly, process flexibility and product flexibility. Adding machines also leads to a loss of volume flexibility. In general, loading the jobs according to SPT, LPT, and FIFO, and dispatching according to FIFO, exhibits a minimal trade-off. Besides enhancing routing flexibility, incorporating more routes in the system may also increase process flexibility by allowing a more efficient utilization of the machines. The schedules that minimize the trade-off between machine flexibility and volume flexibility also minimize the trade-off between routing flexibility and volume flexibility.

The results are markedly different with Shanker \& Tzen loading. Although the performance measure still indicates trade-offs, product variety has a distinct effect. If the 
product variety is not large, SPT and EDD perform well to contain the trade-off between product flexibility and volume flexibility. For large product variety, LPT shows a gain in volume flexibility with product flexibility. However, as the statistical analysis suggests, LPT expectedly shows the highest JWT. FIFO, EDD, and Arrival time display a negligible trade-off. SPT and EDD also contain the trade-off between machine flexibility and volume flexibility, but only for the small and large product variety. For medium variety EDD and FIFO perform well. EDD also exhibits good performance with respect to the trade-off between routing flexibility and volume flexibility.

\subsubsection{Machine Idle Time}

Machine idle time exhibits a sharp decrease whenever the number of machines and routes are simultaneously decreased. SPT/WINQ shows very good performance in that it increases the volume flexibility of the system as the product variety is enhanced. SPT/FIFO displays a similar trend but only for small system configurations. LPT/FIFO, EDD/FIFO, and EDD/WINQ also show good performance. LPT/WINQ, SPT/WINQ, and LPT/FIFO show a lower trade-off between machine flexibility and volume flexibility. As routes are added, LPT/FIFO renders the system more volume flexible. For the small system configuration, Arrival Time/FIFO, Arrival Time/WINQ, and FIFO/FIFO show a similar trend. For small product variety, 
LPT/WINQ causes a concurrent gain in routing flexibility and volume flexibility.

The Shanker \& Tzen loading algorithm appears to prefer configurations with five routes instead of three. SPT provides a gain in volume flexibility as product variety is increased. FIFO, LPT, and Arrival Time display a similar trend but only when product variety is large. There is no trade-off evident when FIFO is used for small to medium product variety and EDD is used for large product variety. Adding machines or routes causes a loss of volume flexibility. The trade-offs are minimal when EDD and WINQ are used for small product variety. Medium product variety favors SPT and WINQ. SPT displays the lowest trade-off for large product variety.

\subsection{IMPLICATIONS}

There are some general trends that are evident from the preceding discussion. These trends can be segmented according to the loading strategy applied. The simple loading rules do not balance the work load; the incoming jobs are directly loaded according to the rule in effect. In contrast, the Shanker \& Tzen loading algorithm iterates through a number of steps to ensure that the work load is balanced among the machines and the jobs satisfy certain constraints. However, this algorithm has the disadvantage of being complex. Thus, it is hard to implement and it requires signifi- 
cantly more computer resources as compared with the simple loading rules.

If simple loading rules are used then SPT and FIFO loadings are capable of containing all the flexibility tradeoffs. In addition, as implied by the statistical analysis, these two loadings also show the lowest JWT. LPT/FIFO also shows good performance. On the basis of MIT, IPT/FIFO shows the lowest flexibility trade-offs. If product and machine flexibilities are of importance then SPT/WINQ should be implemented. If the system configuration is to kept small then SPT/FIFO or FIFO/FIFO would be a good choice. If the product variety is small then LPT/WINQ should be implemented.

If Shanker \& Tzen loading is used then SPT and EDD exhibit the lowest flexibility trade-offs. FIFO performs well but it also increases JWT. A decision based on MIT would prefer SPT. Overall, SPT shows the lowest trade-offs. If machine flexibility is of importance then SPT, EDD, and WINQ should be selected. SPT and WINQ also optimize on routing flexibility. EDD has the advantage of meeting due dates. However, the statistical analysis shows that EDD has high MIT.

Finally, we would like to comment on some interesting observations. A noticeable one is the sharp decrease in MIT as the product variety is increased. This decrease is not due to the product variety itself; it is caused by a reduc- 
tion in the number of machines and routes, and it indicates full utilization of the resources. The implication is that with adequate control of the FMS, it is possible to maintain high product flexibility and volume flexibility by operating with small systems configurations. As opposed to the usual conjecture, it is not necessary for product flexibility to depend on machine flexibility and process flexibility.

SPT, which is considered as one of the better rules, proved to be very effective in minimizing both the flexibility trade-offs and the performance measures. FIFO, which is considered as one of the inferior rules has performed measurably better than most of the rules besides SPT. The global rule WINQ does not exhibit results that are significantly superior to other dispatching rules.

Arrival time consistently shows poor performance. This observation is particularly significant. Arrival time is the only loading rule that negates the effect of permuting the jobs (section 4.5.2). The jobs are loaded according to the sequence that they arrive in the system, which is the job type. Thus, all the jobs of type 1 are loaded first, jobs of type 2 are loaded second, and so on. These jobs share identical characteristics and therefore do not make an effective use of the flexibility of the system. It is therefore important not only to provide flexibility in a system, but also to utilize it. 
A choice of the loading algorithm has far-reaching ramifications not only on the flexibility of the system but also on the dispatching rules being used. It is apparent that the Shanker \& Tzen loading algorithm is superior to the simple loading rules. It also has some drawbacks as we mentioned earlier. The choice of an appropriate loading algorithm would be influenced by these considerations. Similarly, a decision to use either Job waiting time or Machine idle time as the performance measure would depend on factors such as the ease of computing each measure, the promise that the measure shows in providing useful information, and which measure is more detrimental to the operation of the system.

As a last note, we would like to state that this study is based on simulation and it is, therefore, assuming in nature. The results are system specific and may not be generalized to other systems.

\subsection{DIRECTIONS FOR FURTHER RESEARCH}

The research in manufacturing flexibility is still in the conception stage. This study leads to many unexplored avenues in this field. We have used job waiting time and machine idle time as the performance measures. A use of some of the other performance measures is also possible. A natural progression would be the combination of these measures in the form of a multi-criteria decision making problem. We have considered the effect of a change in a system parameter 
by keeping the other parameters constant. The empirical results of this study could also be used to evaluate configurations in which two or more parameters are altered. It would also be interesting to incorporate the effect of events such as machine breakdowns, setup times, and transport times. 


\section{BIBLIOGRAPHY}

Abed, S Y, Barta, T A, and McRoberts, K L, "A Qualitative Comparison of three Simulation Languages: GPSS/H, SLAM, SIMSCRIPT", Computers and Industrial Engineering, 9(1), $1985 a, 35-43$.

Abed, S Y, Barta, $\mathrm{T} A$, and McRoberts, K L, "A Quantitative Comparison of three Simulation Languages: SLAM, GPSS/H, SIMSCRIPT", Computers and Industrial Engineering, $9(1)$, $1985 \mathrm{~b}, 45-66$.

Abernathy, $\mathrm{W} \mathrm{J}, \mathrm{Clark}, \mathrm{K}$ B, and Kantrow, A M, "The Industrial Competition", Harvard Business Review, 59(5), $1981,68-81$.

Agerwala, T, "Putting Petri-nets to Work", IEEE Computer, $12(12), 1979,85-94$.

Aggarwal, S C, "MRP, JIT, OPT, FMS? - Special Report", Harvard Business Review, $63(5), 1985,8-16$.

Agosta, J M, "Flexibility in the Design of an Assembly Cell", Working Paper, Engineering-Economic Systems Department, Stanford University, CA, May 1987.

Alanche, P, Benzakour, F, Dolle, F, Gillet, P, Rodrigues, P, and Vallette, $R$, "PSI: A Petri-net Based Simulator for Flexible Manufacturing Systems", Advances in Petri-nets, (eds Rosenberg et al), 1984, Springer-Verlag, London, NY.

Avonts, L H, Gelders, L $\mathrm{F}$, and Van Wassenhove, I $\mathrm{N}$, "Allocating Work between an FMS and a Conventional Job Shop: A case study", European Journal of Operational Research, 33(3), 1988, 245-256.

Azzone, G, and Bertele, U, "Comparing Manufacturing Systems with Different Flexibility: A New Approach", Proc

Decision Sciences Institute, Boston, MA, 1987, 690-693.

Balci, O, and Sargent, R G, "A Bibliography on the Credibility, Assessment, and Validation of Simulation and Mathematical Models", Simuletter, 15(3), 1984 , $15-27$.

Banks, J, and Carson, J S, Discrete-Event System Simulation, Prentice-Hall, Englewood Cliffs, NJ, 1984. 
Barad, $M$, and Sipper, $D$, "Flexibility in Manufacturing Systems: Definitions and Petri-net Modeling", International Journal of Production Research, 26(2), $1988,237-248$.

Bastos, J M, "Batching and Routing: Two Functions in the Operational Planning of Flexible Manufacturing Systems", European Journal of Operational Research, 33(3), 1988, $230-244$.

Bell, R, and Bilalis, $N$, "Loading and Control Strategies for an FMS for Rotational Parts", Proc 1st International Conference on FMS, Brighton, UK, 1982, 77-87.

Biegel, JE, "The Future of Artificial Intelligence", Computers and Industrial Enqineering, 11(1-4), 1986, $473-475$.

Bobillier, P A, Kahan, B C, and Probst, A R, Simulation with GPSS and GPSS V, Prentice-Hall, Englewood Cliffs, NJ, 1976 .

Bobrowski, P M, and Mabert, V A, "Alternate Routing Strategies in Batch Manufacturing: An Evaluation", Decision Sciences, 19(4), 1988, 713-733.

Branstrator, J, and McCormick, M, "Computer Simulation Justifies Construction of CIBA-GEIGY Dyestuff Production Facility", Industrial Engineering, 21(5), 1989, 17-20.

Brill, $P H$, and Mandelbaum, M, "On Measures of Flexibility in Manufacturing Systems", International Journal of Production Research $, 27(5), 1989,747-756$.

Browne, J, Dubois, D, Rathmill, K, Sethi, S P, and Stecke, K E, "Classification of Flexible Manufacturing Systems", The FMS Magazine, 2(2), 1984, 114-117.

Buzacott, J A, "Optimal Operating Rules for Automated Manufacturing Systems", IEEE Transactions on Automatic Control, $\mathrm{AC}-27(1), 1982 \mathrm{a}, 80-86$.

Buzacott, J A, "The Fundamental Principles of Flexibility in Manufacturing Systems", Proc 1st International Conference on FMS, Brighton, UK, 1982b, 23-30.

Buzacott, J A, and Mandelbaum, M, "Flexibility and Productivity in Manufacturing Systems", Proc Annual IIE Conference, Los Angeles, CA, 1985, 404-413.

Buzacott, J A, and Shanthikumar, J G, "Models for Understanding Flexible Manufacturing Systems", AIIE Transactions, $12(4), 1980,339-350$. 
Buzacott, J A, and Yao, D D, "Flexible Manufacturing Systems: A Review of Analytical Models", Management Science, 32(7), 1986, 890-905.

Carmer, S G, and Swanson, M R, "An Evaluation of Ten Pairwise Multiple Comparison Procedures by Monte Carlo Methods", Journal of the American Statistical Association, 68(341), 1973, 66-74.

Carter, M F, "Designing Flexibility into Automated Manufacturing Systems, Proc 2nd ORSA/TIMS Conference on FMS: OR Models and Applications, Ann Arbor, MI, 1986, $107-118$.

Chan, T S, and Pak, H A, "Heuristical Job Allocation in a Flexible Manufacturing System", The International Journal of Advanced Manufacturing Technology, 1(2), $1986,69-90$.

Chang, Y L, Sullivan, R S, and Bagchi, U, "Experimental Investigation of Quasi-Real time Scheduling in Flexible Manufacturing Systems", PrOC 2nd ORSA/TIMS Conference on FMS, Ann Arbor, MI, 1986, 307-312.

Chatterjee, A, Cohen, M, Maxwell, W, and Miller, L, "Manufacturing Flexibility: Models and Measurements", Proc 1st ORSA/TIMS Conference on FMS, Ann Arbor, MI, $1984,49-64$.

Cho, Y K, "Japanese Manufacturing Approaches for Preserving and Enhancing Flexibility", Proc Decision Sciences Institute, Boston, MA, 1987, $\frac{694-696 .}{6}$

Choi, R H, and Malstrom, E M, "Evaluation of Traditional Work Scheduling Rules in a Flexible Manufacturing System with a Physical Simulator", Journal of Manufacturing Systems, $7(1), 1988,33-45$.

Christy, D P, and Watson, $H$ J, "The Application of Simulation: A Survey of Industry Practice", Interfaces, $13(5), 1983,47-52$.

Classen, $R \mathrm{~J}$, and Malstrom, $E \mathrm{M}$, "Effective Capacity Planning for Automated Factories Requires Workable Simulation Tools and Responsive Shop Floor Controls", Industrial Engineering, 14(4), 1982, 73-79.

Co, $\mathrm{H} \mathrm{C}$, Jaw, $\mathrm{T} J$, and Chen, $\mathrm{S} K$, "Sequencing in Flexible Manufacturing Systems and other Short Queue-Length Systems", Journal of Manufacturing Systems, $7(1), 1988$, $1-9$.

Conway, $R \mathrm{~W}$, "Priority Dispatching and Job Lateness in a Job Shop", The Journal of Industrial Engineering, 16(4), $1965,228-237$. 
DeGarmo, E P, Black, J T, and Kohser, $R A$, Materials and Processes in Manufacturing, 6th edition, Macmillan Publishing Company, NY, 1984.

De Meyer, A, Nakane, J, Miller, J G, and Ferdows, $K$, "Flexibility: The Next Competitive Battle. The Manufacturing Futures Survey", Strategic Management Journal, $10(2), 1989,135-144$.

Denzler, $D R$, and Boe, $W \mathrm{~J}$, "Experimental Investigation of Flexible Manufacturing System Scheduling Decision Rules", International Journal of Production Research, $25(7), 1987 a, 979-994$.

Denzler, $D R$, and Boe, $W \mathrm{~J}$, "An Evaluation of Part Scheduling Rules in a Random FMS", Proc Decision Sciences Institute, Boston, MA, 1987b, 787-789.

Denzler, D R, Boe, $\mathrm{W} J$, and Duplaga, E, "An Experimental Investigation of FMS Scheduling Rules Under Uncertainty", Journal of Operations Management, $7(1 \& 2)$, $1987,139-151$.

Diesch, $\mathrm{K} \mathrm{H}$, and Malstrom, $\mathrm{E} M$, "Physical Simulator Analyzes Performance of a Flexible Manufacturing System", Industrial Engineering, $17(6), 1985,66-77$.

Dubois, D, and Stecke, K E, "Using Petri-nets to represent Production Processes", Proc 22nd IEEE Conference on Decision and Control, San Antonio, TX, 1983, 1062-1067.

Dupont-Gatelmand, C, "A Survey of Analytical and Simulation Models for the Design and Control of Flexible Manufacturing Systems", 14 th CIRP International Seminar on Manufacturing Systems, 1982 .

Edghill, J S, and Davies, A, "Flexible Manufacturing Systems - the Myth and Reality", International Journal of Advanced Manufacturing Technology, 1(1), 1985, 37-54.

ElMaraghy, H A, "Simulation and Graphical Animation of Advanced Manufacturing Systems", Journal of Manufacturing Systems, $1(1), 1982,53-63$.

Eppink, D J, "Planning for Strategic Flexibility", Long Range Planning, 11(4), 1978, 9-15.

Falkner, $\mathrm{CH}$, "Flexibility in Manufacturing Plants", Proc 2nd ORSA/TIMS Conference on FMS: OR Models and Applications, Ann Arbor, MI, 1986, 95-106.

Frazelle, E H, "Flexibility: A Strategic Response in Changing Times", Industrial Engineering, 18(3), 1986, $17-20$. 
Gere, $W S$, "Heuristics in Job Shop", Management Science, 13(3), 1966, 167-190.

Gerwin, D, "Do's and Dont's of Computerized Manufacturing", Harvard Business Review, 60(2), 1982, 107-116.

Gerwin, D, "A Framework for Analyzing the Flexibility of Manufacturing Processes", Working Paper, School of Business Administration, University of Wisconsin Milwaukee, WI, 1985.

Gerwin, D, "Manufacturing Flexibility in the CAM Era", Business Horizons, 32(1), 1989, 78-84.

Gold, B, "CAM Sets New Rules for Production", Harvard Business Review, $60(6), 1982,88-94$.

Goldhar, J, and Jelinek, M, "Plan for Economies of Scope", Harvard Business Review, 61(6), 1983, 141-148.

Groover, M P, Automation, Production Systems, and Computer Aided Manufacturing, Prentice-Hall Inc, Englewood Cliffs, NJ, 1985.

Gupta, D, and Buzacott, J A, "Notions of Flexibility in Manufacturing Systems", Working Paper, Dept of Management Science, University of Waterloo, ON, 1987.

Gupta, Y P, Gupta, M C, and Bector, C R, "A Review of Scheduling Rules in Flexible Manufacturing Systems", Working Paper, School of Business, University of Louisville, KY, 1989 .

Gupta, Y P, Gupta, M C, and Narang, S, "Flexible Manufacturing Systems. Flexibility and Availability: An Information Theory Approach", Working Paper, School of Business, University of Louisville, KY, 1989b.

Gustavsson, S, "Flexibility and Productivity of Complex Processes", International Journal of Production Research, 22(5), 1984, 801-808.

Hahne, $\mathrm{E} H$, "Dynamic Routing in an Unreliable Manufacturing Network with Limited Storage", MSC Thesis (LIDS TH 1063), Laboratory for Information and Decision Systems, MI T, MA, 1981.

Harrigan, K R, "Deterrents to Divestiture", Academy of Management Journal, 24(2), 1981, 306-323.

Harrington, J, Understanding the Manufacturing Process, Marcel Drekker Inc, NY, 1984.

Hatvany, J, World Survey on CAM, Butterworths, Kent, UK, 1983. 
Hayes, R H, and Jaikumar, R, "Manufacturing's Crisis: New Technologies, Obsolete Organizations", Harvard Business Review, 66(5), 1988, 77-85.

Hayes, $\mathrm{R} H$, and Wheelwright, $\mathrm{S} C$, Restoring our Competitive Edge - Competing Through Manufacturing, Wiley, NY, 1984.

Henriksen, J O, "GPSS: Finding the Appropriate World View", Proc 1981 Winter Simulation Conference, San Diego, CA.

Henriksen, $J O$, and Crain, R C, GPSS/H User's Manual, 2nd edition, Wolverine Software Corporation, Annandale, VA, 1983 .

Hildebrand, R R, "Scheduling Flexible Machining Systems using Mean Value Analysis", Proc 19th IEEE Conference on Decision and Control, New Mexico, USA, 1980, 701-706.

Hill, T J, Manufacturing Strategy - The Strategic Management of the Manufacturing Function, Macmillan Education, London, 1984.

Hutchinson, G K, and Sinha, D, "A Quantification of the Value of Flexibility", Journal of Manufacturing Systems, $8(1), 1989,47-57$.

Jaikumar, R, "Postindustrial Manufacturing", Harvard Business Review, $64(6), 1986,69-76$.

Kaplan, R S, "Measuring Manufacturing Performance: A New Challenge for Managerial Account Research", The Accounting Review, LVIII(4), 1983, 686-705.

Kaplan, R S, "Must CIM be Justified by Faith Alone?", Harvard Business Review, $64(2), 1986,87-95$.

Kelton, W D, "Designing Computer Simulation Experiments", Proc 1988 Winter Simulation Conference, San Diego, CA, $15-18$.

Kumar, $v$, "On Measurement of Flexibility in Flexible Manufacturing Systems: An Information Theoretic Approach", Proc 2nd ORSA/TIMS Conference on FMS: OR Models and Applications, Ann Arbor, MI, 1986, 131-143.

Kumar, V, "Entropic Measures of Manufacturing Flexibility", International Journal of Production Research, $25(7)$, 1987a, 957-966.

Kumar, V, "Some Approaches in Measuring Manufacturing Flexibility", Proc ASAC Conference, Toronto, ON, 1987b, 28-39. 
Kusiak, A, "Flexible Manufacturing Systems: A Structural Approach", International Journal of Production Research, $23(6), 1985,1057-1073$.

Law, A M, "Simulation of Manufacturing Systems", Proc 1988 Winter Simulation Conference, San Diego, CA, 40-51.

Law, A M, and Kelton, W D, Simulation Modeling and Analysis, McGraw-Hill, NY, 1982 .

Lim, S H, "Flexibility in Flexible Manufacturing Systems - A Comparative Study of Three Systems", in Managing

Advanced Manufacturing Technology, (ed voss, CA ), IFS (Publications) Ltd, UK; Springer-Verlag, NY, 1986, $125-147$.

Lin, $L E$, and Lu, $C Y$, "The Scheduling Problem in Random Flexible Manufacturing System", Proc 2nd ORSA/TIMS Conference, Ann Arbor, MI, 1986, 278-283.

Linder, J, "Design of Production Systems for High Flexibility and High Capital Utilization", in Flexible Manufacturing, (eds Rouf, $A$, and Ahmad, S I), Elsevier Science Publishing Co Inc, NY, USA, 1985, 45-54.

Mandelbaum, M, "Flexibility in Decision Making: An Exploration and Unification", PhD Thesis, Department of Industrial Engineering, University of Toronto, ON, 1978.

Mandelbaum, $M$, and Brill, $P H$, "Examples of Measurement of Flexibility and Adaptivity in Manufacturing Systems", Journal of Operational Research Society, $40(6), 1989$, 603-609.

Mandelbaum, M, and Buzacott, J A, "Flexibility and Decision Making", Working Paper, York University, ON, 1986.

Mascarenhas, B, "Planning for Flexibility", Long Range Planning, 14(5), 1981, 78-82.

Merchant, $M E$, "World Trends in Flexible Manufacturing Systems", The FMS Magazine, 1(4), 1982.

Montgomery, D C, Design and Analysis of Experiments, 2nd ed, Wiley, NY, 1984 .

Muramatsu, R, Ishii, K, and Takahashi, K, "Some Ways to Increase Flexibility in Manufacturing systems", International Journal of Production Research, 23(4), $1985,691-703$.

Narahari, $Y$, and Visvandham, N, "A Petri-net Approach to the Modeling and Analysis of Flexible Manufacturing

Systems", Annals of Operations Research, 3, 449, 1985. 
Nof, S Y, Barash, M M, and Solberg, J J, "Operational Control of Item Flow in Versatile Manufacturing Systems", International Journal of Production Research, $17(5), 1979,479-489$.

Olker, R, "Application of the Minicomputer to Control a Large Flexible Machining System", Understanding Manufacturing Systems, Kearney \& Trecker Co, 1978.

Pak, HA, Mejtsky, G J, Rahnejat, H, and Hibberd, R D, "An Assessment of the Existing Simulation Languages for use in Manufacturing Environment", SERC Report 1 - Grant $\mathrm{GR} / \mathrm{C} 19325$, Imperial College, 1984 .

Peterson, J L, Petri-net Theory and the Modeling of Systems, Prentice Hall, Englewood Cliffs, NJ, 1981.

Porter, M E, Competitive Strategy, Free Press, NY, 1980.

Preece, D A, "Organizations, Flexibility, and New Technology", Managing Advanced Manufacturing Technology, (ed Voss, C A), IFS (Publications) Ltd, UK; SpringerVerlag, NY, 1986, 367-382.

Primrose, $P$ L, and Leonard, R, "Conditions under which Flexible Manufacturing is Financially Viable", Proc 3rd International Conference on FMS, Boeblingen, W Germany, $1984,121-132$.

Pritsker, A A B, The GASP IV Simulation Language, Wiley, NY, 1974 .

Pritsker, A A B, Modeling and Analysis Using Q-GERT, Halsted, NY, 1979.

Pritsker, A A B, "Perspective on Simulation", Industrial Engineering, 31(5), 1989, 19.

Pritsker, A A B, and Pegden, C D, Introduction to Simulation and SLAM, Halsted, NY, 1979.

Rahnejat, H, "Simulation Aids Design for Flexible Automation", The International Journal of Advanced Manufacturing Technology, 1(2), 1986, 91-108.

Ranky, $P$, The Design and Operation of FMS, IFPS Ltd, UK, North-Holland Publishing Co, 1983.

Richardson, $P R$, and Gordon, J R M, "Measuring Total Manufacturing Performance", Sloan Management Review, $21(2), 1980,47-58$.

Rolstadas, A, "Flexible Design of Production Planning Systems", International Journal of Production Research, $26(3), 1988,507-520$. 
SAS Institute Inc, SAS User's Guide: Basics, Version 5 edition, Cary, NC: SAS Institute Inc, 1985.

SAS Institute Inc, SAS User's Guide: Statistics, Version 5 edition, Cary, NC: SAS Institute Inc, 1985.

Sargent, R G, "A Tutorial on Validation and Verification of Simulation Models", Proc 1988 Winter Simulation Conference, San Diego, CA, 33-39.

Schlesinger, S, Crosbie, $\mathrm{R}$ E, Gagne, R E, Innis, G S, Lalwani, C S, Loch, J, Sylvester, R J, Wright, R D, Kheir, $N$, and Bartos, $D$, "Terminology for Model Credibility", Simulation, 32(3), 1979, 103-104.

Schneible, S R, "Flexible Manufacturing Systems", Proc IIE Fall Conference, Toronto, ON, 1983, 214-220.

Schonberger, $R \mathrm{~J}$, Japanese Manufacturing Techniques, Free Press, 1982 .

Schriber, T J, Simulation Using GPSS, Wiley, NY, 1974.

Schriber, T J, "A GPSS/H Model for a Hypothetical Flexible Manufacturing System", Annals of Operations Research, 3, 1985.

Shanker, K, and Tzen, $Y \mathrm{~J} J$, "A Loading and Dispatching Problem in a Random Flexible Manufacturing System", International Journal of Production Research, $23(3)^{3}$, $1985,579-595$.

Shannon, R E, System Simulation: The Art and Science, Prentice-Hall, Englewood Cliefs, NJ, 1975.

Shanthikumar, J G, and Sargent, R G, "A Hybrid Simulation/ Analytic Model for a Computerized Manufacturing System", Proc 9th International conference on Operations Research, 1981, 901-916.

Sifakis, J, "Use of Petri-nets for Performance Evaluation", Acta Cybernetica, 4(2), 1977, 185-202.

Skinner, $W$, Manufacturing: The Formidable competitive Weapon, Riley, Ipsilanti, Michigan, 1985.

Slack, N, "Flexibility as a Manufacturing Objective", International Journal of Production Management, $3(3)$, $1983,4-13$.

Smith, M L, Ramesh, R, Dudek, $\mathrm{R} A$, and Blair, E I, "Characteristics of US Flexible Manufacturing Systems A Survey", Proc 2nd ORSA/TIMS Conference on FMS: OR Models and Applications, Ann Arbor, MI, 1986, 477-486. 
Solberg, J J, "A Mathematical Model of Computerized Manufacturing Systems", Conference on Optimal Planning of Computerized Manufacturing systems project, Purdue University, IN, 1977.

Solberg, $J J$, and Nof, $S Y$, "Analysis of Flow Control in Alternative Manufacturing Configurations", Trans ASME $\frac{\text { Journal of Dynamic Systems, Measurements and Control, }}{102,1980 \text {. }}$

Son, $Y \mathrm{~K}$, and Park, C S, "Economic Measure of Productivity, Quality, and Flexibility in Advanced Manufacturing Systems", Journal of Manufacturing Systems, $6(3), 1987$, 193-206.

Stecke, K E, "Production Planning Problems for Flexible Manufacturing Systems", PhD Dissertation, Purdue University, IN, 1981.

Stecke, $K E$, "Formulation and Solution of Non-linear Integer Production Planning for Flexible Manufacturing Systems", Management Science, 29(3), 1983, 273-288.

Stecke, K E, and Kim, I, "Performance Evaluation for Systems of Pooled Machines of Unequal Sizes: Unbalancing versus Balancing", European Journal of Operational Research, $42(1), 1989, \frac{22-38}{22}$

Stecke, $\mathrm{K} E$, and Solberg, $J \mathrm{~J}$, "Loading and Control Policies for a Flexible Manufacturing System", International Journal of Production Research, $19(5), \frac{1}{1981,481-490}$.

Swamidass, P, "Manufacturing Flexibility: Strategic Issues", Discussion Paper 305, Graduate School of Business, Indiana University, IN, 1985.

Thesen, A, and Travis, L, "Introduction to Simulation", Proc 1988 Winter Simulation Conference, San Diego, CA, 7-14.

Van Beek, P, and Van Putten, C, "OR Contributions to Flexibility Improvement in Production/Inventory Systems", European Journal of Operational Research, $31(1), 1987,52-60$.

Vaithianathan, $R$, and McRoberts, $\mathrm{K} L$, "On Scheduling in a GT Environment", SME Technical Paper MS81-492S, 1981.

Walker, $T$ C, and Miller, $R \mathrm{~K}$, Expert Systems 1986: An Assessment of Technology and Applications, Madison, SEAI Technical Publications, Madison, GA, 1986, 121-128.

Weston, F C, "OR Techniques Relevant to Corporate Planning Functions Practices, an Investigative Look", Operations Research Bulletin, 19(2), 1971. 
Wilhelm, WE, and Subhash, C S, "Models for the Design of Flexible Manufacturing Systems", Proc IIE Annual Conference, Louisville, KY, 1983.

Yao, D D, "Material and Information Flows in Flexible Manufacturing Systems", Material Flows, (Special issue on Flexible Manufacturing Systems), 2, 1985, 143-149.

Yasai-Ardekani, M, "Effects of Environmental Scarcity and Munificence on the Relationship of Context to Organizational Structure", Academy of Management Journal, $32(1), 1989,131-156$.

Yilmaz, O S, and Davis, R P, "Flexible Manufacturing Systems: Characteristics and Assessments", Engineering Management International, $4(3), 1987,209-212$.

Zelenovic, D M, "Flexibility - A Condition for Effective Production Systems", International Journal of Production Research, $20(3), 1982,319-337$. 
Appendix

GRAPHICAL OUTPUT. SIMPLE LOADING RULES 

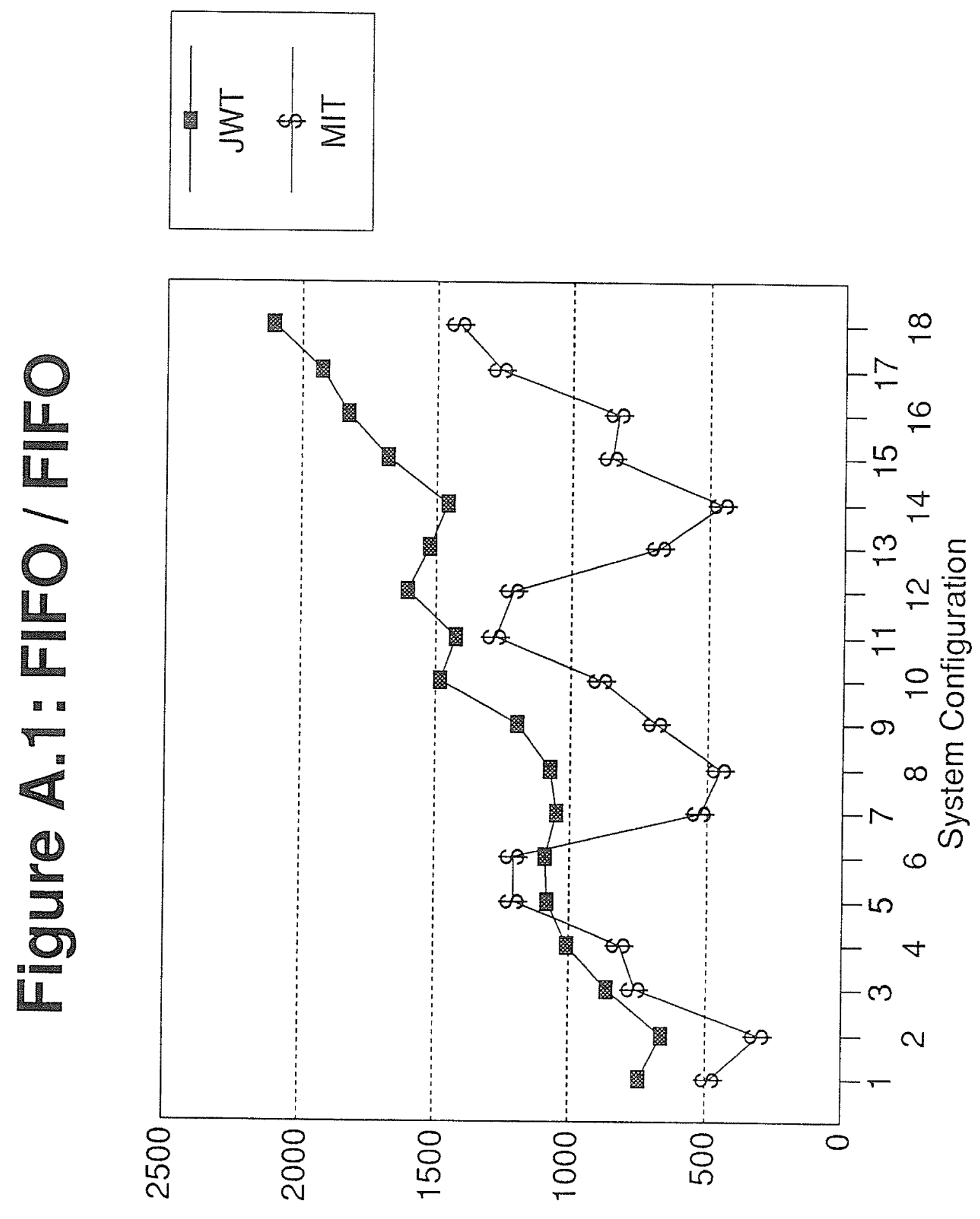

(sərnulu) $\perp I W / \perp M \Gamma$ 

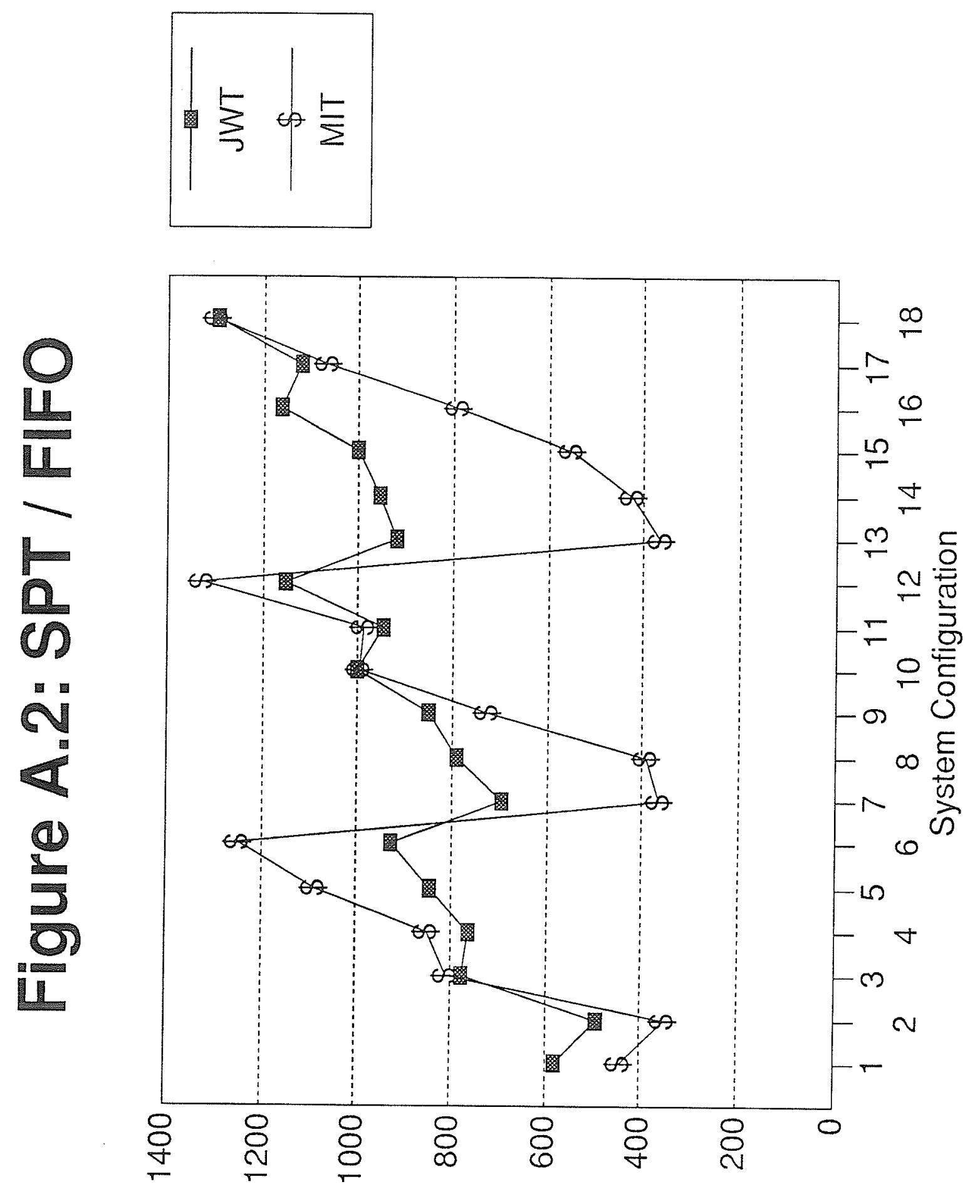

(səłnu!m) $\perp I W / \perp M \Gamma$ 

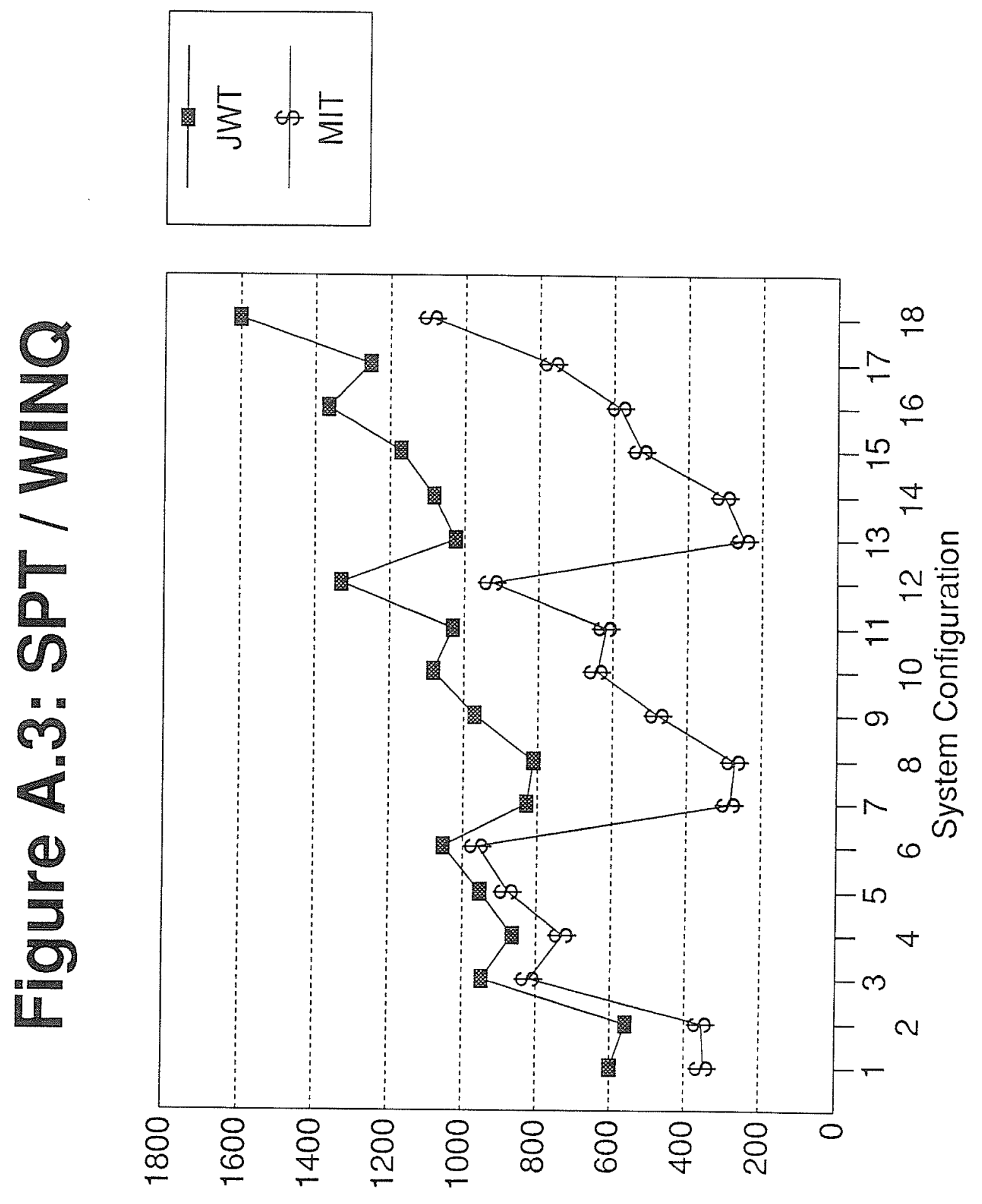

(səłnulu) $\perp \mid W / \perp M \Gamma$ 

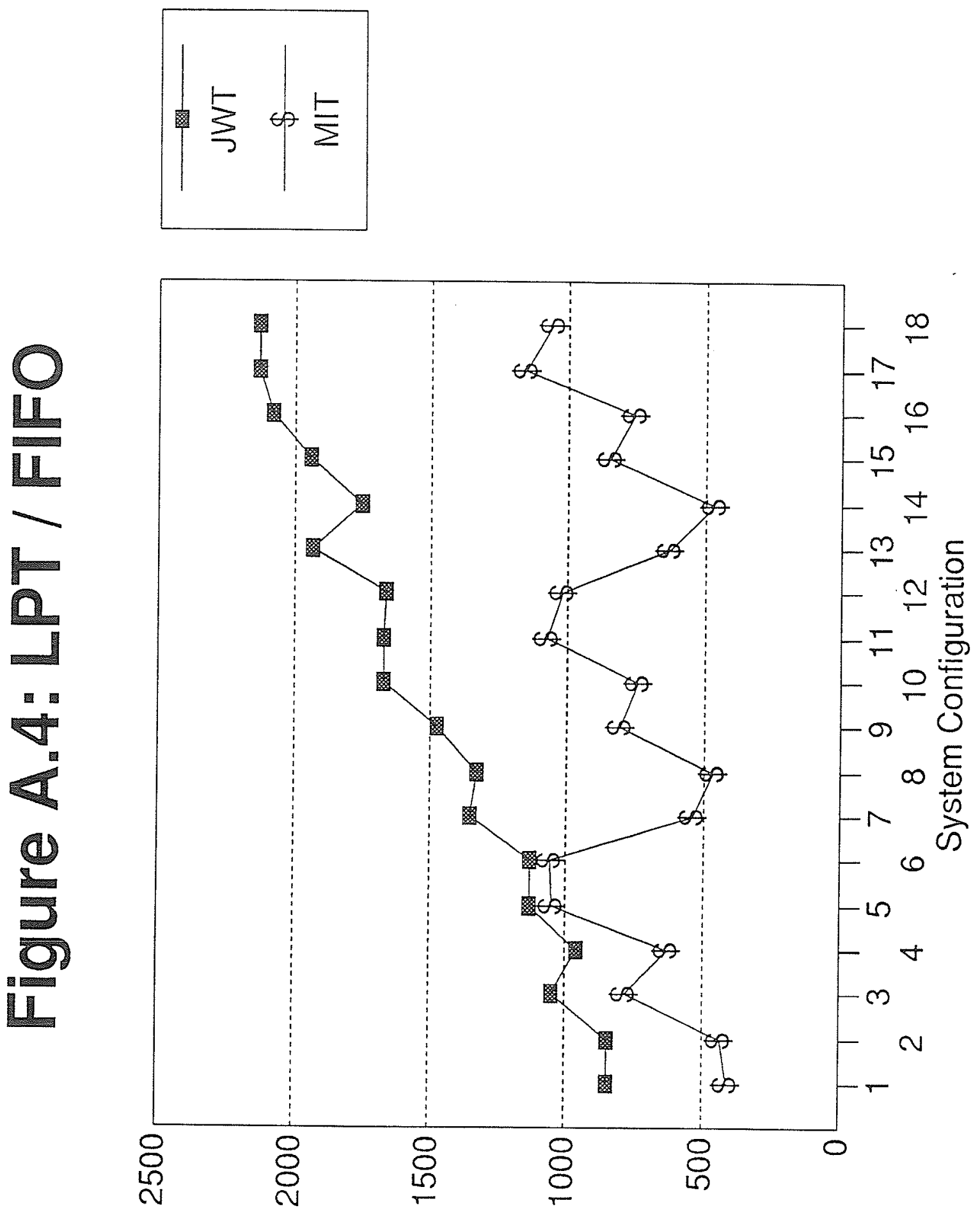

(səłnu!w) $\perp I N / \perp M \Gamma$ 

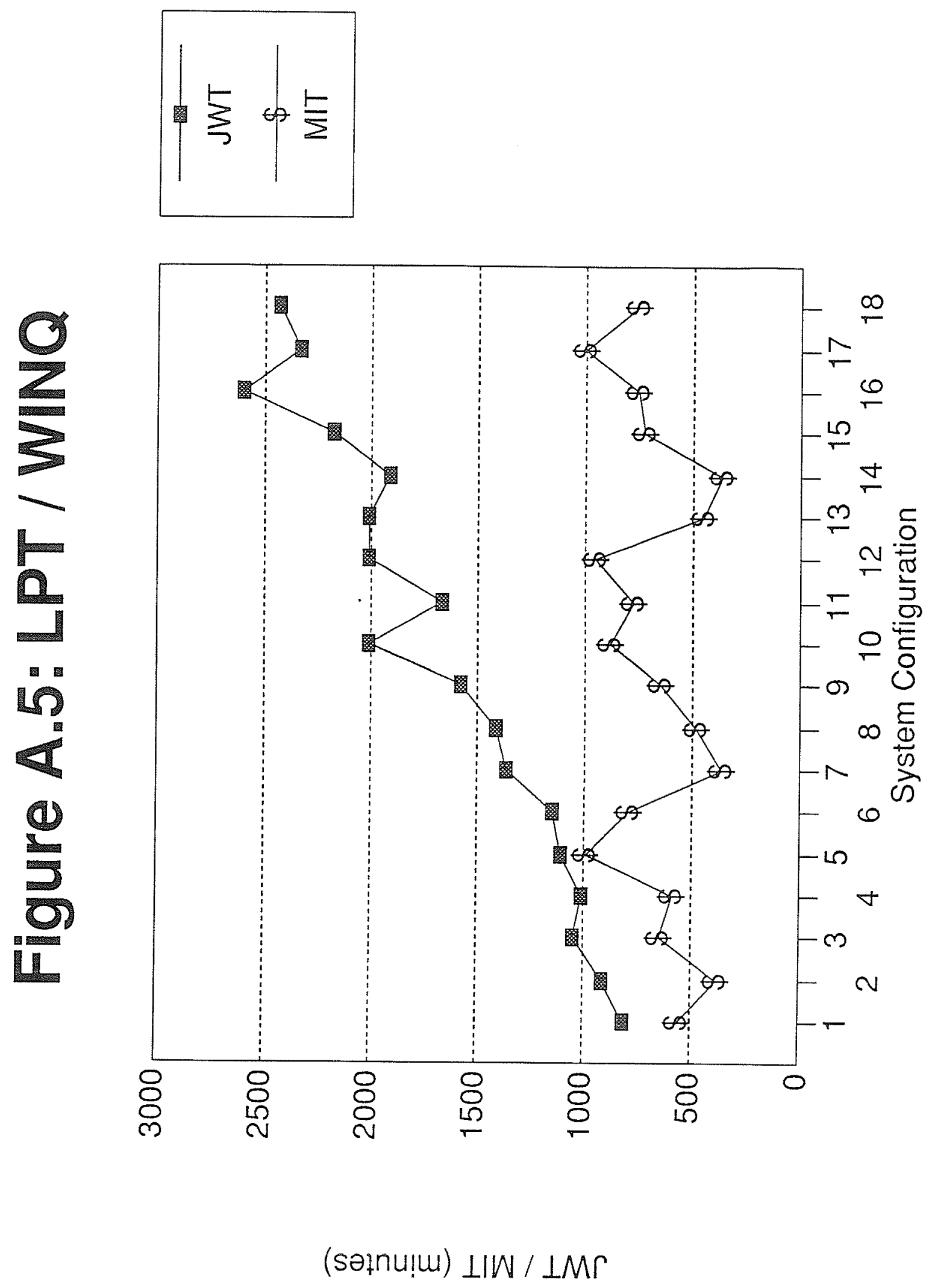

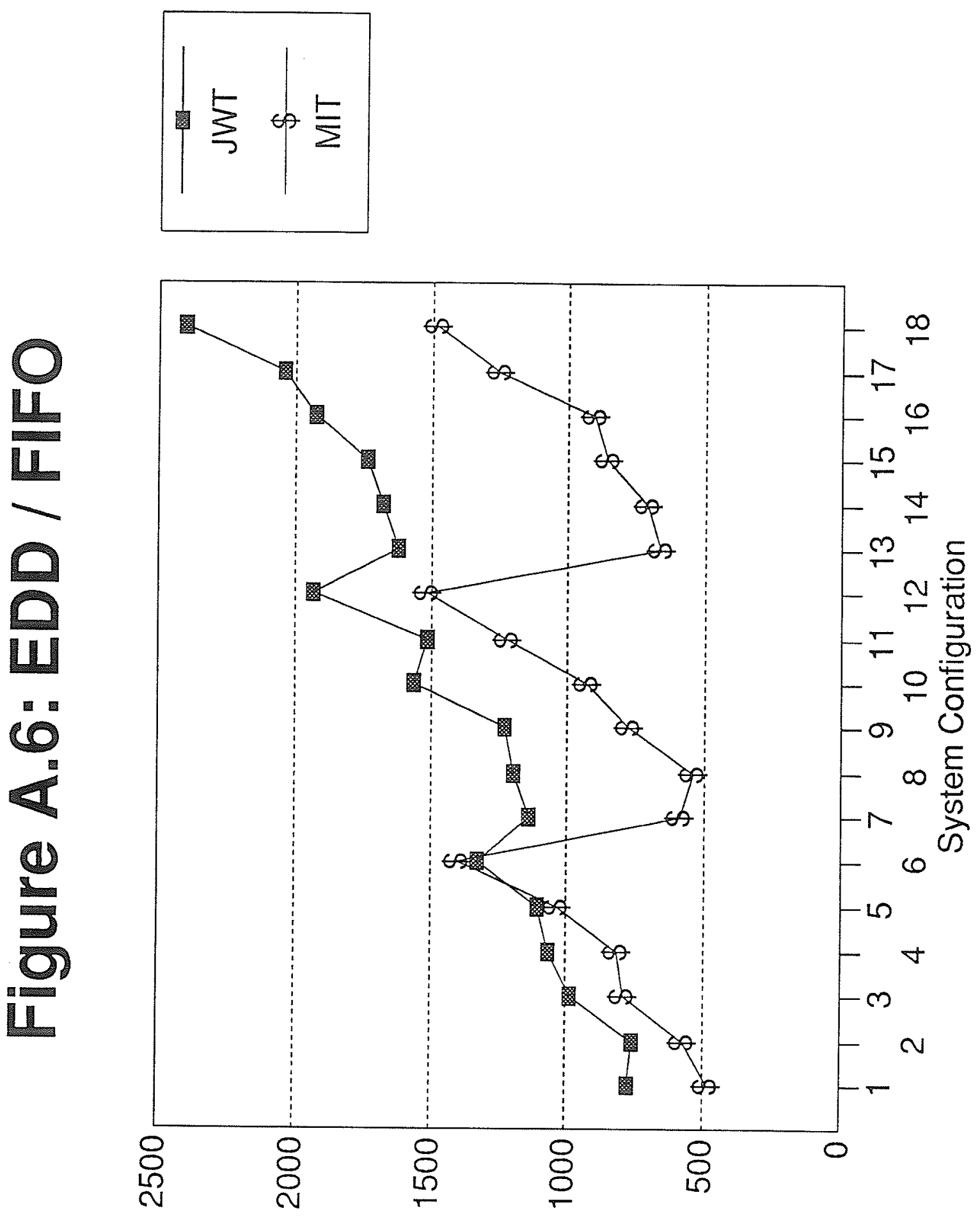

(sәłnu!lu) $\perp I N / \perp M \Gamma$ 

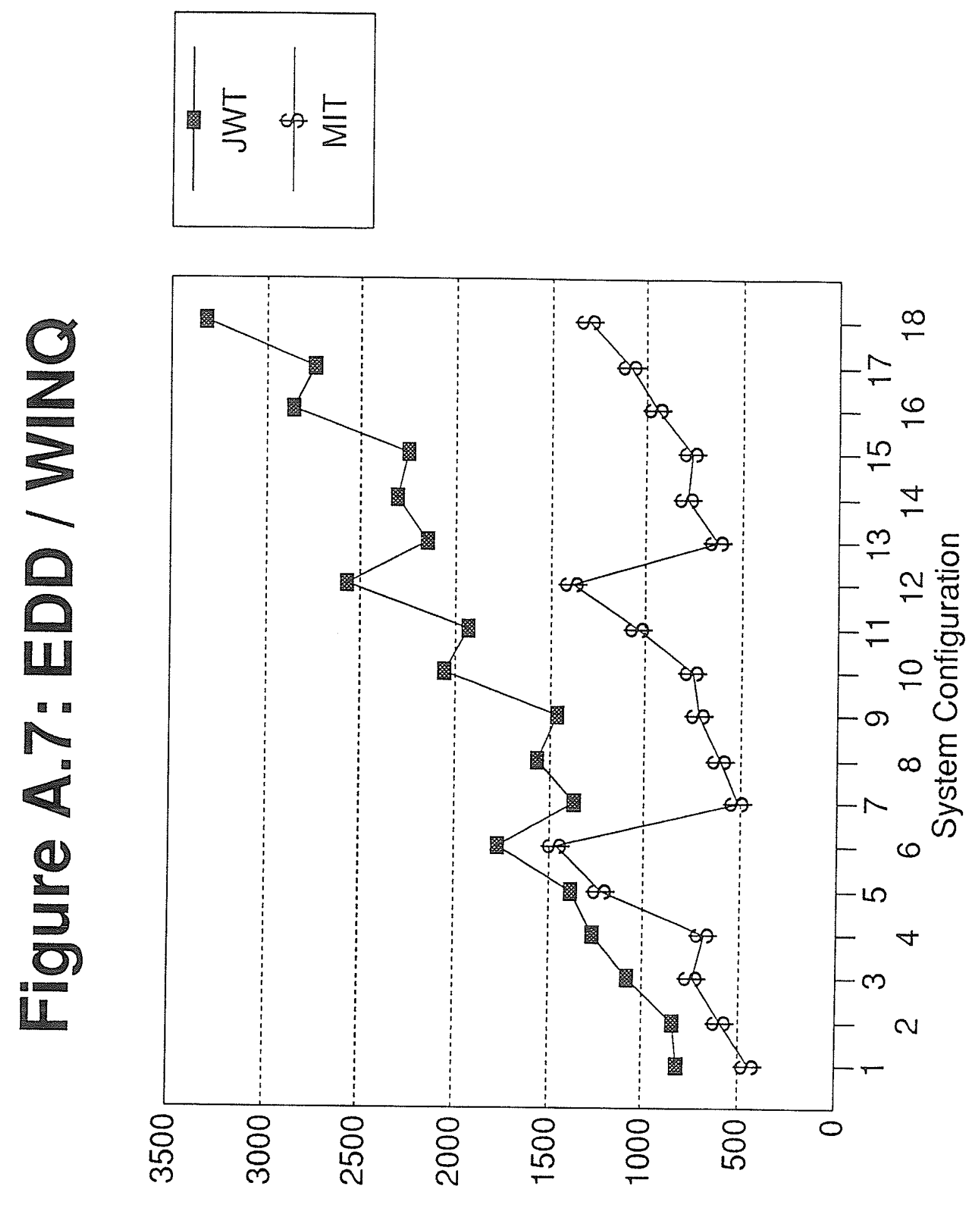

(sołnu!̣) $\perp \mid W / \perp M \Gamma$ 

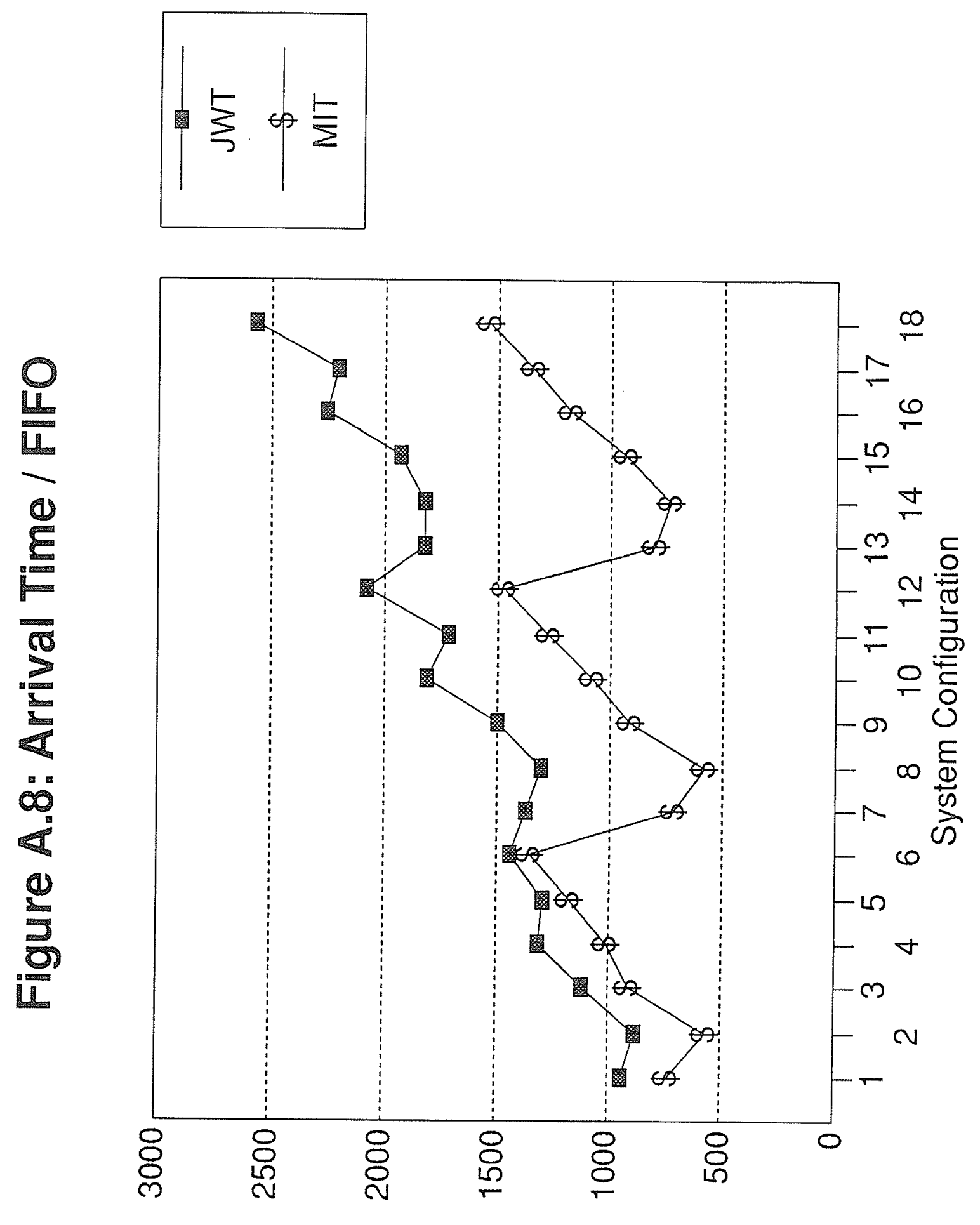

(səłnulu) $\perp I N / \perp M \Gamma$ 

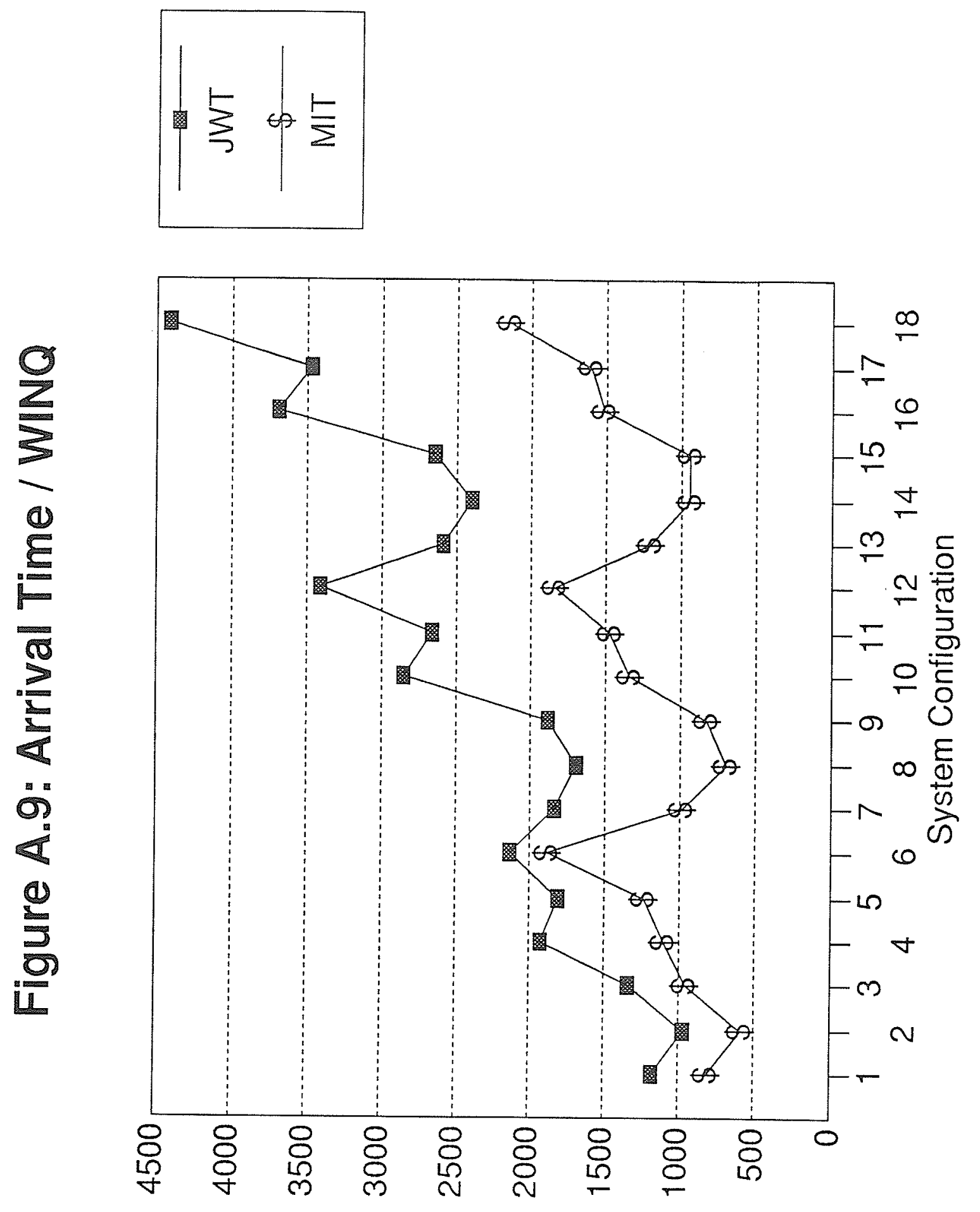

(səłnu!u) $\perp I W / \perp M \Gamma$ 


\begin{abstract}
Appendix B
GRAPHICAL OUTPUT. SHANKER \& TZEN LOADING
\end{abstract}




$$
\text { 牙步的高 }
$$
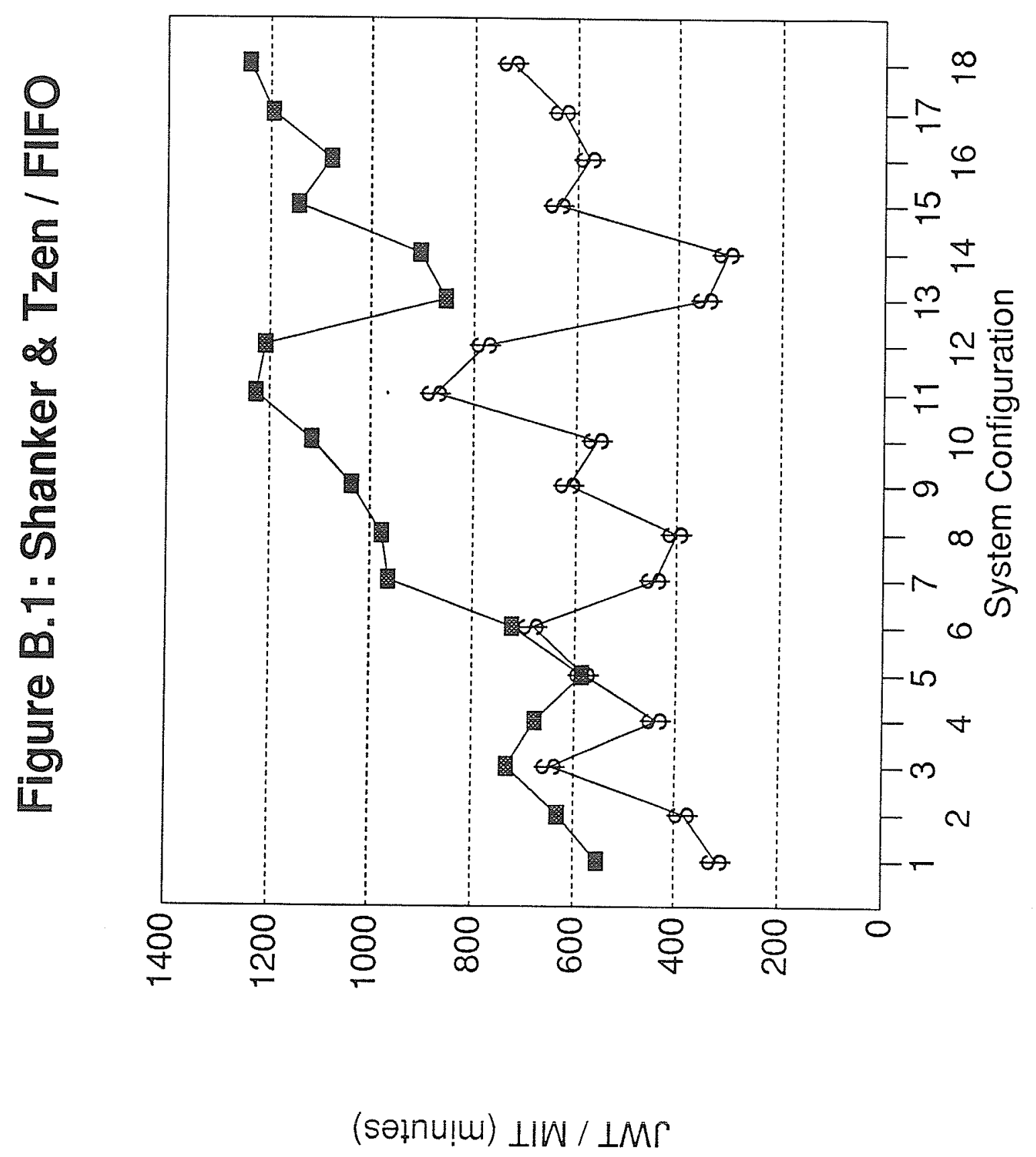

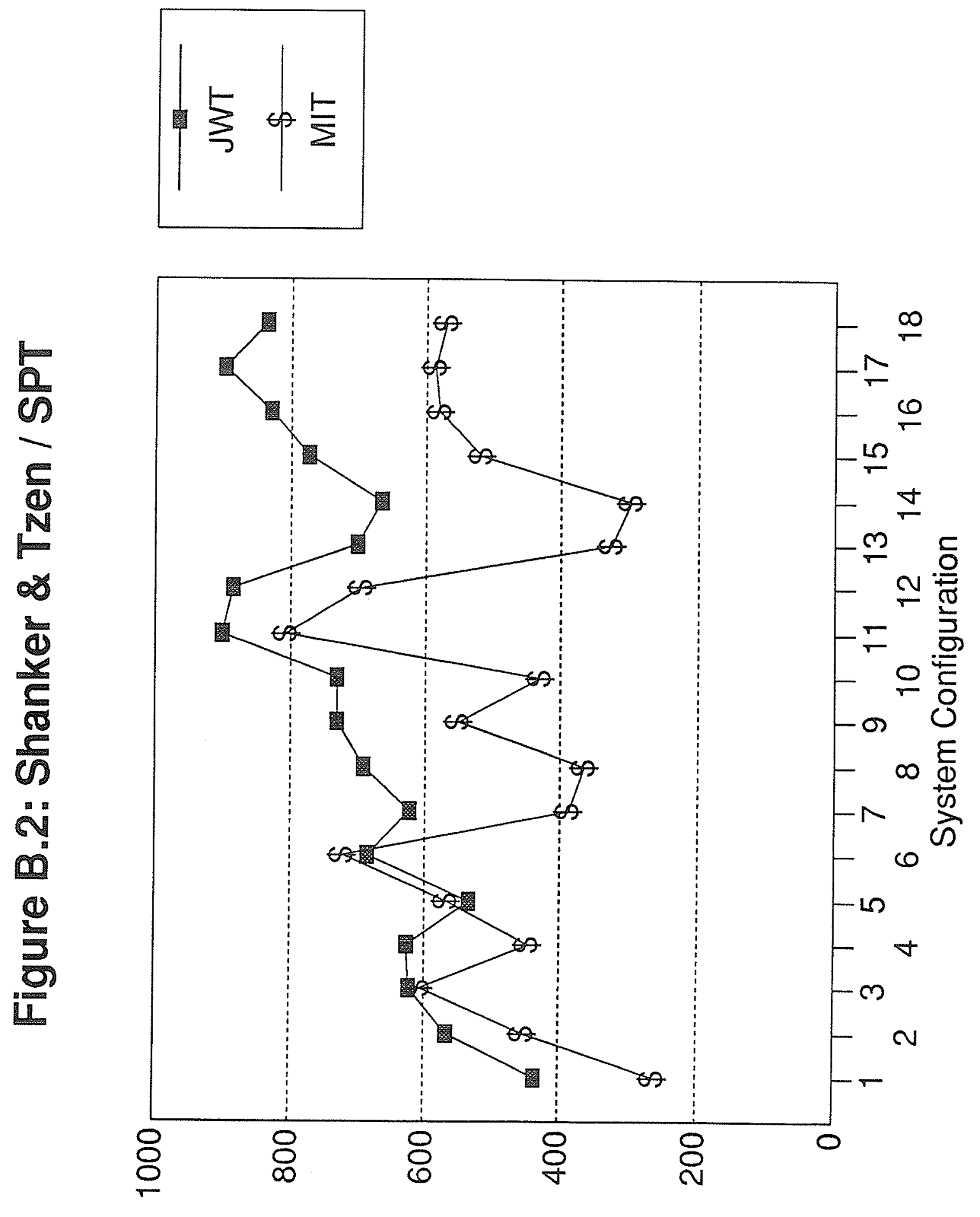

(səłnu!̣u) $\perp I W / \perp M \Gamma$ 

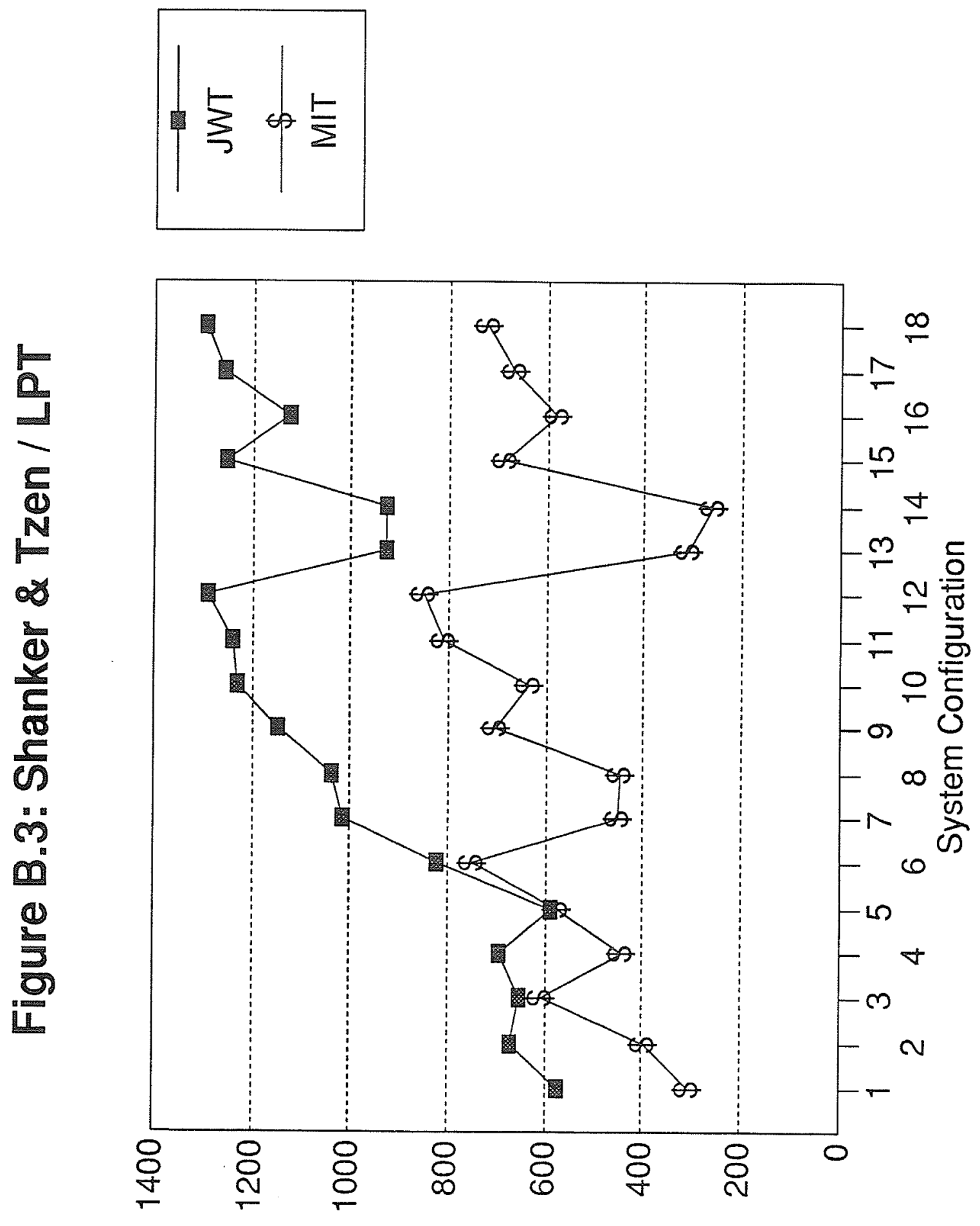

(səłnu!u) $\perp I N / \perp M \Gamma$ 


$$
1 \sum \Leftrightarrow
$$
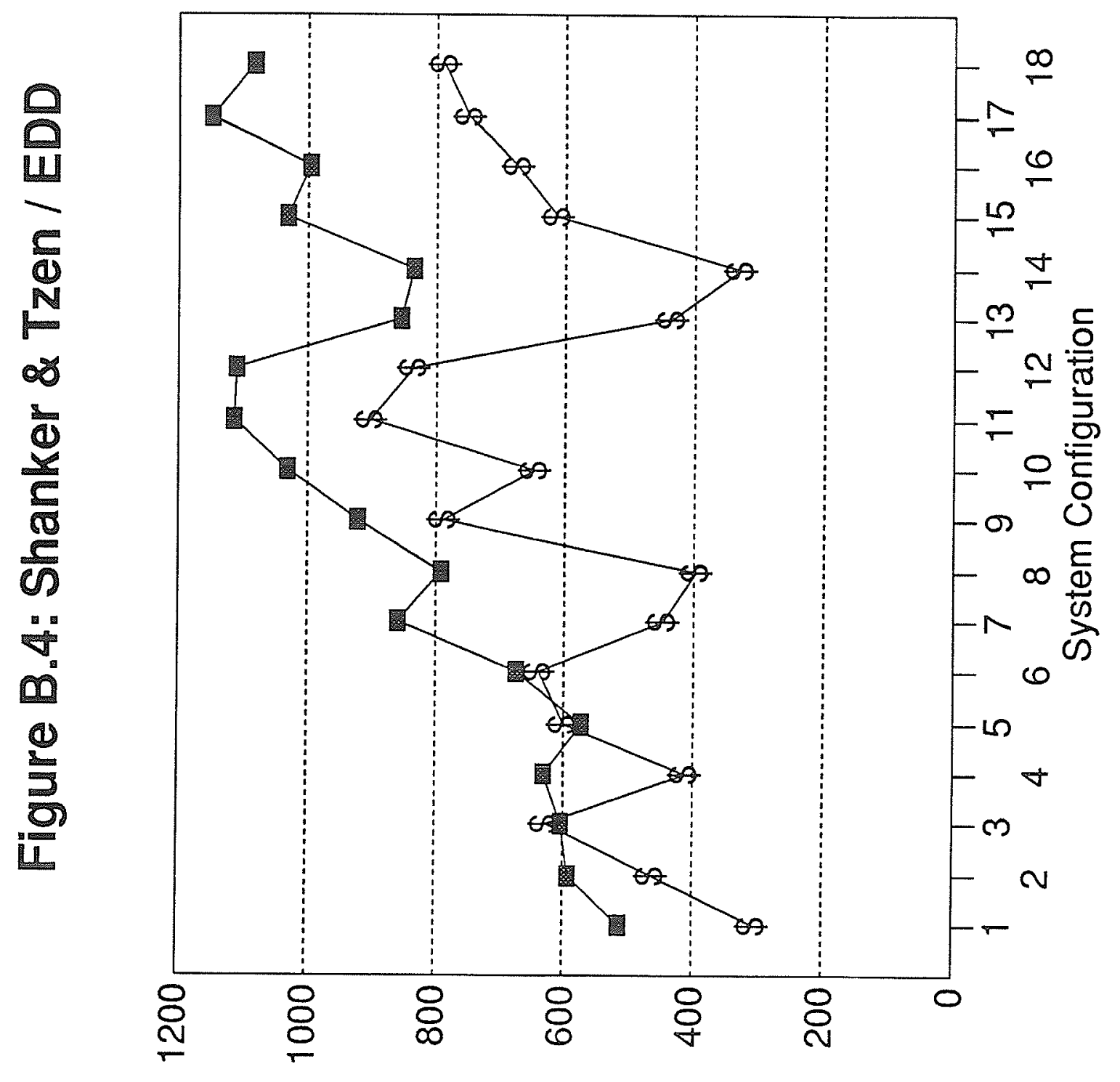

(səłnuḷ) $\perp I W / \perp M \Gamma$ 

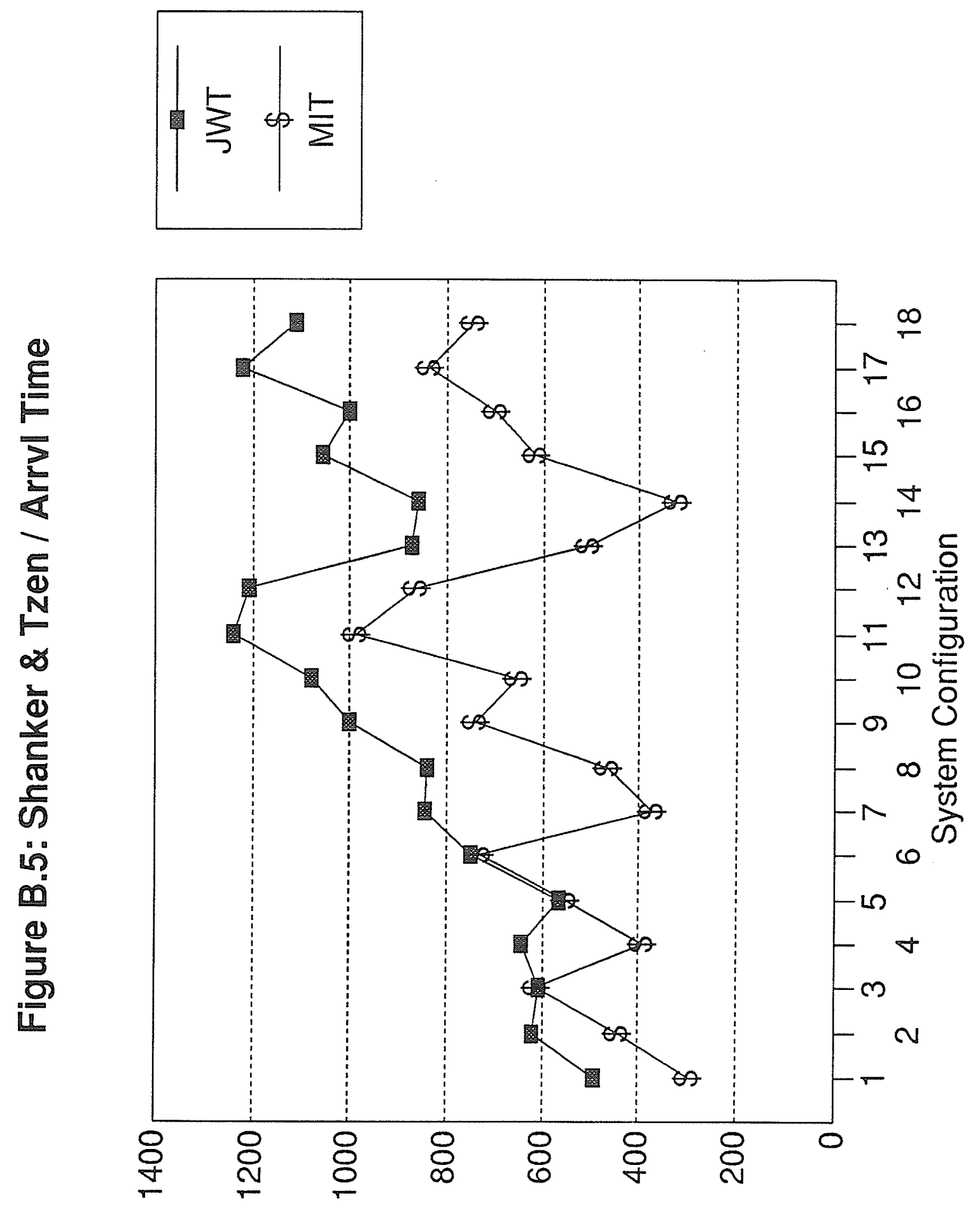

(səınu!̣) $\perp I N / \perp M \Gamma$ 

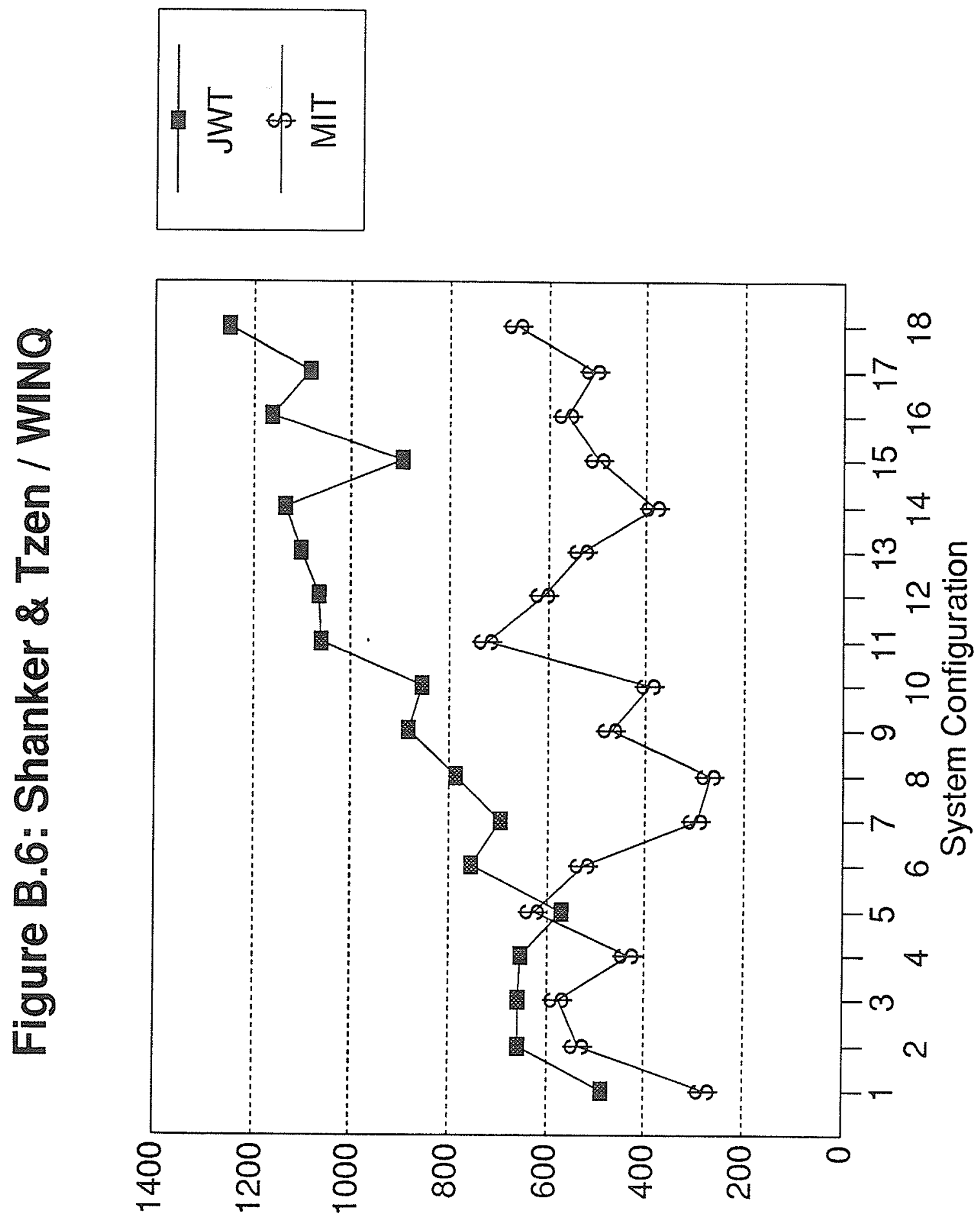

(səłnu!lu) $\perp I W / \perp M \Gamma$ 


\begin{abstract}
Appendix $\mathrm{C}$
MULTIPLE COMPARISONS OF THE MEAN JOB WAITING TIMES USING THE LSD METHOD. SIMPLE LOADING RULES
\end{abstract}

\author{
7 Job types - 6 Machines - 3 Routes \\ Schedule Mean JWT $T$ Grouping
}

$\begin{array}{rrr}\text { AT/WINQ } & 1174 & \mathrm{a} \\ \text { AT/FIFO } & 938 & \mathrm{~b} \\ \text { LPT/FIFO } & 844 & \mathrm{~b} \\ \mathrm{EDD} / \text { WINQ } & 819 & \mathrm{~b} \\ \text { LPT/WINQ } & 813 & \mathrm{~b} \\ \mathrm{EDD/FIFO} & 776 & \mathrm{~b} \mathrm{c} \\ \mathrm{FIFO/FIFO} & 742 & \mathrm{~b} \mathrm{c} \\ \text { SPT/WINQ } & 597 & \mathrm{c} \\ \text { SPT/FIFO } & 578 & \mathrm{C}\end{array}$

7 Job types - 6 Machines - 5 Routes

Schedule Mean JWT T Grouping

$\begin{array}{rlllll}\text { AT/WINQ } & 974 & & \mathrm{a} & & \\ \text { LPT/WINQ } & 913 & & \mathrm{a} & & \\ \text { AT/FIFO } & 876 & \mathrm{a} & \mathrm{b} & \\ \text { EDD/WINQ } & 848 & \mathrm{a} & \mathrm{b} & \\ \text { LPT/FIFO } & 845 & \mathrm{a} & \mathrm{b} & \\ \mathrm{EDD} / \text { FIFO } & 761 & \mathrm{a} & \mathrm{b} & \mathrm{c} & \\ \mathrm{FIFO/FIFO} & 664 & & \mathrm{~b} & \mathrm{c} & \mathrm{a} \\ \mathrm{SPT} / \text { WINQ } & 560 & & & \mathrm{c} & \mathrm{d} \\ \mathrm{SPT} / \mathrm{FIFO} & 492 & & & \mathrm{~d}\end{array}$




\begin{tabular}{ccc}
7 Job types & -8 Machines & -3 Routes \\
Schedule & Mean JWT & T Groupin \\
\hline & & \\
AT/WINQ & 1334 & $\mathrm{a}$ \\
AT/FIFO & 1117 & $\mathrm{a} \mathrm{b}$ \\
$\mathrm{EDD} /$ WINQ & 1079 & $\mathrm{a} \mathrm{b}$ \\
LPT/FIFO & 1051 & $\mathrm{~b}$ \\
LPT/WINQ & 1047 & $\mathrm{~b}$ \\
EDD/FIFO & 984 & $\mathrm{~b} c$ \\
SPT/WINQ & 944 & $\mathrm{~b} \mathrm{c}$ \\
FIEO/FIFO & 867 & $\mathrm{~b} \mathrm{c}$ \\
SPT/FIFO & 777 & $\mathrm{c}$
\end{tabular}

7 Job types - 8 Machines - 5 Routes

Schedule Mean JWT T Grouping

$\begin{array}{rrrlll}\text { AT/WINQ } & 1922 & \mathrm{a} & & \\ \text { AT/FIFO } & 1314 & & \mathrm{~b} & \\ \text { EDD/WINQ } & 1262 & & \mathrm{~b} & \mathrm{c} & \\ \text { EDD/FIFO } & 1071 & & \mathrm{~b} & \mathrm{c} & \mathrm{d} \\ \text { FIFO/FIFO } & 1014 & & \mathrm{c} & \mathrm{d} & \mathrm{e} \\ \text { LPT/WINQ } & 1004 & & \mathrm{c} & \mathrm{d} & \mathrm{e} \\ \text { LPT/FIFO } & 959 & & & \mathrm{~d} & \mathrm{e} \\ \text { SPT/WINQ } & 866 & & & \mathrm{~d} & \mathrm{e} \\ \text { SPT/FIFO } & 763 & & & & \mathrm{e}\end{array}$

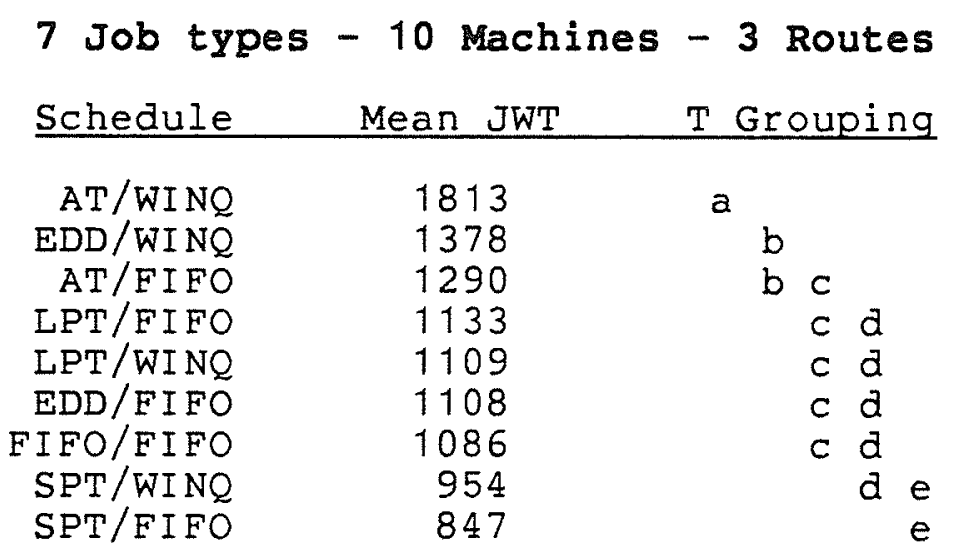


7 Job types - 10 Machines - 5 Routes Schedule Mean JWT $\quad T$ Grouping

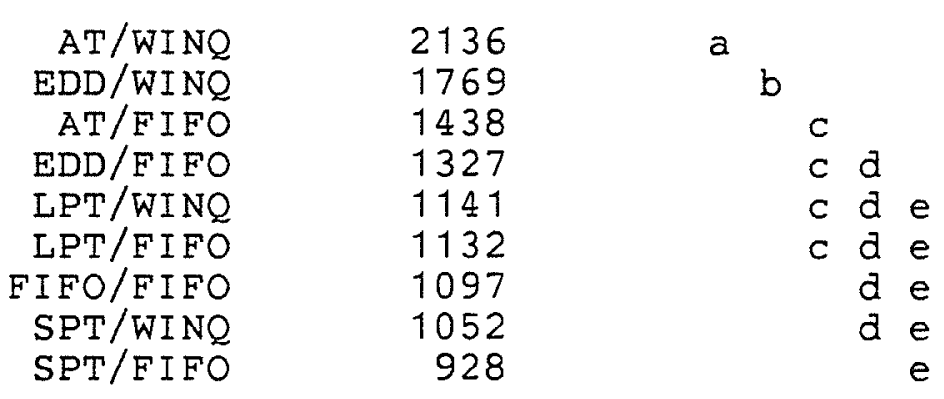

\begin{tabular}{|c|c|c|}
\hline Schedule & Mean JWT & $T$ Grouping \\
\hline AT/WINQ & 1831 & a \\
\hline EDD/WINQ & 1375 & $b$ \\
\hline $\mathrm{AT} / \mathrm{FIFO}$ & 1366 & b \\
\hline LPT/WINQ & 1357 & b \\
\hline $\mathrm{LPT} / \mathrm{FIFO}$ & 1351 & $b$ \\
\hline$E D D / F I F O$ & 1140 & b c \\
\hline FIFO/FIFO & 1054 & b c \\
\hline SPT/WINQ & 830 & c d \\
\hline FIF & 6 & \\
\hline
\end{tabular}

11 Job types - 6 Machines - 5 Routes Schedule Mean JWT T Grouping

$\begin{array}{rrrrrrr}\text { AT/WINQ } & 1684 & \mathrm{a} & & \\ \text { EDD/WINQ } & 1565 & \mathrm{a} & \mathrm{b} & & \\ \text { LPT/WINQ } & 1409 & & \mathrm{~b} & \mathrm{c} & \\ \text { LPT/FIFO } & 1333 & & \mathrm{c} & \\ \text { AT/FIFO } & 1302 & & \mathrm{c} & \mathrm{d} \\ \text { EDD/FIFO } & 1201 & & \mathrm{c} & \mathrm{d} \\ \text { FIFO/FIFO } & 1079 & & & \mathrm{~d} & \\ \text { SPT/WINQ } & 808 & & & & \mathrm{e} \\ \text { SPT/FIFO } & 792 & & & & \mathrm{e}\end{array}$




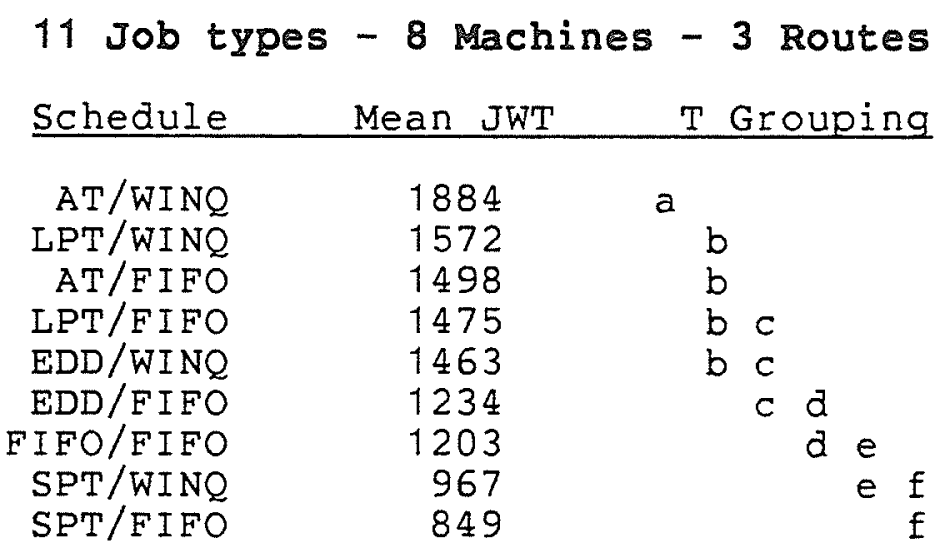

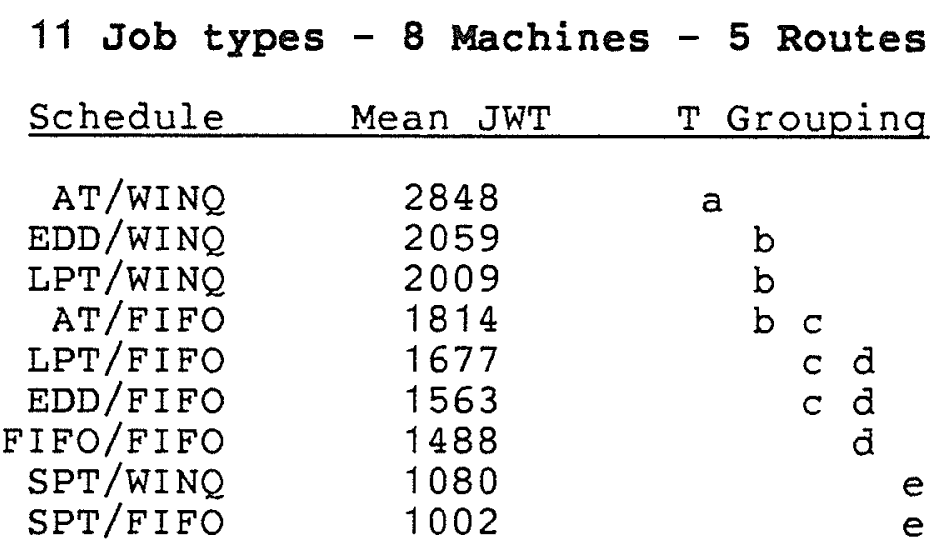

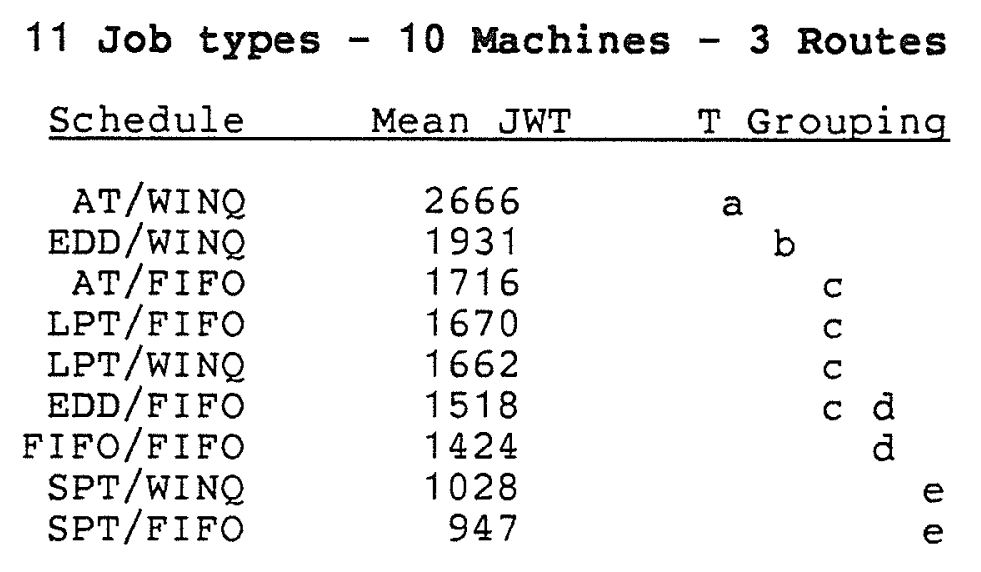




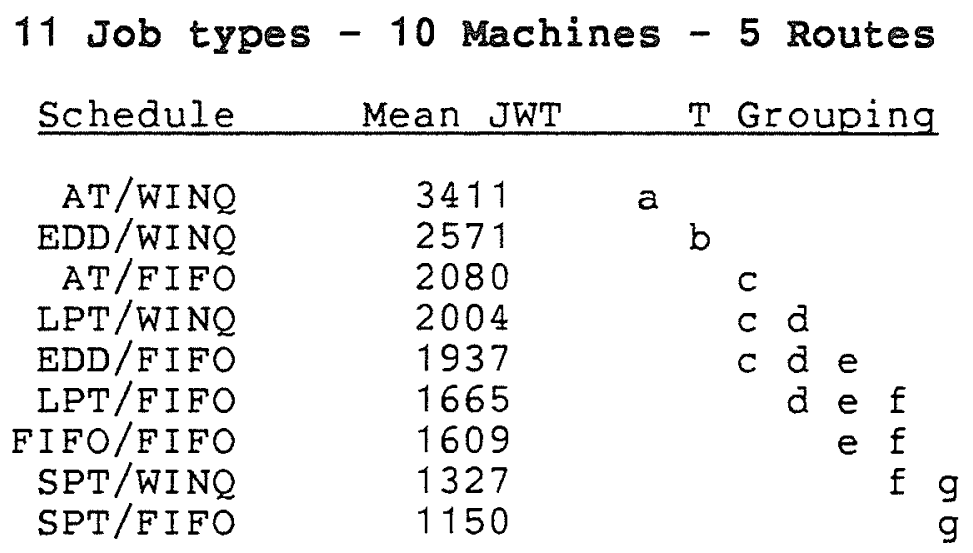

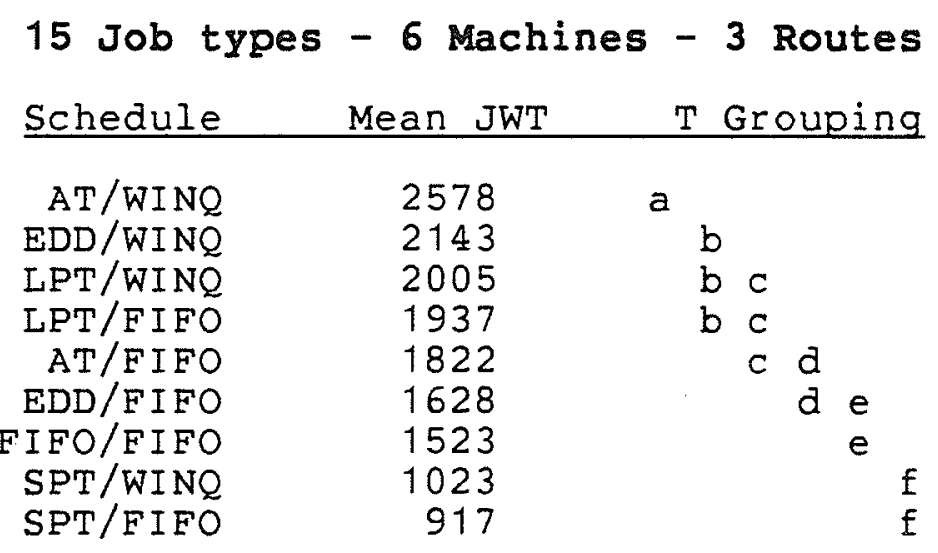

\begin{tabular}{|c|c|c|c|c|}
\hline Schedule & Mean JWT & $\mathrm{T}$ & $\mathrm{GrOl}$ & upin \\
\hline $\mathrm{AT} / \mathrm{WINQ}$ & 2387 & & a & \\
\hline $\mathrm{EDD} / \mathrm{WINQ}$ & 2306 & & a & \\
\hline LPT / WINQ & 1907 & & b & \\
\hline $\mathrm{AT} / \mathrm{EIFO}$ & 1821 & & $b$ & \\
\hline $\mathrm{LPT} / \mathrm{FIFO}$ & 1757 & & $\mathrm{~b}$ & $\mathrm{C}$ \\
\hline $\mathrm{EDD} / \mathrm{FIFO}$ & 1685 & & b & $\mathrm{C}$ \\
\hline IFO/FIFO & 1458 & & & $\mathrm{C}$ \\
\hline SPT/WINQ & 1080 & & & d \\
\hline $\mathrm{SPT} / \mathrm{FIFO}$ & 957 & & & 7 \\
\hline
\end{tabular}




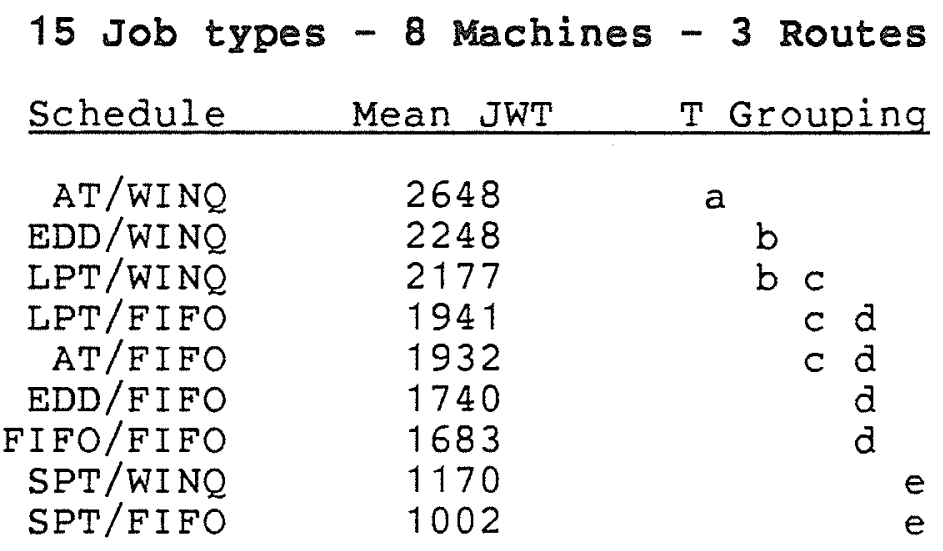

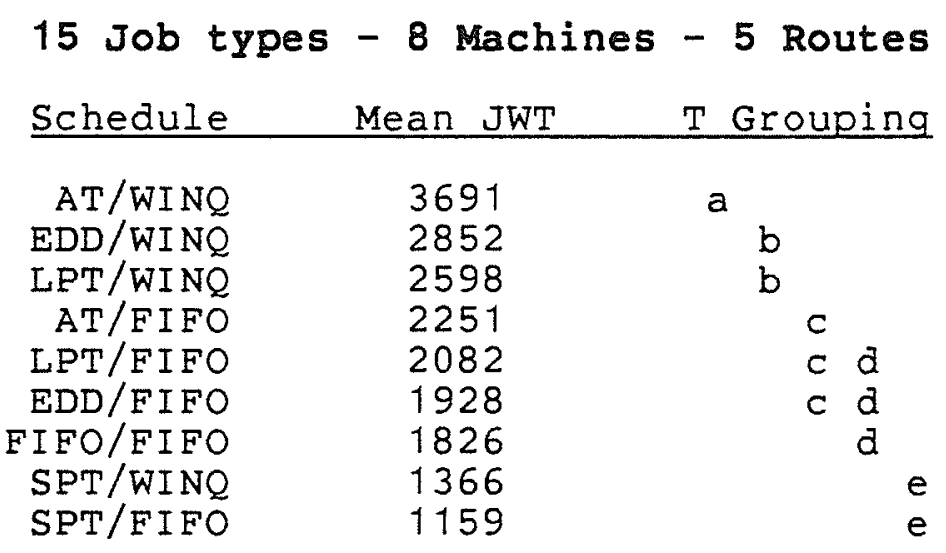

\begin{tabular}{|c|c|c|c|c|}
\hline Schedule & Mean JWT & $\mathrm{T}$ & Group & oing \\
\hline $\mathrm{AT} / \mathrm{WINQ}$ & 3474 & a & & \\
\hline EDD/WINQ & 2739 & & $b$ & \\
\hline LPT/WINQ & 2329 & & c & \\
\hline $\mathrm{AT} / \mathrm{FIFO}$ & 2202 & & $c d$ & \\
\hline LPT/FIFO & 2131 & & $c d$ & $e$ \\
\hline $\mathrm{EDD} / \mathrm{F}$ IFO & 2040 & & a & e \\
\hline FIFO/FIFO & 1925 & & & $\mathrm{e}$ \\
\hline $\mathrm{SPT} / \mathrm{WINQ}$ & 1249 & & & $\mathrm{f}$ \\
\hline $\mathrm{SPT} / \mathrm{FIFO}$ & 1118 & & & $f$ \\
\hline
\end{tabular}




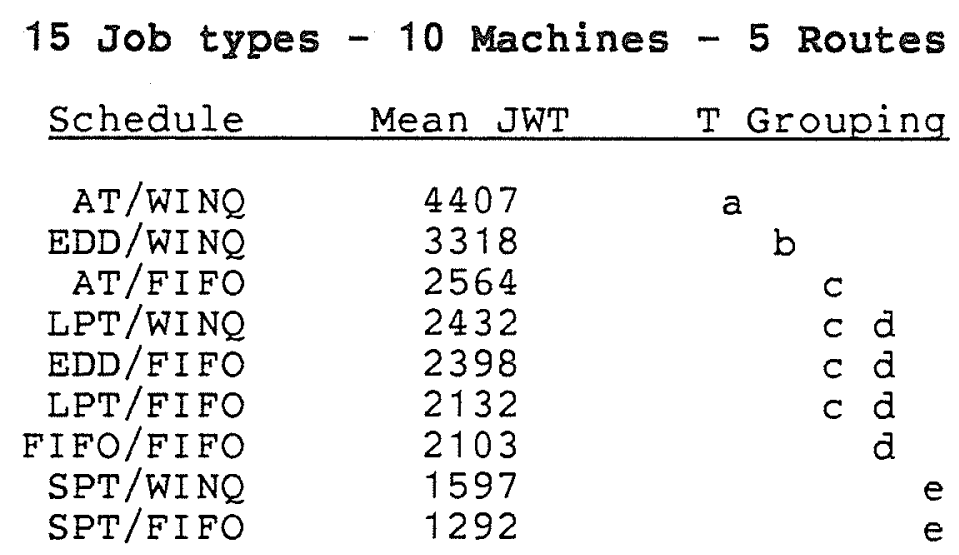




\section{Appendix D}

MULTIPLE COMPARISONS OF THE MEAN MACHINE IDLE TIMES USING THE LSD METHOD. SIMPLE LOADING RULES

7 Job types - 6 Machines - 3 Routes

Schedule Mean MIT T Grouping

$\begin{array}{rlrl}\text { AT/WINQ } & 804 & \mathrm{a} & \\ \mathrm{AT} / \mathrm{FIFO} & 737 & \mathrm{a} \mathrm{b} \\ \mathrm{LPT} / \text { WINQ } & 554 & & \mathrm{~b} \mathrm{c} \\ \mathrm{IFO} / \mathrm{FIFO} & 478 & & \mathrm{c} \\ \mathrm{EDD} / \mathrm{FIFO} & 477 & & \mathrm{c} \\ \mathrm{EDD} / \text { WINQ } & 446 & & \mathrm{c} \\ \mathrm{SPT} / \mathrm{FIFO} & 444 & & \mathrm{c} \\ \mathrm{LPT} / \mathrm{FIFO} & 409 & & \mathrm{c} \\ \mathrm{SPT} / \text { WINQ } & 348 & & \mathrm{c}\end{array}$

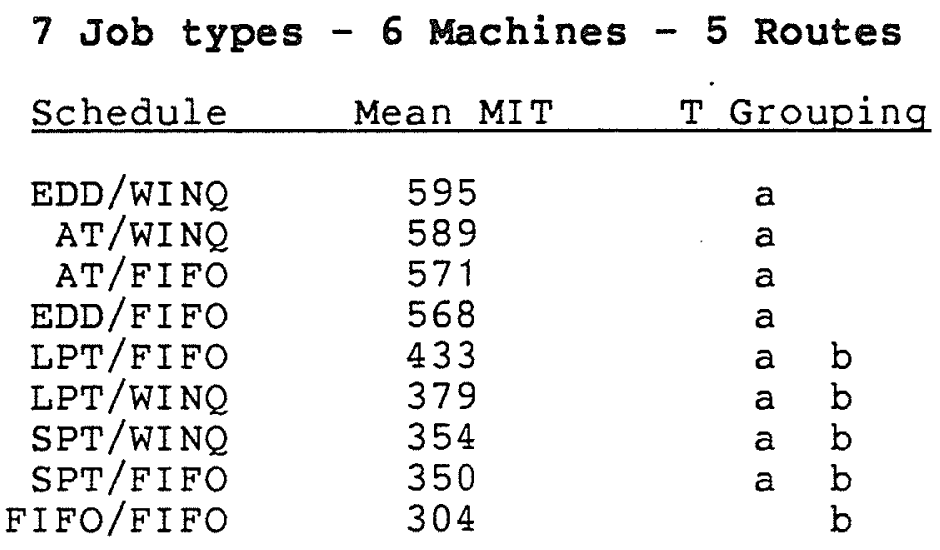


7 Job types - 8 Machines - 3 Routes

Schedule Mean MIT T Grouping

$\begin{array}{rll}\text { AT/WINQ } & 950 & \mathrm{a} \\ \text { AT/FIFO } & 911 & \mathrm{a} \\ \text { SPT/WINQ } & 814 & \mathrm{a} \\ \text { SPT/FIFO } & 808 & \mathrm{a} \\ \text { EDD/FIFO } & 790 & \mathrm{a} \\ \text { LPT/FIFO } & 785 & \mathrm{a} \\ \text { FIFO/FIFO } & 755 & \mathrm{a} \\ \text { EDD/WINQ } & 738 & \mathrm{a} \\ \text { LPT/WINQ } & 645 & \mathrm{a}\end{array}$

\section{Job types - 8 Machines - 5 Routes}

Schedule Mean MIT T Grouping

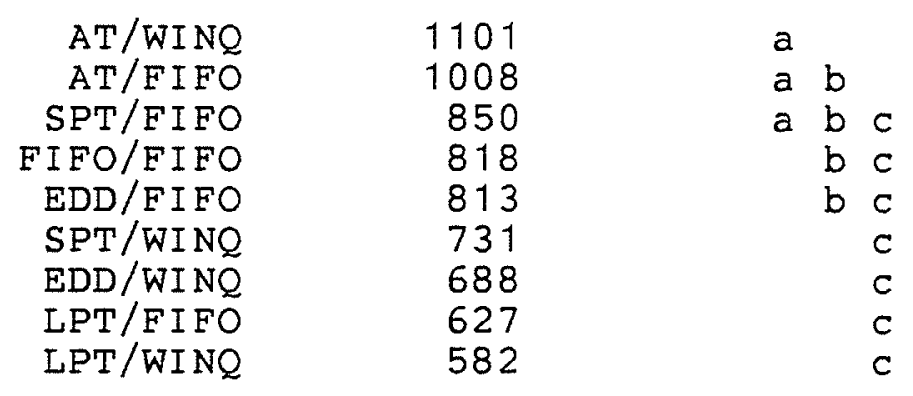

7 Job types - 10 Machines - 3 Routes Schedule Mean MIT T Grouping

$\begin{array}{rrll}\text { AT/WINQ } & 1239 & \mathrm{a} & \\ \mathrm{EDD} / \text { WINQ } & 1225 & \mathrm{a} & \\ \text { FIFO/FIFO } & 1207 & \mathrm{a} & \\ \mathrm{AT} / \mathrm{FIFO} & 1177 & \mathrm{a} & \\ \mathrm{SPT} / \mathrm{FIFO} & 1086 & \mathrm{a} & \mathrm{b} \\ \mathrm{LPT} / \mathrm{FIFO} & 1053 & \mathrm{a} & \mathrm{b} \\ \mathrm{EDD} / \mathrm{FIFO} & 1033 & \mathrm{a} & \mathrm{b} \\ \mathrm{LPT} / \text { WINQ } & 987 & \mathrm{a} & \mathrm{b} \\ \mathrm{SPT} / \text { WINQ } & 875 & & \mathrm{~b}\end{array}$




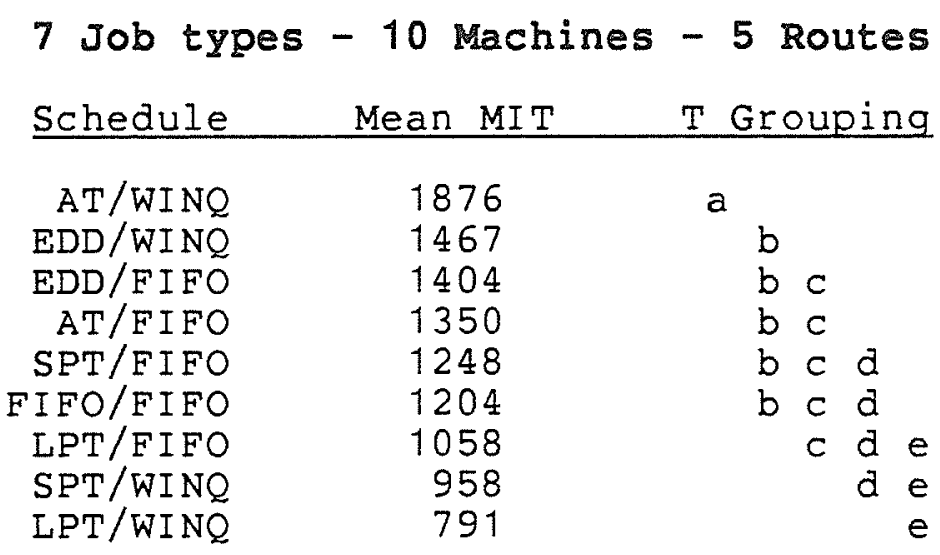

\section{Job types - 6 Machines - 3 Routes} Schedule Mean MIT T Grouping

$\begin{array}{rlllll}\text { AT/WINQ } & 976 & \mathrm{a} & & \\ \text { AT/FIFO } & 710 & \mathrm{a} & \mathrm{b} & & \\ \mathrm{EDD} / \text { FIFO } & 584 & & \mathrm{~b} & \mathrm{c} & \\ \mathrm{LPT} / \text { FIFO } & 539 & & \mathrm{~b} & \mathrm{c} & \mathrm{d} \\ \mathrm{FIFO/FIFO} & 523 & & \mathrm{~b} & \mathrm{c} & \mathrm{d} \\ \mathrm{EDD} / \text { WINQ } & 517 & & \mathrm{~b} & \mathrm{c} & \mathrm{d} \\ \mathrm{SPT} / \mathrm{FIFO} & 365 & & \mathrm{c} & \mathrm{d} \\ \mathrm{LPT} / \text { WINQ } & 363 & & \mathrm{c} & \mathrm{d} \\ \mathrm{SPT} / \text { WINQ } & 281 & & & \mathrm{~d}\end{array}$

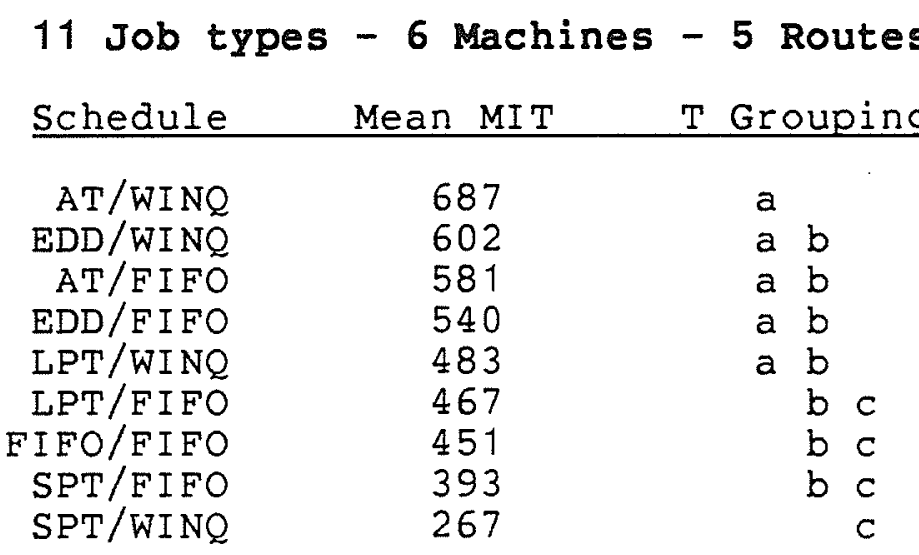


11 Job types - 8 Machines - 3 Routes

Schedule Mean MIT T Grouping

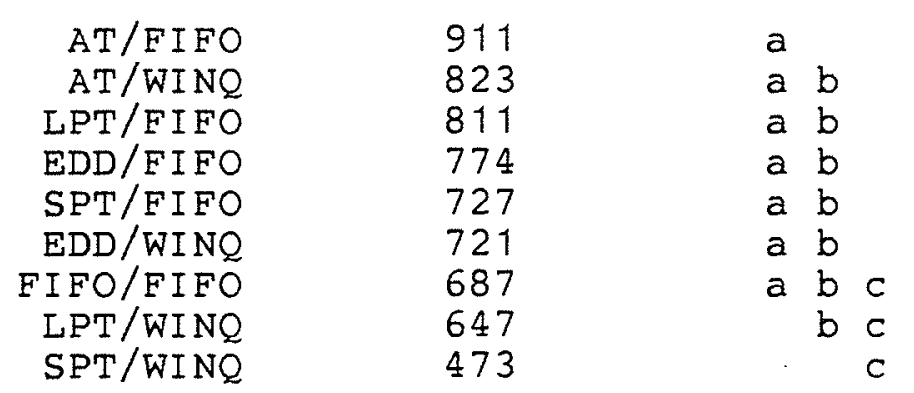

\begin{tabular}{|c|c|c|c|}
\hline Schedule & Mean MIT & $T \mathrm{Gr}$ & oupin \\
\hline $\mathrm{AT} / \mathrm{WINQ}$ & 1331 & a & \\
\hline $\mathrm{AT} / \mathrm{FIFO}$ & 1080 & $a$ & b \\
\hline SPT/FIFO & 995 & & b c \\
\hline EDD/FIFO & 927 & & $\mathrm{~b} \quad \mathrm{c}$ \\
\hline FIFO/FIFO & 886 & & $\begin{array}{lll}b & c \\
\text { b }\end{array}$ \\
\hline LPT/WINQ & 877 & & b c c \\
\hline EDD/WINQ & 751 & & c \\
\hline LPT/FIFO & 741 & & $c$ \\
\hline $\mathrm{SPT} / \mathrm{WINQ}$ & 642 & & \\
\hline
\end{tabular}

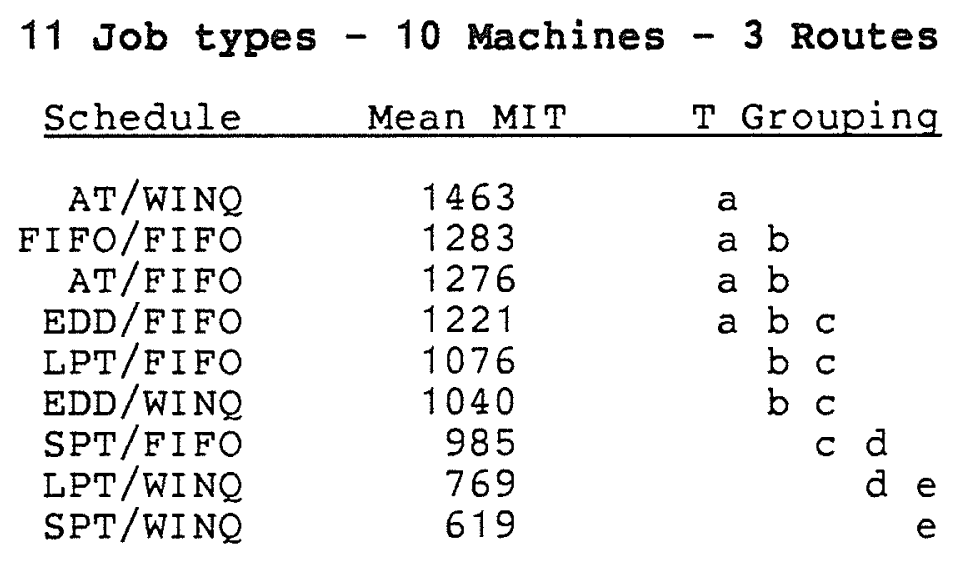




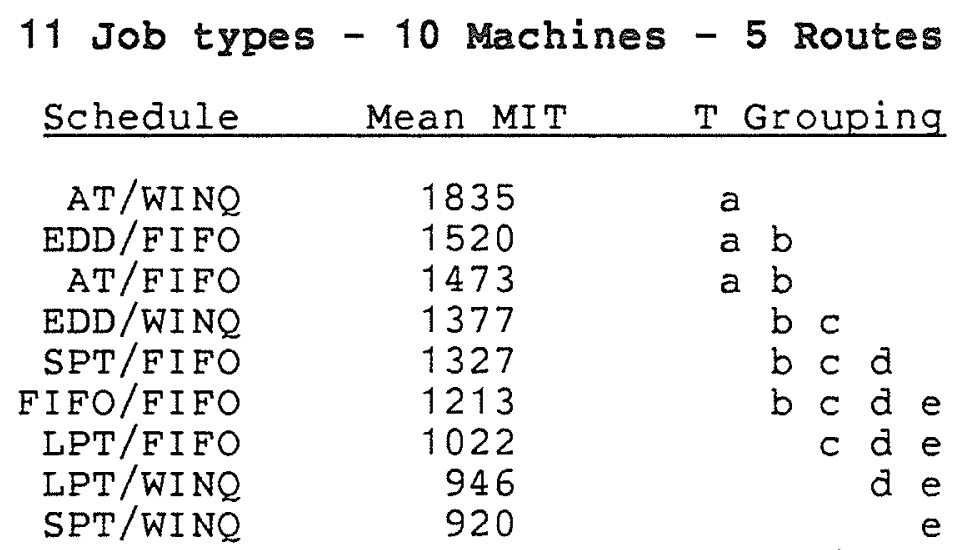

15 Job types - 6 Machines - 3 Routes Schedule Mean MIT T Grouping

$\begin{array}{rrrlll}\text { AT/WINQ } & 1204 & \mathrm{a} & & \\ \text { AT/FIFO } & 806 & & \mathrm{~b} & & \\ \text { FIFO/FIFO } & 673 & & \mathrm{~b} & \mathrm{c} & \\ \text { EDD/FIFO } & 663 & & \mathrm{~b} & \mathrm{c} & \\ \text { EDD/WINQ } & 631 & & \mathrm{~b} & \mathrm{c} & \mathrm{d} \\ \text { LPT/FIFO } & 628 & & \mathrm{~b} & \mathrm{c} & \mathrm{d} \\ \text { LPT/WINQ } & 451 & & \mathrm{c} d \mathrm{~d} \\ \text { SPT/FIFO } & 366 & & & \mathrm{~d} & \mathrm{e} \\ \text { SPT/WINQ } & 243 & & & & \mathrm{e}\end{array}$

15 Job types - 6 Machines - 5 Routes Schedule Mean MIT T Grouping

$\begin{array}{rlllll}\text { AT/WINQ } & 943 & & \mathrm{a} & & \\ \text { EDD/WINQ } & 784 & & \mathrm{a} & & \\ \text { AT/FIFO } & 738 & & \mathrm{a} & \mathrm{b} & \\ \text { EDD/FIFO } & 705 & & \mathrm{a} & \mathrm{b} & \mathrm{c} \\ \text { LPT/FIFO } & 461 & & \mathrm{~b} & \mathrm{c} & \mathrm{d} \\ \text { FIFO/FIFO } & 445 & & & \mathrm{c} & \mathrm{d} \\ \text { SPT/FIFO } & 423 & & & & \mathrm{~d} \\ \mathrm{LPT} / \text { WINQ } & 360 & & & & \mathrm{~d} \\ \text { SPT/WINQ } & 298 & & & \mathrm{~d}\end{array}$




\begin{tabular}{ccc}
15 Job types & -8 Machines & -3 Routes \\
Schedule & Mean MIT & T Grouping \\
\hline & & \\
AT/WINQ & 938 & $\mathrm{a}$ \\
AT/FIFO & 932 & $\mathrm{a}$ \\
EDD/FIFO & 855 & $\mathrm{a}$ \\
FIFO/FIFO & 853 & $\mathrm{a}$ \\
LPT/FIFO & 851 & $\mathrm{a}$ \\
EDD/WINQ & 766 & $\mathrm{a} b$ \\
LPT/WINQ & 727 & $\mathrm{a} b \mathrm{c}$ \\
SPT/FIFO & 554 & $\mathrm{~b} \mathrm{c}$ \\
SPT/WINQ & 521 &
\end{tabular}

15 Job types - 8 Machines - 5 Routes

Schedule Mean MIT T Grouping

$\begin{array}{rrrrrr}\text { AT/WINQ } & 1510 & \mathrm{a} & & \\ \text { AT/FIFO } & 1170 & & \mathrm{~b} & \\ \text { EDD/WINQ } & 944 & \mathrm{~b} & \mathrm{c} & \\ \text { EDD/FIFO } & 902 & \mathrm{~b} & \mathrm{c} & \\ \text { FIFO/FIFO } & 831 & & \mathrm{c} & \mathrm{d} \\ \text { SPT/FIFO } & 791 & & \mathrm{c} & \mathrm{d} \\ \mathrm{LPT} / \text { FIFO } & 758 & & \mathrm{c} & \mathrm{d} \\ \mathrm{LPT} / \text { WINQ } & 750 & & \mathrm{c} & \mathrm{d} \\ \mathrm{SPT} / \text { WINQ } & 579 & & & \mathrm{~d}\end{array}$

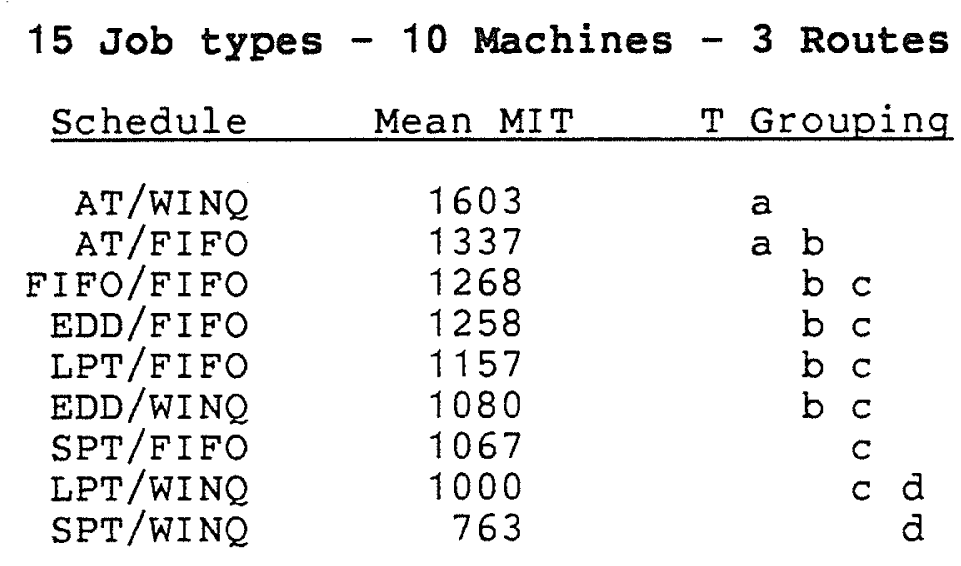




\section{Job types - 10 Machines - 5 Routes}

Schedule Mean MIT T Grouping

$\begin{array}{rrrllll}\text { AT/WINQ } & 2144 & \mathrm{a} & & \\ \text { AT/FIFO } & 1536 & & \mathrm{~b} & \\ \text { EDD/FIFO } & 1483 & & \mathrm{~b} & \mathrm{c} & \\ \text { FIFO/FIFO } & 1421 & & \mathrm{~b} & \mathrm{c} & \\ \mathrm{EDD} / \text { WINQ } & 1303 & \mathrm{~b} & \mathrm{c} & \\ \mathrm{SPT} / \text { FIFO } & 1297 & \mathrm{~b} & \mathrm{c} & \\ \mathrm{SPT} / \text { WINQ } & 1089 & & \mathrm{c} & \mathrm{d} \\ \mathrm{LPT} / \text { FIFO } & 1060 & & \mathrm{c} & \mathrm{d} \\ \mathrm{LPT} / \text { WINQ } & 748 & & & \mathrm{~d}\end{array}$




\begin{abstract}
Appendix $\mathrm{E}$
MULTIPLE COMPARISONS OF THE MEAN JOB WAITING

TIMES USING THE LSD METHOD. SHANRER \& TZEN

LOADING ALGORI THM
\end{abstract}

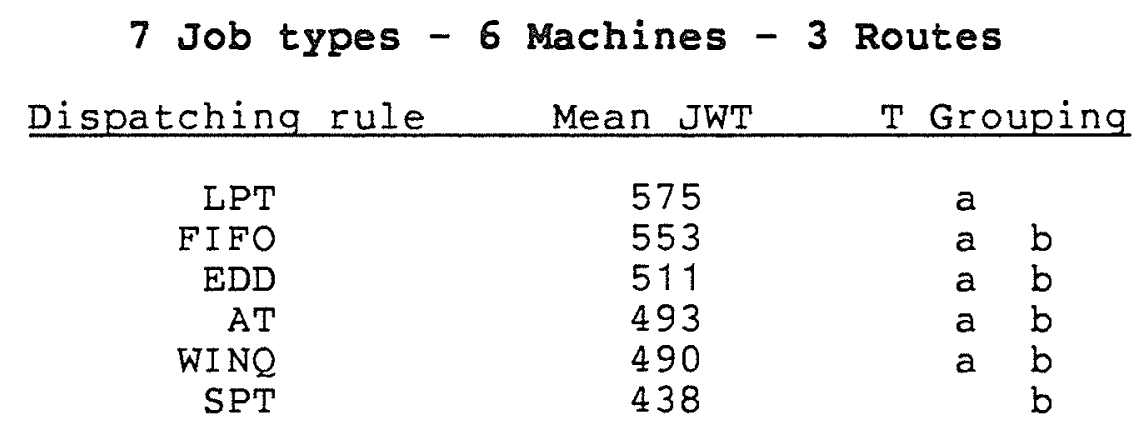
7 Job types - 6 Machines - 5 Routes
Dispatching rule Mean JWT T Grouping

$\begin{array}{rll}\text { LPT } & 670 & \mathrm{a} \\ \text { WINQ } & 660 & \mathrm{a} \\ \text { FIFO } & 630 & \mathrm{a} \\ \text { AT } & 623 & \mathrm{a} \\ \text { EDD } & 591 & \mathrm{a} \\ \text { SPT } & 569 & \mathrm{a}\end{array}$

\title{
7 Job types - 8 Machines - 3 Routes
}

Dispatching rule Mean JWT T Grouping

$\begin{array}{rll}\text { FIFO } & 729 & \mathrm{a} \\ \text { WINQ } & 656 & \mathrm{a} \\ \text { LPT } & 655 & \mathrm{a} \\ \text { SPT } & 623 & \mathrm{a} \\ \text { AT } & 606 & \mathrm{a} \\ \text { EDD } & 604 & \mathrm{a}\end{array}$




\begin{tabular}{ccc}
7 Job types -8 & Machines -5 & Routes \\
Dispatching rule & Mean JWT & T Grouping \\
\hline LPT & 694 & $\mathrm{a}$ \\
FIFO & 677 & $\mathrm{a}$ \\
WINQ & 653 & $\mathrm{a}$ \\
AT & 646 & $\mathrm{a}$ \\
EDD & 629 & $\mathrm{a}$ \\
SPT & 628 & $\mathrm{a}$
\end{tabular}

7 Job types - 10 Machines - 3 Routes Dispatching rule Mean JWT T Grouping

$\begin{array}{rll}\text { LPT } & 587 & \mathrm{a} \\ \text { FIFO } & 585 & \mathrm{a} \\ \text { WINQ } & 571 & \mathrm{a} \\ \text { EDD } & 570 & \mathrm{a} \\ \text { AT } & 565 & \mathrm{a} \\ \text { SPT } & 534 & \mathrm{a}\end{array}$

\begin{tabular}{rcc}
7 Job types - 10 Machines -5 & Routes \\
Dispatching rule & Mean JWT & T Grouping \\
\hline LPT & 822 & \\
WINQ & 753 & $\mathrm{a}$ \\
AT & 751 & $\mathrm{a}$ \\
FIFO & 720 & $\mathrm{a}$ \\
SPT & 685 & $\mathrm{a}$ \\
EDD & 675 & $\mathrm{a}$ \\
\end{tabular}

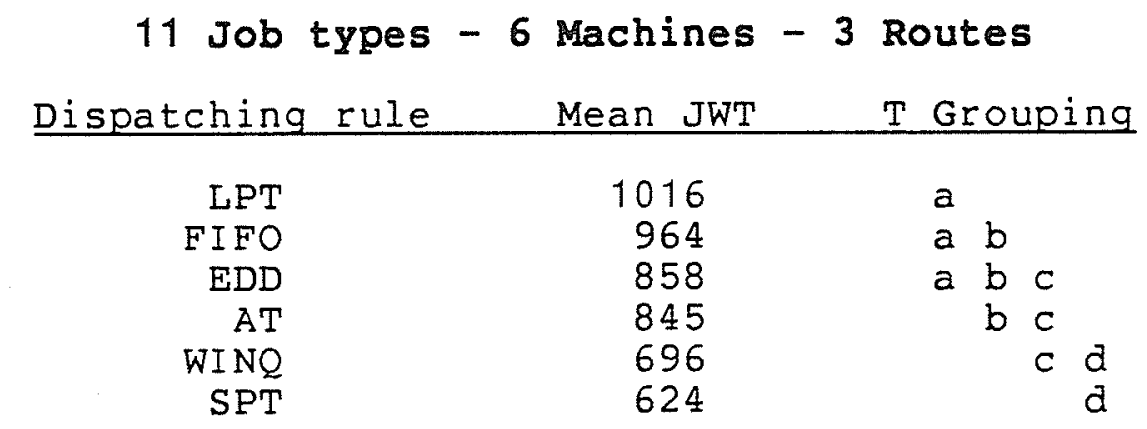




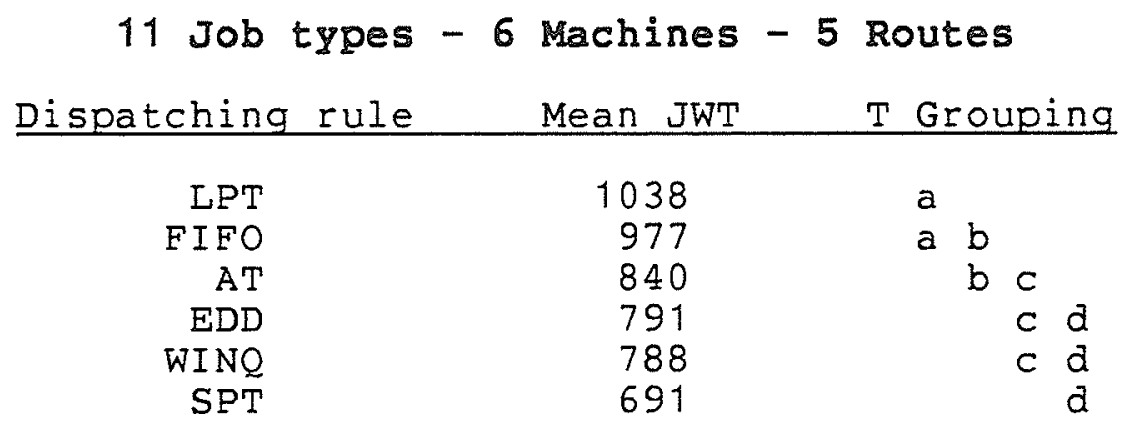

\begin{tabular}{rccc}
11 Job types -8 Machines -3 Routes & \\
Dispatching rule & Mean JWT & T Grouping \\
\hline LPT & 1149 & a & \\
FIFO & 1036 & a b & \\
AT & 1000 & b c & \\
EDD & 922 & b c & \\
WINQ & 883 & & C \\
SPT & 730 & &
\end{tabular}

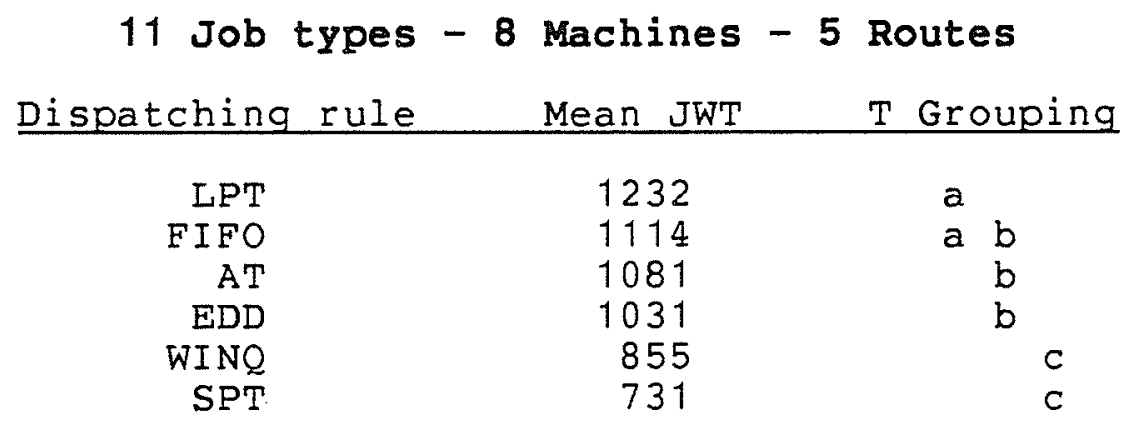

11 Job types - 10 Machines - 3 Routes

Dispatching rule Mean JWT T Grouping

$\begin{array}{rrlr}\text { AT } & 1241 & \mathrm{a} & \\ \text { LPT } & 1239 & \mathrm{a} & \\ \text { FIFO } & 1223 & \mathrm{a} & \\ \text { EDD } & 1111 & \mathrm{a} & \mathrm{b} \\ \text { WINQ } & 1060 & & \mathrm{~b} \mathrm{c} \\ \text { SPT } & 902 & & \mathrm{c}\end{array}$




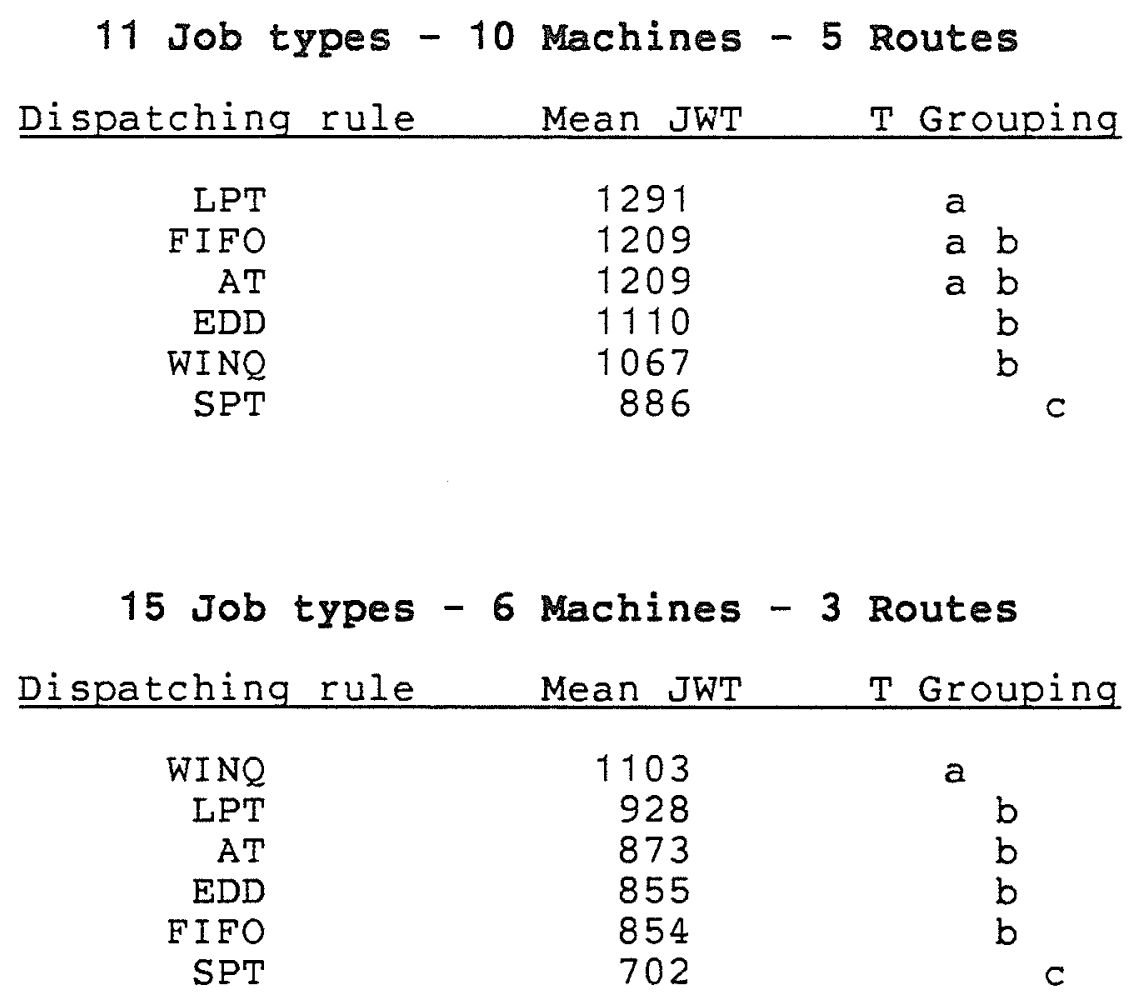

\section{Job types - 6 Machines - 5 Routes

Dispatching rule Mean JWT T Grouping

$\begin{array}{rr}\text { WINQ } & 1134 \\ \text { LPT } & 929 \\ \text { FIFO } & 904 \\ \text { AT } & 861 \\ \text { EDD } & 833 \\ \text { SPT } & 667\end{array}$
a
b
b
b
b
$c$

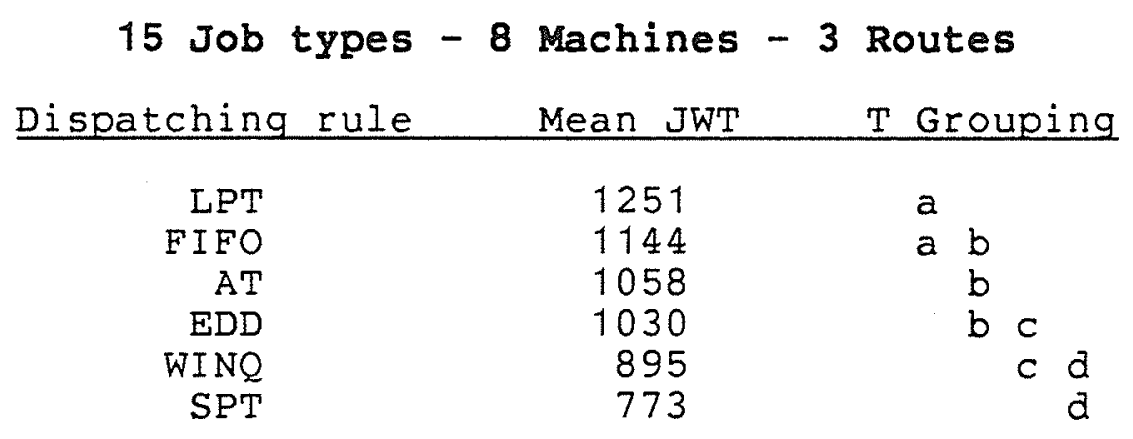


15 Job types - 8 Machines - 5 Routes

Dispatching rule Mean JWT

T Grouping

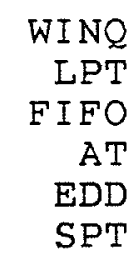
1159
1123
1080
1000
995
830
a
a $b$
a $b$
$\mathrm{b}$
b
c

\begin{tabular}{|c|c|c|}
\hline Dispatching rule & Mean JWT & T Grouping \\
\hline LPT & 1258 & a \\
\hline $\mathrm{AT}$ & 1220 & $a \quad b$ \\
\hline FIFO & 1191 & $a b$ \\
\hline EDD & 1150 & $a b$ \\
\hline WINQ & 1082 & b \\
\hline SPT & 897 & C \\
\hline
\end{tabular}

\begin{tabular}{ccc}
15 Job types - 10 Machines -5 Routes \\
Dispatching rule & Mean JWT & T Grouping \\
\hline LPT & 1293 & a \\
WINQ & 1248 & a b \\
FIFO & 1238 & a b \\
AT & 1112 & a b \\
EDD & 1088 & \\
SPT & 835 & $\mathrm{~b}$
\end{tabular}




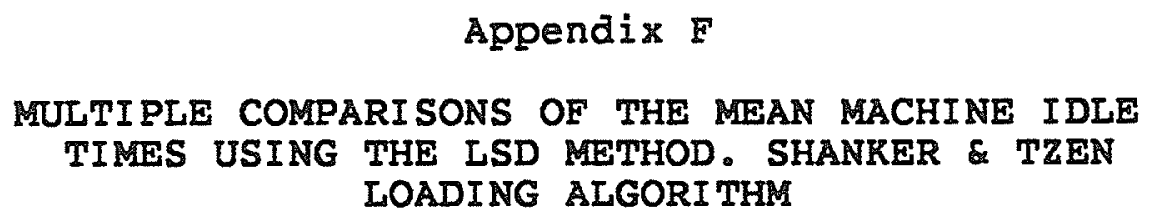

\begin{tabular}{ccc}
7 Job types -6 & Machines -3 & Routes \\
Dispatching rule & Mean MIT & T Grouping \\
\hline FIFO & 320 & \\
EDD & 306 & $\mathrm{a}$ \\
LPT & 305 & $\mathrm{a}$ \\
AT & 298 & $\mathrm{a}$ \\
WINQ & 280 & $\mathrm{a}$ \\
SPT & 261 & $\mathrm{a}$ \\
ST &
\end{tabular}

7 Job types - 6 Machines - 5 Routes

Dispatching rule Mean MIT T Grouping

$\begin{array}{rll}\text { WINQ } & 534 & \mathrm{a} \\ \text { EDD } & 460 & \mathrm{a} \\ \text { SPT } & 455 & \mathrm{a} \\ \text { AT } & 443 & \mathrm{a} \\ \text { LPT } & 396 & \mathrm{a} \\ \text { FIFO } & 383 & \mathrm{a}\end{array}$

7 Job types - 8 Machines - 3 Routes Dispatching rule Mean MIT $\quad$ T Grouping

$\begin{array}{rll}\text { FIFO } & 645 & \mathrm{a} \\ \text { EDD } & 626 & \mathrm{a} \\ \text { AT } & 611 & \mathrm{a} \\ \text { SPT } & 607 & \mathrm{a} \\ \text { LPT } & 606 & \mathrm{a} \\ \text { WINQ } & 575 & \mathrm{a}\end{array}$




\begin{tabular}{ccc}
7 Job types - 8 & Machines - 5 & Routes \\
Dispatching rule & Mean MIT & T Grouping \\
\hline SPT & 448 & \\
IPT & 443 & $\mathrm{a}$ \\
FIFO & 437 & $\mathrm{a}$ \\
WINQ & 435 & $\mathrm{a}$ \\
EDD & 409 & $\mathrm{a}$ \\
AT & 392 & $\mathrm{a}$ \\
& & $\mathrm{a}$
\end{tabular}

\begin{tabular}{ccc}
7 Job types -10 & Machines -3 & Routes \\
Dispatching rule & Mean MIT & T Grouping \\
\hline WINQ & 628 & \\
EDD & 600 & $\mathrm{a}$ \\
FIFO & 582 & $\mathrm{a}$ \\
IPT & 575 & $\mathrm{a}$ \\
SPT & 568 & $\mathrm{a}$ \\
AT & 553 & $\mathrm{a}$ \\
\end{tabular}

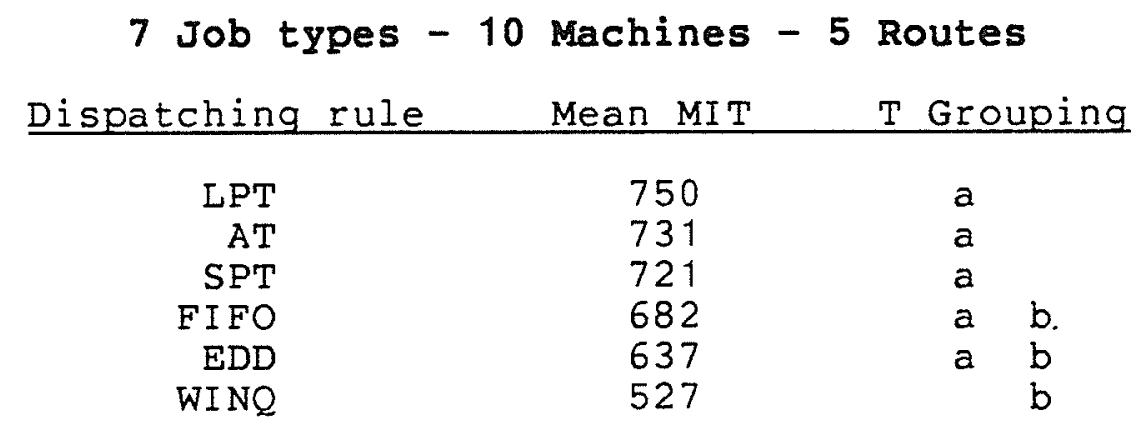

11 Job types - 6 Machines - 3 Routes Dispatching rule Mean MIT T Grouping

$\begin{array}{rll}\text { LPT } & 453 & \mathrm{a} \\ \text { EDD } & 447 & \mathrm{a} \\ \text { FIFO } & 444 & \mathrm{a} \\ \text { SPT } & 389 & \mathrm{a} \\ \text { AT } & 376 & \mathrm{a} \\ \text { WINQ } & 297 & \mathrm{a}\end{array}$




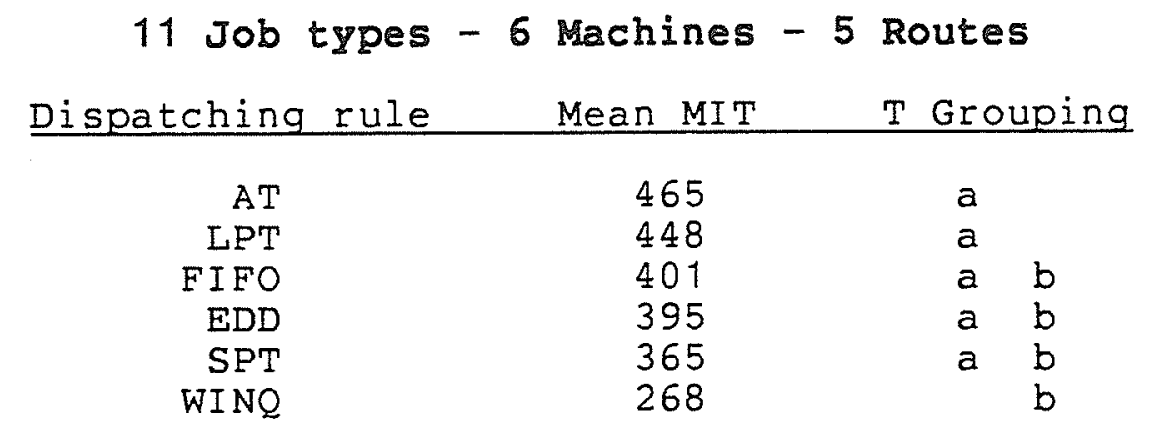

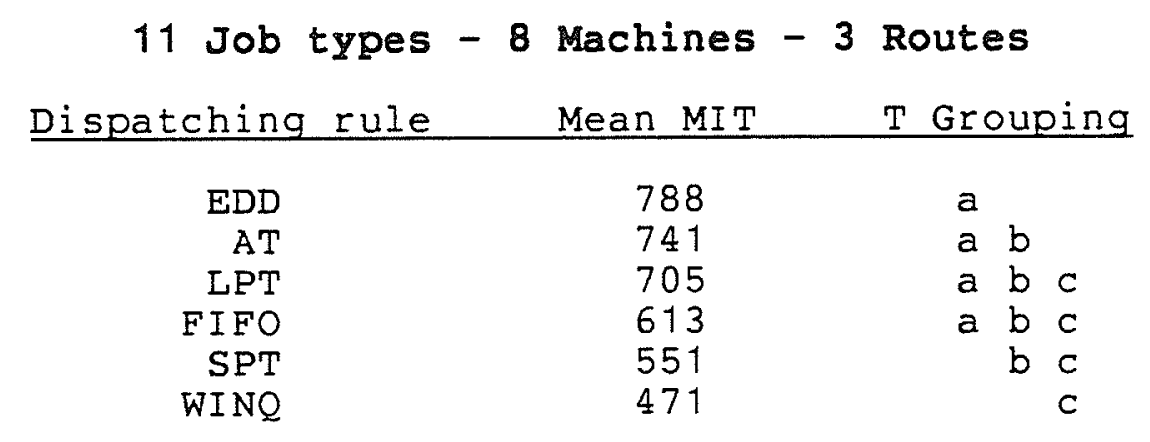

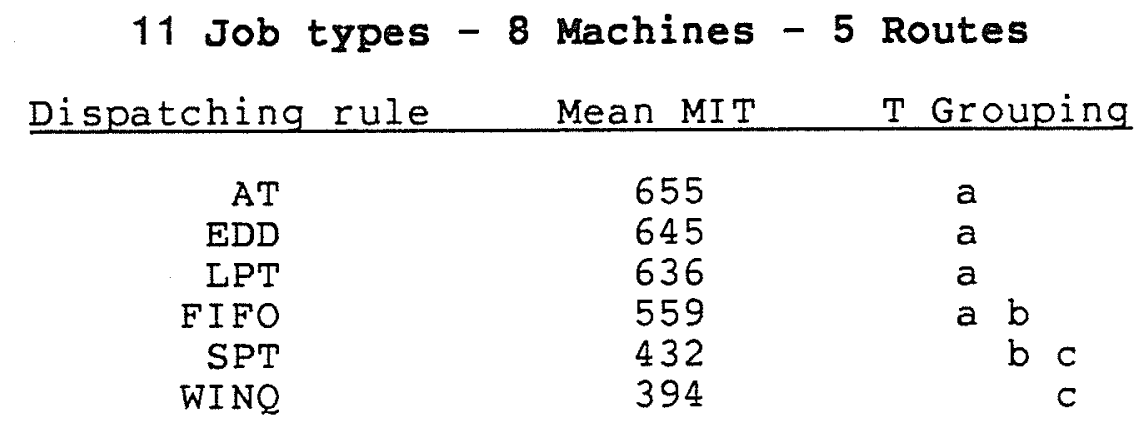

11 Job types - 10 Machines - 3 Routes Dispatching rule Mean MIT T Grouping

$\begin{array}{rlll}\text { AT } & 988 & \mathrm{a} & \\ \text { EDD } & 903 & \mathrm{a} & \mathrm{b} \\ \text { FIFO } & 875 & \mathrm{a} & \mathrm{b} \\ \text { LPT } & 808 & \mathrm{a} & \mathrm{b} \\ \text { SPT } & 805 & \mathrm{a} & \mathrm{b} \\ \text { WINQ } & 720 & & \mathrm{~b}\end{array}$


11 Job types - 10 Machines - 5 Routes Dispatching rule Mean MIT T Grouping

AT
LPT
EDD
FIFO
SPT
WINQ

865
852
835
775
696
606

a

a

a $\quad b$

a $\quad b$

\begin{tabular}{ccc}
15 Job types -6 & Machines -5 & Routes \\
Dispatching rule & Mean MIT & T Grouping \\
\hline & & \\
WINQ & 383 & $\mathrm{a}$ \\
EDD & 327 & $\mathrm{a}$ \\
AT & 322 & $\mathrm{a}$ \\
FIFO & 305 & $\mathrm{a}$ \\
SPT & 297 & $\mathrm{a}$ \\
LPT & 259 & $\mathrm{a}$
\end{tabular}

15 Job types - 8 Machines - 3 Routes Dispatching rule Mean MIT T Grouping

LPT
FIFO
AT
EDD
SPT
WINQ

685

637

615

612

518

499
a
a
a
a
a
a 
15 Job types - 8 Machines - 5 Routes

Dispatching rule Mean MIT T Grouping

AT
EDD
SPT
LPT
FIFO
WINQ

699

672

581

580

575

561
a
a
a
a
a
a

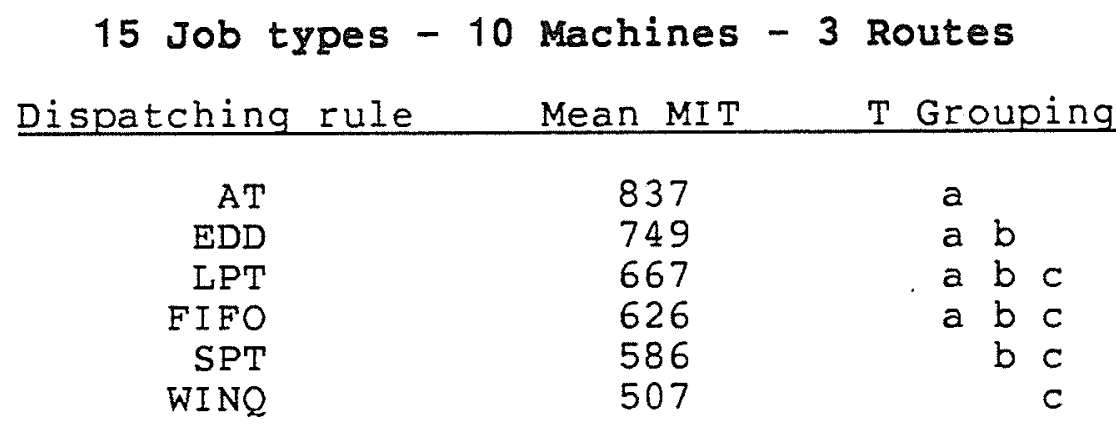

\begin{tabular}{ccc}
15 Job types - 10 Machines -5 Routes \\
Dispatching rule & Mean MIT & T Grouping \\
\hline EDD & 788 & \\
AT & 746 & $\mathrm{a}$ \\
FIFO & 725 & $\mathrm{a}$ \\
LPT & 722 & $\mathrm{a}$ \\
WINQ & 662 & $\mathrm{a}$ \\
SPT & 572 & $\mathrm{a}$ \\
SPT & & $\mathrm{a}$
\end{tabular}


Appendix $G$

GPSS IMPLEMENTATION OF THE SHANRER \& TZEN LOADING ALGORITHM 


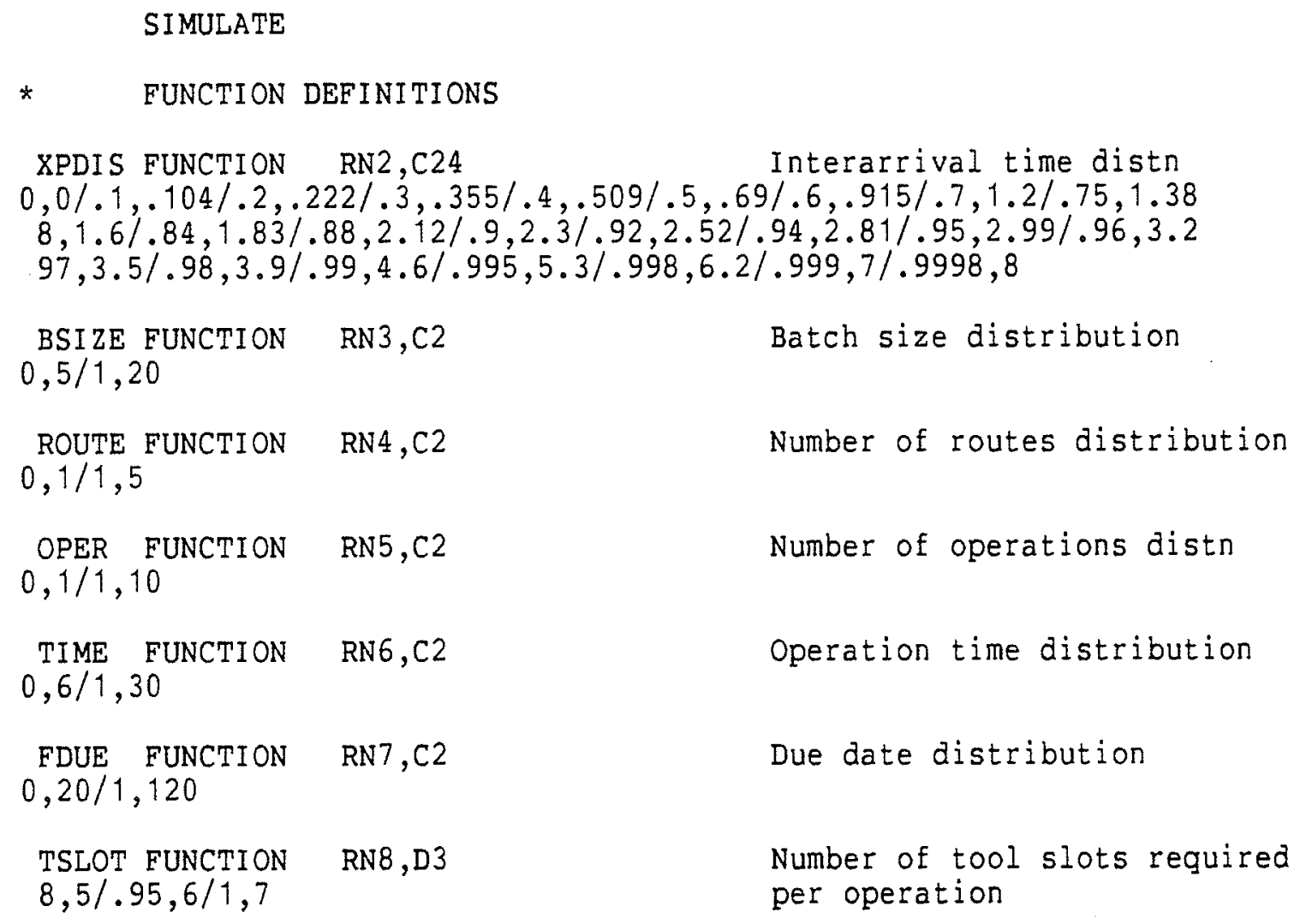

INITIAL XH\$JTOT, $15 /$ XH\$MTOT , 10/XH\$MINZ, 15000

INITIAL X\$RCAP1,1440/X\$RCAP2,1410/X\$RCAP3, 1380/X\$RCAP4, 1350

INITIAL X\$RCAP5,1320/X\$RCAP6,1290/X\$RCAP7, 1260

INITIAL X\$RCAP8,1230/X\$RCAP9,1200/X\$RCAPO 1170

INITIAL X\$CAP1,1440/X\$CAP2,1410/X\$CAP3, 1380/X\$CAP4, 1350

INITIAL $\quad$ \$CAP5,1320/X\$CAP6,1290/X\$CAP7, 1260

INITIAL X\$CAP8,1230/X\$CAP9, 1200/X\$CAPO, 1170

$\begin{array}{llll}1 & \text { MATRIX } & \mathrm{H}, 32,17 & \text { Job information matrix } \\ 2 & \text { MATRIX } & \mathrm{H}, 12,2 & \text { Infeasible m/c \& route \#s } \\ 3 & \text { MATRIX } & \mathrm{H}, 55,40 & \text { RPT list in descending order } \\ 4 & \text { MATRIX } & \mathrm{H}, 45,30 & \text { Feasible jobs matrix } \\ 5 & \text { MATRIX } & \mathrm{H}, 12,20 & \text { Loading allocation matrix } \\ 6 & \text { MATRIX } & \mathrm{H}, 15,2 & \text { Feasible routes matrix } \\ 7 & \text { MATRIX } & \mathrm{H}, 15,2 & \text { End times of jobs being proc } \\ & & & \text { Total number of jobs } \\ \text { JTOT } & \text { EQU } & 76, \mathrm{H} & \text { Total number of machines } \\ \text { MTOT } & \text { EQU } & 77, \mathrm{H} & \text { Objective function } \\ \text { OBJF } & \text { EQU } & 81, \mathrm{H} & \text { Minimum } Z \text { value } \\ \text { MINZ EQU } & 82, \mathrm{H} & \text { Remaining capacity of m/c } 1 \\ \text { RCAP1 EQU } & 21, \mathrm{X} & & \\ \text { RCAP2 EQU } & 22, \mathrm{X} & & \\ \text { RCAP3 } & \text { EQU } & 23, \mathrm{X} & \end{array}$




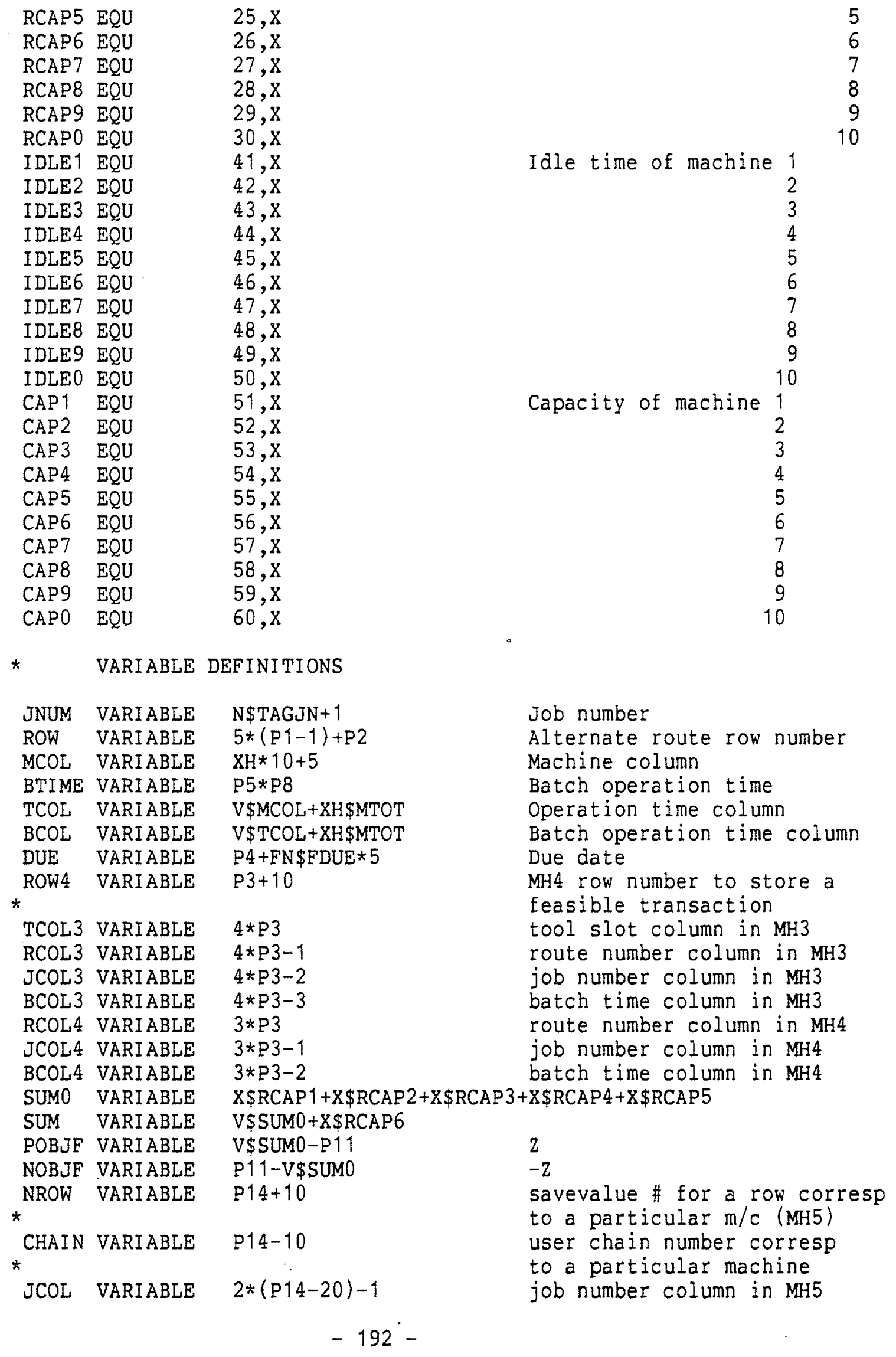




\begin{tabular}{|c|c|c|c|}
\hline CHAN & VARIABLE & $\mathrm{P} 1+10$ & used for emptying UCs $11-20$ \\
\hline RCOL & VARIABLE & V\$JCOL +1 & route number column in MH5 \\
\hline NCHAN & VARI ABLE & $\mathrm{P} 3+10$ & user chain number \\
\hline SAVE & VARI ABLE & $\mathrm{P} 14+20$ & used to update idle time of \\
\hline & & & the machines \\
\hline I DLE & VARIABLE & $\mathrm{MH} 7(\mathrm{P} 1,1)-\mathrm{C} 1$ & idle time of the machine \\
\hline CAP & VARI ABLE & $\mathrm{P} 14+30^{\circ}$ & remaining capacities \\
\hline MNUM & VARIABLE & $\mathrm{P} 14-20$ & machine number \\
\hline IDLEJ & VARIABLE & $\mathrm{MH} 7(\mathrm{~V} \$ \mathrm{MNUM}, 2)-\mathrm{C} 1$ & job idle time \\
\hline CHANE & VARIABLE & P17-30 & UC number used for unlinking \\
\hline ENDT & VARIABLE & $\mathrm{C} 1+\mathrm{P} 11$ & end time of a job currently \\
\hline * & & & not being processed \\
\hline ENDTM & VARIABLE & $\mathrm{C} 1+\mathrm{P} 11+\mathrm{P} 16$ & $\begin{array}{l}\text { end time of a job currently } \\
\text { being processed }\end{array}$ \\
\hline PAUSE & VARIABLE & $27000-\mathrm{C} 1$ & \\
\hline FSBL & BVARIABLE & $\left(\mathrm{P} 1^{\prime} \mathrm{NE} \mathrm{X}^{\prime} \mathrm{MH} 2(\mathrm{XH} 79,1)\right)+\left(\mathrm{P} 2^{\prime}\right.$ & $\left.\mathrm{E}^{\prime} \mathrm{MH} 2(\mathrm{XH} 79,2)\right)$ \\
\hline & 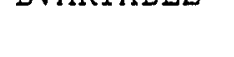 & used to check whether th & he job is feasible wrt the \\
\hline & & tool slot constraint & \\
\hline REPT & BVARIABLE & P1'E'MH5 (XH80, V\$JCOL) & \\
\hline * ROTE & & $\begin{array}{l}\text { used to check whether } \mathrm{X} \text { a } \\
\left(\mathrm{P} 1^{\prime} \mathrm{E}^{\prime} \mathrm{MH} \text { (P1,1))*(P2'NE'}\right.\end{array}$ & $\begin{array}{l}\text { act is already present in MH5 } \\
\text { 'MH6 }(\mathrm{P} 1,2) \text { ) }\end{array}$ \\
\hline * RUIL & BVARIABLE & used to check whether $x$ & act is already present in $\mathrm{MH} 6$ \\
\hline BUSY & BVARIABLE & $\begin{array}{l}\left(\mathrm{MH} 7(\mathrm{P} 1,1)^{\prime} \mathrm{G}^{\prime} 0\right) *(\mathrm{MH} 7(\mathrm{~V} \$ \mathrm{~N} \\
\text { used to check whether th }\end{array}$ & $\begin{array}{l}\text { MNUM, 2)' } G \text { '0) } \\
\text { he job and machine are busy }\end{array}$ \\
\hline * & Create the & Job Information Matrix & (MH1) \\
\hline & GENERATE & 70,FN\$XPDIS, XH\$JTOT, 17 & \\
\hline TAGJN & ASSIGN & $1, \mathrm{~V} \$ \mathrm{JNUM}$ & $\mathrm{P} 1=$ job number \\
\hline & MARK & & $\mathrm{P} 4=$ arrival time \\
\hline & ASSIGN & 5, FN\$BSIZE & P5 = batch size \\
\hline & ASSIGN & 6, FN\$ROUTE & P6 $=$ number of routes -1 \\
\hline & ASSIGN & $9, \mathrm{\$ DUE}$ & $P 9$ = due date \\
\hline & SPLIT & $\mathrm{P} 6, \mathrm{VISIT}, 2$ & $\mathrm{P} 2$ = route number \\
\hline VISIT & ASSIGN & 7, FN\$OPER & P7 = number of operations -1 \\
\hline & SPLIT & P7, PRMUT, 3 & P3 = machine num (visit seg) \\
\hline PRMUT & ADVANCE & 500,495 & permute machine numbers \\
\hline & ASSIGN & 8, EN\$TIME & $\mathrm{P} 8$ = operation time \\
\hline & ASSIGN & 11, V\$BTIME & P11 = batch operation time \\
\hline & ASSIGN & $10, \mathrm{~V} \$ \mathrm{ROW}$ & P10 = row number \\
\hline & ASSIGN & $7+, 1$ & $\mathrm{P} 7=\mathrm{P7}+1$ (total \# opers) \\
\hline & ASSIGN & 12, FN\$TSLOT & P12 = num of tool slots regd \\
\hline & MSAVEVALUE & $1, \mathrm{P} 10,1, \mathrm{P} 1, \mathrm{H}$ & record job numbers \\
\hline & MSAVEVALUE & $1, \mathrm{P} 10,2, \mathrm{P} 7, \mathrm{H}$ & record total num of operations \\
\hline & MSAVEVALUE & $1, \mathrm{P} 10,3, \mathrm{P} 5, \mathrm{H}$ & batch size \\
\hline & SAVEVALUE & $\mathrm{P} 10+, 1, \mathrm{H}$ & $\mathrm{xH} * 10=$ num of next operation \\
\hline & MSAVEVALUE & $1, \mathrm{P} 10, \mathrm{~V} \$ \mathrm{MCOL}$, & record machine number \\
\hline & MSAVEVALUE & 1,P10,V\$TCOL,P8,H & operation time \\
\hline & MSAVEVALUE & $1+, \mathrm{P} 10,4, \mathrm{P} 11, \mathrm{H}$ & update total operation time \\
\hline & MSAVEVALUE & $1, \mathrm{P} 10,5, \mathrm{~V} \$ \mathrm{DUE}, \mathrm{H}$ & d due date \\
\hline
\end{tabular}


MSAVEVALUE $1, \mathrm{P} 10, \mathrm{~V} \$ B C O L, \mathrm{P} 11, \mathrm{H}$

batch operation time

* Create the Infeasible Job/Route number matrix (MH2)

\begin{tabular}{|c|c|c|c|}
\hline & $\begin{array}{l}\text { TEST E } \\
\text { SAVEVALUE } \\
\text { MSAVEVALUE } \\
\text { MSAVEVALUE }\end{array}$ & $\begin{array}{l}\mathrm{P} 12,7, \mathrm{FEASB} \\
78+, 1, \mathrm{H}\end{array}$ & $\begin{array}{l}\text { if } \mathrm{P} 12=7 \text { then infeasible } \\
\mathrm{XH78}=\text { row num of infeasible } \\
\text { route (MH2) } \\
\text { store job \# of infeasible xac } \\
\text { route \# of infeas xact }\end{array}$ \\
\hline & L OA D I N & J & \\
\hline $\begin{array}{l}\text { FEASB } \\
\text { NEXT }\end{array}$ & $\begin{array}{l}\text { LINK } \\
\text { ADVANCE } \\
\text { UNLINK } \\
\text { SAVEVALUE } \\
\text { MSAVEVALUE } \\
\text { MSAVEVALUE } \\
\text { MSAVEVALUE } \\
\text { MSAVEVALUE }\end{array}$ & $\begin{array}{l}\mathrm{P} 3, \mathrm{P} 11, \mathrm{NEXT} \\
500 \\
\mathrm{P} 3, \mathrm{NEXT}, 1, \mathrm{BACK} \\
\mathrm{P} 3+, 1 \\
3, \mathrm{X} * 3, \mathrm{~V} \$ \mathrm{BCOL} 3, \mathrm{P} 11, \mathrm{H} \\
3, \mathrm{X} * 3, \mathrm{~V} \$ \mathrm{COL} 3, \mathrm{P} 1, \mathrm{H} \\
3, \mathrm{X} * 3, \mathrm{~V} \$ \mathrm{RCOL} 3, \mathrm{P} 2, \mathrm{H} \\
3, \mathrm{X} * 3, \mathrm{~V} \$ \mathrm{TCOL} 3, \mathrm{P} 12, \mathrm{H}\end{array}$ & $\begin{array}{l}\text { link on UC according to } \mathrm{m} / \mathrm{c} \text { \# } \\
\text { unlink from the back for } \\
\text { descending order } \\
\text { increment MH3 row number } \\
\text { store batch operation time } \\
\text { job number } \\
\text { route number } \\
\text { tool slot requirement }\end{array}$ \\
\hline${ }^{\star}$ CHEK & $\begin{array}{l}\text { SAVEVALUE } \\
\text { TEST LE } \\
\text { TEST E } \\
\text { SAVEVALUE } \\
\text { TRANSFER }\end{array}$ & $\begin{array}{l}79,1, \mathrm{H} \\
\text { XH79,XH78, DONE } \\
\text { BV\$FSBL, 1, OUT } \\
79+, 1, \mathrm{H} \\
\text { CHEK }\end{array}$ & $\begin{array}{l}\text { MH2 row against which a xact } \\
\text { is checked for feasibility } \\
\text { test if checking is complete } \\
\text { if xact is feasible then } \\
\text { increment MH2 row }\end{array}$ \\
\hline DONE & $\begin{array}{l}\text { ASSIGN } \\
\text { SAVEVALUE } \\
\text { MSAVEVALUE } \\
\text { MSAVEVALUE } \\
\text { MSAVEVALUE }\end{array}$ & $\begin{array}{l}13, \mathrm{~V} \$ \mathrm{ROW} 4 \\
\mathrm{P} 13+, 1 \\
4, \mathrm{X} * 13, \mathrm{~V} \$ \mathrm{BCOL} 4, \mathrm{P} 11, \mathrm{H} \\
4, \mathrm{X} * 13, \mathrm{~V} \$ \operatorname{COL} 4, \mathrm{P} 1, \mathrm{H} \\
4, \mathrm{X} * 13, \mathrm{~V} \$ \mathrm{RCOL} 4, \mathrm{P} 2, \mathrm{H}\end{array}$ & $\begin{array}{l}\mathrm{P} 13=\mathrm{MH} 4 \text { row number } \\
\text { increment MH4 row number } \\
\text { store batch operation time } \\
\text { job number } \\
\text { route number }\end{array}$ \\
\hline
\end{tabular}

* Create the Loading Allocation matrix (MH5)

\begin{tabular}{|c|c|c|c|}
\hline \multirow{3}{*}{ * BLOK } & TEST NE & BV\$ROTE , 1, OUT & \multirow{3}{*}{$\begin{array}{l}\text { terminate xact with same job } \\
\text { num but different route num } \\
\text { link onto user chain NCHAN } \\
\text { according to batch proc time } \\
\text { if first xact with unig job\# } \\
\text { then store job number } \\
\text { route number }\end{array}$} \\
\hline & LINK & V\$NCHAN , P11, BLOK & \\
\hline & $\begin{array}{l}\text { TEST NE } \\
\text { MSAVEVALUE } \\
\text { MSAVEVALUE }\end{array}$ & $\begin{array}{l}\text { BV \$ROTE, } 1, \text { OUT } \\
6, \mathrm{P} 1,1, \mathrm{P} 1, \mathrm{H} \\
6, \mathrm{P} 1,2, \mathrm{P} 2, \mathrm{H}\end{array}$ & \\
\hline \multirow[t]{3}{*}{ ADV } & ADVANCE & 500 & \multirow{3}{*}{$\begin{array}{l}\text { XH80 = row num of MH5 against } \\
\text { which xact checked for reptn } \\
\text { P14 = max RCAPi } \\
\text { P15 = savevalue \# of the row }\end{array}$} \\
\hline & SAVEVALUE & $80,1, \mathrm{H}$ & \\
\hline & $\begin{array}{l}\text { SELECT MAX } \\
\text { ASSIGN }\end{array}$ & $\begin{array}{l}14, \text { RCAP } 1, \text { RCAPO, } \\
15, \mathrm{~V} \$ \text { NROW }\end{array}$ & \\
\hline
\end{tabular}


$\star$

\begin{tabular}{|c|c|c|}
\hline CHECK & TEST LE & $\mathrm{XH} 80, \mathrm{X} * 15, \mathrm{CALCZ}$ \\
\hline & TEST NE & BV $\$ R E P T, 1$, UNLNK \\
\hline & SAVEVALUE & $80+, 1, \mathrm{H}$ \\
\hline & TRANSFER & , CHECK \\
\hline CALCZ & TEST LE & V\$POBJE, 0, ELSE \\
\hline & SAVEVALUE & OBJE, V\$NOBJE, $\mathrm{H}$ \\
\hline & TRANSFER & ,PROCD \\
\hline ELSE & SAVEVALUE & OBJF, V\$POBJF, $\mathrm{H}$ \\
\hline PROCD & TEST LE & XH\$OBJF, XH\$MINZ,OUT \\
\hline & SAVEVALUE & MINZ, XH\$OBJF , H \\
\hline & SAVEVALUE & $\mathrm{P} 14-, \mathrm{P} 11$ \\
\hline & & \\
\hline & UNLINK & V\$CHAIN , BLOK, 1, BACK \\
\hline$\star$ & & \\
\hline & SAVEVALUE & $\mathrm{P} 15+, 1$ \\
\hline 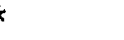 & & \\
\hline & MSAVEVALUE & $5, \mathrm{X} * 15, \mathrm{~V} \$ \mathrm{JCOL}, \mathrm{P} 1, \mathrm{H}$ \\
\hline & MSAVEVALUE & $5, \mathrm{X} * 15, \mathrm{~V} \$ \mathrm{RCOL}, \mathrm{P} 2, \mathrm{H}$ \\
\hline & & \\
\hline
\end{tabular}

UNLNK UNLINK V\$NCHAN, BLOK, 1, BACK

*

OUT TERMINATE

* Empty the user chains

$\begin{array}{lll} & \text { GENERATE } & 26000 \\ \text { ASSIGN } & 1, \text { XH\$MTOT } \\ \text { NLNK } & \text { UNLINK } & \text { V\$CHAN, BLOK, ALL } \\ & \text { LOOP } & 1, \text { NLNK } \\ \text { TERMINATE } & \end{array}$

$*$

D I S P A T C H I N G
\# corresp to a particular $\mathrm{m} / \mathrm{c}$ test if checking complete unlink if xact already in $\mathrm{MH5}$ increment MH5 row

if $P O B J F<=0$ then

$O B J F=-P O B J F$

else $O B J F=P O B J F$

if $O B J F<=$ MINZ then

$\mathrm{MINZ}=\mathrm{OBJF}$

update remaining capacity of corresponding machine

unlink from the back of the corresponding user chain increment row counter for storing a value in $\mathrm{MH} 5$ store job number route number

unlink from the back of the corresponding user chain

$P 1=$ total \# of machines

$\mathrm{P} 1=\mathrm{P} 1-1$ link onto UC corresponding to $\mathrm{m} / \mathrm{c} \#$ acc to batch proc time update remaining capacity of the corresponding machine check if job \& machine busy ,ELS if job finishes after the required machine then P16 = machine idle time update idle time of the $\mathrm{m} / \mathrm{c}$ $\mathrm{P} 16=$ job idle time store end time of job store time $\mathrm{m} / \mathrm{c}$ will be free job stays idle 


\begin{tabular}{|c|c|c|c|}
\hline CHEC & $\begin{array}{l}\text { TEST NE } \\
\text { ASSIGN } \\
\text { MSAVEVALUE } \\
\text { MSAVEVALUE } \\
\text { ADVANCE } \\
\text { SAVEVALUE } \\
\text { TRANSFER }\end{array}$ & $\begin{array}{l}\text { MH7 (P1,1), 0, VRFY } \\
16, \text { V\$IDLE } \\
7, \mathrm{P} 1,1, \mathrm{~V} \$ \text { ENDTM }, \mathrm{H} \\
7, \mathrm{~V} \$ \mathrm{MNUM}, 2, \mathrm{~V} \$ \text { ENDTM }, \mathrm{H} \\
\mathrm{P} 16 \\
\text { V\$SAVE+, P16 } \\
\text {,SEZ }\end{array}$ & $\begin{array}{l}\text { check if job being processed } \\
\text { P16 = machine idle time } \\
\text { store end time of job } \\
\text { store time } \mathrm{m} / \mathrm{c} \text { will be free } \\
\text { machine stays idle } \\
\text { update idle time of the m/c }\end{array}$ \\
\hline VRFY & $\begin{array}{l}\text { TEST NE } \\
\text { ASSIGN } \\
\text { MSAVEVALUE } \\
\text { MSAVEVALUE } \\
\text { ADVANCE } \\
\text { TRANSFER }\end{array}$ & $\begin{array}{l}\text { MH7 (V\$MNUM , } 2), 0, \text { PROC } \\
16, \text { V\$IDLEJ } \\
7, \text { P1, 1,V\$ENDTM , H } \\
7, \text { V \$MNUM, 2, V\$ENDTM , H } \\
\text { P16 } \\
\text {,SEZ }\end{array}$ & $\begin{array}{l}\text { check if machine busy } \\
\text { P16 = job idle time } \\
\text { store end time of job } \\
\text { store time m/c will be free } \\
\text { job stays idle }\end{array}$ \\
\hline PROC & $\begin{array}{l}\text { MSAVEVALUE } \\
\text { MSAVEVALUE }\end{array}$ & $\begin{array}{l}7, \mathrm{P} 1,1, \mathrm{~V} \$ \text { ENDT }, \mathrm{H} \\
7, \mathrm{~V} \$ \mathrm{MNUM}, 2, \mathrm{~V} \$ \text { ENDT }, \mathrm{H}\end{array}$ & $\begin{array}{l}\text { store end time of job } \\
\text { store time } \mathrm{m} / \mathrm{c} \text { will be free }\end{array}$ \\
\hline SEZ & $\begin{array}{l}\text { ADVANCE } \\
\text { SEIZE } \\
\text { ADVANCE } \\
\text { RELEASE }\end{array}$ & $\begin{array}{l}\text { P14 } \\
\text { P11 } \\
\text { P14 }\end{array}$ & $\begin{array}{l}\text { engage the machine } \\
\text { operation time elapses } \\
\text { release the machine }\end{array}$ \\
\hline & $\begin{array}{l}\text { TEST E } \\
\text { MSAVEVALUE }\end{array}$ & $\begin{array}{l}\operatorname{MH} 7(\mathrm{P} 1,1), \mathrm{C} 1, \mathrm{FRE} \\
7, \mathrm{P} 1,1,0, \mathrm{H}\end{array}$ & $\begin{array}{l}\text { if job is done then } \\
\text { indicate job has been procsd }\end{array}$ \\
\hline FRE & $\begin{array}{l}\text { TEST E } \\
\text { MSAVEVALUE }\end{array}$ & $\begin{array}{l}\text { MH7 (V\$MNUM , 2) , C1, ULNK } \\
7, \mathrm{~V} \$ \text { MNUM }, 2,0, \mathrm{H}\end{array}$ & $\begin{array}{l}\text { if machine is free then } \\
\text { indicate machine is free }\end{array}$ \\
\hline ULNK & $\begin{array}{l}\text { SELECT MAX } \\
\text { UNLINK } \\
\text { TERMINATE }\end{array}$ & $\begin{array}{l}\text { 17,CAP1,CAPO, }, \mathrm{X} \\
\text { V\$CHANE,NXT, } 1\end{array}$ & $\begin{array}{l}\mathrm{P} 17=\max \mathrm{CAPi} \\
\text { send next job for processing }\end{array}$ \\
\hline & $\begin{array}{l}\text { GENERATE } \\
\text { TERMINATE } \\
\text { START } \\
\text { END }\end{array}$ & $\begin{array}{l}31000 \\
1 \\
1\end{array}$ & \\
\hline
\end{tabular}

